\title{
Copy No

\section{INTERIM REPORT ON THE USE OF SM-2 ELEMENTS \\ IN SM-1, SM-1A AND PM-2A CORES}




\section{DISCLAIMER}

This report was prepared as an account of work sponsored by an agency of the United States Government. Neither the United States Government nor any agency Thereof, nor any of their employees, makes any warranty, express or implied, or assumes any legal liability or responsibility for the accuracy, completeness, or usefulness of any information, apparatus, product, or process disclosed, or represents that its use would not infringe privately owned rights. Reference herein to any specific commercial product, process, or service by trade name, trademark, manufacturer, or otherwise does not necessarily constitute or imply its endorsement, recommendation, or favoring by the United States Government or any agency thereof. The views and opinions of authors expressed herein do not necessarily state or reflect those of the United States Government or any agency thereof. 


\section{DISCLAIMER}

Portions of this document may be illegible in electronic image products. Images are produced from the best available original document. 
APAE Memo No. 291

Copy No.

AEC Research and Development

Report

UC-81, Reactors - Power

(Special Distribution)

INTERIM REPORT ON THE USE OF

SM-2 ELEMENTS IN SM-1, SM-1A AND

PM-2A CORES

By:

S. L. Davidson

J。 P。 Oggerino

Approved By:

J. G. Gallagher - Head, Nuclear Technology Unit

Issued: June 20,1961

Contract No. AT(30-1)-2639

with U. S. Atomic Energy Commission

New York Operations Office

ALCO PRODUCTS, INC.

Nuclear Power Engineering Department

Post Office Box 414

Schenectady 1, N。Y。 


\section{AEC LEGAL NOTICE}

This report was prepared as an account of Government sponsored work. Neither the United States, nor the Commission, nor any person acting on behalf of the Commission:

A. Makes any warranty or representation, expressed or implied, with respect to the accuracy, completeness, or usefulness of the information contained in this report, or that the use of any information, apparatus, method, or process disclosed in this report may not infringe privately owned rights: or

B. Assumes any liabilities with respect to the use of, or for damages resulting from the use of any information, apparatus, method, or process disclosed in this report.

As used in the above, "person acting on behalf of the Commission" includes any employee or contractor of the Commission, or employee of such contractor, to the extent that such employee or contractor of the Commission, or employee of such contractor prepares, disseminates; or provides access to, any information pursuant to his employment or contract with the Commission, or his employment with such contractor.

\section{ALCO LEGAL NOTICE}

This report was prepared by Alco Products, Incorporated in the course of work under, or in connection with, Contract No. AT(30-1)-2639 issued by U.S. Atomic Energy Commission, NYOO; and subject only to the rights of the United States, under the provisions of this contract, Alco Products, Incorporated makes no warranty or representation, express or implied, and shall have no liability with respect to this report or any of its contents or with respect to the use thereof or with respect to whether any such use will infringe the rights of others. 
THIS PAGE

\section{WAS INTENTIONALLY \\ LEFT BLANK}


External

Copies

$1-2$ New York Operations Office

U. S. Atomic Energy Commission

376 Hudson Street

New York, 14, New York

Attention: Chief, Army Reactors Staff Reactor Division

$3-5$ U. S. Atomic Energy Commissioñ

Washington $25, \mathrm{D}$ 。 $\mathrm{C}$.*

Attention: Chief, Water Systems Project

Branch (Army Reactors)

Division of Reactor Development

Mail Station F-311

6

U. S. Atomic Energy Commission

Washington $25, D_{0}$ C 。

Attention: Chief, Evaluation and Planning Branch

Civilian Reactors, Division of

Reactor Development

7

U. S. Atomic Energy Commission

Chief, New York Patent Group

Brookhaven National Laboratóry

Upton, New York

Attention: Harman Potter

U. S。 Atomic Energy Commission

Idaho Operations Office

P. O. Box 2108

Idaho Falls, Idaho

Attention: Director, Division of Military

Reactors 
U. S. Atomic Energy Commission

Reports and Statistic Branch

Division of Reactor Development

Washington, 25, D. C .

$10-11$ Office of the Chief of Engineers

Department of the Army

Building $\mathrm{T}-7$

Washington, 25, D。C.

Attention: Chief, Projects Branch

Nuclear Power Division

12 - 14 Nuclear Power Field Office

U. S。 Army Engineer Reactors Group

Fort Belvoir, Virginia

Attention: Chief, Nuclear Power Field Office

15

Nuclear Power Field Office

U. S. Army Engineer Reactors Group

Fort Belvoir, Virginià

Attention: O. I. C. SM-1

16 Chief, U. S. Army Reactors Group

Fort Greeley, Alaska

APO 733.

Seattle, Washington

Attention: O. I. C. SM-1A

17 Chief, USAPR\&DC

Thule, Greenland

APO 23

New York, New York

Attention: O.I.C.PM-2A 


\section{DISTRIBUTION (CONT'D)}

18- 20 Office of Technical Information Extension

P. O. Box 62

Oak Ridge, Temessee

21. Union Carbide Nuclear Corporation

Oak Ridge National Laboratory

Y-12 Building 9704-1

P. O. Box "Y"

Oak Ridge, Tennessee

Attention: A. L。 Boch

22 The Martin Company

P. O. Box 5042

Middle River, Maryland

Attention: AEC Contract Document Custodian

23. Combustion Engineering, Incorporated

Nuclear Division

Windsor, Connecticut

Attention: Director, Nuclear Division

$24-25$ Alco Products, Inc。

P. O. Box 145

Fort Belvoir, Va.

Attention: W. K. Stromquist

Internal

Copies

K. Kasschau

27

28

29

30

31

32

33

34

35

36

37
J. Gronan

E. B. Gunyou

J. G. Gallagher .

H. L. Hoover

W. S. Brown

P. E. Bobe

W. T. Williams

W. J. McCool

I. Segalman

D. Ho Lee

F。 T. Matthews
38

39 .

40

41

42

43

44

45

46

$47-48$

49

$50-54$
S. L. Davidson

P. L. Bradley

R. H. Beam

S. H. Weiss

B. E. Fried

J. P. Oggerino

S. Paluszkiewicz

E. F. Clancy

M. A. Alford

Core Analysis File

Thermal and Hydraulic File NPED File 
THIS PAGE

WAS INTENTIONALLY

LEFT BLANK 


\section{ABSTRACT}

Interim results of an analytical investigation of nuclear and thermal characteristics of SM-2 type fuel elements in SM-1, SM-1A and PM-2A reactor cores are reported. Utilizing modified two group diffusion theory, predictions of power distribution, and core and rod reactivity were performed. The calculations performed to date indicate that use of SM-2 fuel elements in SM-1, SM-1A and PM-2A is feasible from the nuclear standpoint. Critical experiments and further analysis are expected to verify results of the initial investigation.

A steady state thermal analysis of each plant utilizing SM-2 elements was carried out. This analysis showed that the minimum DNBR's (departure from nuclear boiling ratios) were considerably above the minimum value from the design criteria standpoint at both the operating and scram power levels. The investigation at this point indicated that SM-2 elements can successfully. be employed in SM-1, SM-1A, and PM-2A as replacement core elements. The final thermal analysis based on more accurate estimates of power distribution and internal element flow distribution is expected to verify results of the initial investigation. 
THIS PAGE

\section{WAS INTENTIONALLY \\ LEFT BLANK}


ABSTRACT

1.0 INTRODUCTION

2.0 NUCLEAR ANALYSIS $-\ldots \ldots \ldots \ldots$

2.1 Calculational Approach _............. 6

2.1.1 Nuclear Parameters - - . -

2.1.1.1 Thermal Constants - - -

2.1.1.2 Fast Constants -

2.1.1.3. Nuclear Nomenclature - - - - - - 6

2.1.2 Power Distributions and Reactivity - - -

2.1.2.1 Radial Power Distributions - - - - - 8

2.1.2.2 Axial Power Distributions - - - - - . 8

2.1.2.3 Reactivity Calculations - - - - - - 8

2.2 Power Distribution Calculations _ $\ldots \ldots$

2.2.1 SM-1 Core - $\ldots \ldots 9$

2.2.2 SM-1A Core $\ldots \ldots 14$

2.2.3 PM-2A Core

2.3 Rod Worth, Reactivity, and Rod Bank Positions, SM-1, SM-1A, PM-2A _........... 43

2.4 Results $\ldots \ldots \ldots$

2.5 Conclusion $-\ldots$

3.0 THERMAL ANALYSIS $\ldots \ldots \ldots 1$

3.1 Introduction $\ldots \ldots \ldots 1$ 
3.2. Methods of Analysis $\ldots \ldots \ldots$

3.2.1 Steady State -

3.2.2 Transients

3.3 Power Distribution - _.

3.3.1 Maximum Power for Each Reactor _. _ _ _ 667

3.3.2 Axial and Radial Power Distribution - _-... 67

3.4 Hot Channel Factors _. 68

3.5 Additional Factors Included in the Thermal Analysis - - - 69

3.6 Core Flow Distribution _. 60

3.6.1 SM-1 Core with SM-2 Elements - _ _ _ _ _ - 70

3.6.2 SM-1A Core with SM-2.Elements -

3.6.3 PM-2A Core with SM-2 Elements _ _ _ _ _ 75

3. 7 Performance of SM-2 Elements in the SM-1 Reactor _- - - 75

3.7.1 Steady State Design Conditions - $1 \ldots+\ldots$

3.7.2 Maximum Operating Conditions - $\ldots \ldots \ldots$

3.8 Performance of SM-2 Elements in the SM-1A Reactor - - - 76

3.8.1 Steady State Design Conditions _. $1 . \ldots 76$

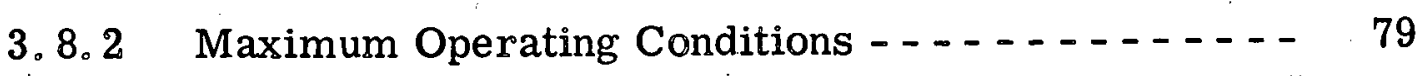

3.9 Performance of SM-2 Elements in the PM-2A Reactor - - 80

3.9.1 Steady State Design Conditions -

3.9.2 Maximum Operating Conditions -

3.10. Transient Operation of the SM-1 Core with SM-2 Elements - 83

3.11 Conclusions _. 89

REFERENCES _... 


\section{LIST OF FIGURES}

Figure

Title

2.1 SM-1 Core Layout

2.2 Relative Power Through Central Radial Plane

Perpendicular to Fuel Plates - Rods Out - SM-1. Core

With SM-2 Elements - $440^{\circ} \mathrm{F}$

2.3 Relative Power Through Central Radial Plane

Parallel to Fuel Plates - Rods Out - SM-1 Core

With SM-2 E'lements $-440^{\circ} \mathrm{F}$

2.4 Relative Power Through Central Radial Plane

Perpendicular to Fuel Plates - 5 Rods in - SM-1 Core With SM-2 Elements - $440^{\circ} \mathrm{F}$

2.5 Relative Power Through Central Radial Plane Parallel to.Fuel Plates - 5 Rods In - SM-1 Core With SM-2 Elements $-440^{\circ} \mathrm{F}$

2.6.Relative Power Through Radial Plane Perpendicular

To Fuel Plates - Rods Out - SM-1 Core With SM-2

Elements - $680 \mathrm{~F}$

2. $7 \quad$ Relative Power Through Central Radial Plane Parallel To Fuel Plates - Rods Out - $68^{\circ} \mathrm{F}$ - SM-1 Core. With SM-2 Elements

2. 8 Relative Power Through Central Radial Plane Perpendicular to Fuel Plate - 5 Rods In - SM-1 Core With SM-2 Elements $-68^{\circ} \mathrm{F}$

2.9 $\quad$ Relative Power Through Central Radial Plane Parallel

To Fuel Plates - 5 Rods In - SM-1 Core With SM-2

Elements $-68^{\circ} \mathrm{F}$

2.10 Relative Power Through Central Radial Plane Perpendicular To Fuel Plates - SM-1 Core I - $440^{\circ} \mathrm{F}$

2.11 Relative Power Through Central Radial Plane Parallel To Fuel Plates - SM-1 Core I - $440^{\circ} \mathrm{F}$

2.12 Relative Power Through Central Radial Plane Perpendicular To Fuel Plates - SM-1 Core I - $68^{\circ} \mathrm{F}$ 
Figure

2.13 Relative Power Through Central Radial Plane

Parallel To Fuel Plates - SM-1 Core I - $68^{\circ} \mathrm{F}$

2.14 Relative Axial Power Distribution - SM-1 Core

With SM-2 Elements Without Flux Suppressors $-440^{\circ} \mathrm{F}$

2.15 Relative Axial Power Distribution SM-1 Core - SM-2

Elements $-440^{\circ} \mathrm{F}-$ With Flux Suppressor

2.16 Relative Axial Power (Windowshade) - SM-1 Core SM-2 Elements $-440^{\circ} \mathrm{F}-$ With Flux Suppressor

2.17 Relative Axial Power (Windowshade) - SM-1 Core I $440^{\circ} \mathrm{F}$ - No Flux Suppressor

$2.18 \cdot$ SM-1A Core Layout

2.19 Relative Power Through Central Radial Plane

Perpendicular To: Fuel Plates - Rods Out - SM-1A Core With SM-2 Elements $-440^{\circ} \mathrm{F}$

2.20 Relative Power Through Central Radial Plane Parallel To Fuel Plates - Rods Out - SM-1A Core. With SM-2

Elements $-440^{\circ} \mathrm{F}$

2. 21 Relative Power Through Central Radial Plane

Perpendicular to Fuel Plates - Rods In - SM-1A Core With SM-2 Elements - $440^{\circ} \mathrm{F}$

Relative Power Through Central Radial Plane Parallel ${ }^{\prime}$

To Fuel Plates - Rods In - SM-1A Core With SM-2

Elements $-440^{\circ} \mathrm{F}$

2. 23 Relative Power Distribution Through Central Radial Plane Perpendicular To Fuel Plates - SM-1A With SM-2

Elements - Rods Out $-68^{\circ} \mathrm{F}$

2.24 Relative Power Distribution Through Central Radial Plane Parallel To Fuel Plates - SM-1A With SM-2 Elements Rods Out $-68^{\circ} \mathrm{F}$

2.25 PM-2A Core Layout 
2.26 Relative Power Through Central Radial Plane Perpendicular To Fuel Plates - Rods Out - PM-2A

2.27 Relative Power Through Central Radial Plane Parallel To. Fuel Plates - Rods Out - PM-2A Core. With SM-2. Elements $-510^{\circ} \mathrm{F}$.

2.28 $\cdots$ Relative Power Through Central Radial Plane Perpendicular to Fuel Plates - Rods In - PM-2A Core With SM-2 Elements - $510^{\circ} \mathrm{F}$

2.29 Relative Power Through Central Radial Plane Parallel To Fuel Plates - Rods In - PM-2A Core With SM-2 Elements $-510^{\circ} \mathrm{F}$

2.30 Relative Power Through Central Radial Plane Perpendicular to Fuel Plates - Rods Out - PM-2A Core With SM-2 Elements - $68^{\mathrm{O}} \mathrm{F}$

2.31 Relative Power Through Central Radial Plane Parallel to Fuel Plates - Rods Out - PM-2A Core With SM-2 Elements $-68^{\circ} \mathrm{F}$.

2.32 Relative Power Through Central Radial Plane Perpendicular To Fuel Plates - Rods In - PM-2A Core With SM-2 Elements $-68^{\circ} \mathrm{F}$.

2.33 Relative Power Through Central Radial Plane Parallel To Fuel Plates - Rods In - PM -2A Core With SM-2 Elements $-68^{\circ} \mathrm{F}$

2.34 : Relative Axial Power Distribution (Valprod) - PM-2A Core With SM-2 Elements - $510^{\circ} \mathrm{F}$ - With Flux Suppressors;

3.1 Normalized Power (P) and Flow (q) vs. Time After Pump Failure On SM-1

3. 2 SM-1 Core Flow Distribution

3.3 SM-1A Core Flow Distribution

3. 4 PM-2A Core Flow Distribution 


\section{LIST OF FIGURES (CONT'D)}

Figure

Title

Page

3.5

SM-2 Elements in SM-1 Core, Hot Channel Plate Surface Temp. \& Bulk Water Temp. vs. Length Along Channel From Bottom of Core Element Position 61

3.6 SM-2 Elements in SM-1 Core, Hot Channel Plate Surface Temp. and Bulk Water Temp。vs。Length Along Channel From Bottom of Core Element Position 44

3.7 SM-2 Elements in.SM-1A Core, Hot Channel Plate Surface Temp。 and Bulk Water Temp。vs. Length Along Channel From Bottom of Core, Element Position 67

3.8 SM-2 Elements in SM-1A Core, Hot Channel Plate Surface Temp。 and Bulk Water Temp。vs. Length Along Channel From Bottom of Core, Element. Position 44

3.9 SM-2 Elements in PM-2A Core, Hot Channel Plate Surface Temp. and Bulk Water Temp。 vs. Length Along Channel From Bottom of Core - Element Position 23

3.10 SM-2 Elements in PM-2A Core, Hot Channel Plate Surface Temp. and Bulk Water Temp。vs. Length Along Channel From Bottom of Core, Element Position 44

3.11 Minimum Burnout Ratio as a Function of Time After Loss of Flow - SM-1 Reactor, Element Position 61, Axial Position, $J=8$ 
Table

2.1 $\cdots$ Table of Core Loadings

2.2 Maximum-to-Average Radial Power Peaking Values

For SM-1 Core I and SM-1 Core With SM-2

Elements

Title

Page

5

11

2.3 Radial Power Factors For SM-1 Core With SM-2

Elements, $\mathrm{T}=440^{\circ} \mathrm{F}$

2.4 Radial Power Factors For SM-1A Core.With SM-2

Elements, $T=440^{\circ} \mathrm{F}$

2. 5 Radial Power Factors For PM-2A With SM-2

Elements, $\mathrm{T}=510^{\circ} \mathrm{F}$

44

2.6 Miscellaneous SM-1 Core Calculations

2.'7 Miscellaneous SM-1A Core Calculations 46

2. 8 Miscellaneous PM-2A Core Calculations

47

3.1 Composite SM-2 Mechanical Hot Channel Factors

69

3.2 Results of Steady State Thermal Analysis - SM-1 Core Reactor Power $10 \mathrm{MW}$

75

3.3 Results of Steady State Thermal Analysis - SM-1 Core Reactor Power 13.45 MW

3.4 Results of Steady State Thermal Analysis - SM-1A Core Reactor Power 20.2 MW.

Results of Steady State Thermal Analysis - SM-1A Core Reactor Power 24.2 MW

Results of Steady State Thermal Analysis - PM-2A Core Reactor Power $10 \mathrm{MW}$ 
This is an interim report covering nuclear and thermal analysis of the use of SM-2 elements in SM-1, SM-1A and PM-2A reactor cores. Critical experiments and further analysis are expected to verify the results of this initial investigation. This investigation is part of Task 3 - Replacement Core Development Program, of the AEC-Army Pressurized Water Support and Development Program.

The major effort in the core analysis area was the prediction of most adverse power distribution. These predictions were performed utilizing one - and two-dimensional diffusion theory calculations. The deviations between calculated power distributions of this task and measured distributions determined in the SM-2 flexible critical experiments program were employed to modify the analytical predictions in this report. Calculations performed to date indicate that the higher fuel loaded SM-2 elements are feasible for use as replacement cores in SM-1, SM-1A and PM-2A.

A detailed steady state thermal analysis of SM-2 elements in SM-1, SM-1A and PM-2A plants was performed. This analysis utilized the IBM-704 code, STDY -3. The flow distributions were based on the full scale air flow test of the reactor vessels. Results to date of the steady state thermal analysis indicate that the cores employing SM-2 elements will operate in SM-1, SM-1A and PM-2A with adequate thermal safety。 
THIS PAGE

\section{WAS INTENTIONALLY \\ LEFT BLANK}




\subsection{INTRODUCTION}

Replacement core development for the SM-1, SM-1A and PM-2A is a major part of the AEC-Army PWR Research and Development Program. The principal effort in the replacement core development program at this time is devoted to utilization of SM-2 fuel elements in SM-1, SM-1A and PM-2A. The SM-2 fuel elements with their increased fuel content relative to the fuel content of the initial cores for these fuel plants offer significant improvements in core life.

This is an interim report on the nuclear and thermal analysis performance to date, as part of the Replacement Core Development Program. The overall Replacement Core Development Program includes nuclear analysis and critical experiments, thermal analysis, laboratory single element flow test, and miniature fuel plate and full size fuel element irradiation. The end product of this work will be procurement specifications for SM-2 fuel elements for use in the three plants. The work in this report is preliminary due to the following limitations:

1. The analytical predictions of power distribution have not been checked against exact critical experiment mockups of SM-2 elements in SM-1, SM-1A, and PM-2A arrays.

2. The velocity variation within the SM-2 fuel elements in the various core structures has been estimated and not as' yet compared with experiment.

3. The loss of pump problem has been treated only as a quasi steady state problem.

Critical experiments are now being performed using SM-2 fuel elements in the exact SM-1, SM-1A, and PM-2A core arrays. The results of these measurements will be utilized to check and correct the analytical predictions of power distribution and reactivity. This will permit the power distribution to be developed with improved accuracy necessary for final thermal analysis. Results of this work will be contained in a final report, which will also contain core burnup studies.

Laboratory tests are now under way in which the velocity variation between the plates within an element will be measured for SM-2 fuel plate bundles in the various end box and core support configurations. The final thermal analysis will utilize the most accurate power distribution, experimentally measured plate-toplate velocity variations, and final estimates of hot channel factors. The final report of this work will be issued in late 1961 . 


\section{THIS PAGE}

\section{WAS INTENTIONALLY \\ LEFT BLANK}




\subsection{NUCLEAR ANALYSIS}

This section contains the preliminary nuclear analys is of the use of SM-2 type fuel elements in the SM-1, SM-1A and PM-2A. Table 2.1 lists the loadings of the SM-2 fuel elements compared to those of the original cores.

It is seen that the boron and uranium loadings for the SM-2 elements are significantly higher than the loading of the original cores; this will result in a more adverse power distribution.

In the SM-1 Core I and SM-1A Core I, five of the seven control rods are operated as a bank with the two remaining rods nearly fully withdrawn. However, for preliminary studies with SM-2 elements, it was decided to utilize a seven rod bank for the SM-1 and SM-1A with SM-2 elements. Therefore, both the critical experiments and the analyses presented in this report are based upon seven rod bank operation in the SM-1 and SM-1A. The decision for utilization of a seven rod bank was based upon stuck rod considerations. For five rod bank operation the re is a possibility that one or both of the remaining rods could stick in the full out position; however, for seven rod bank operation, if one or more rods should stick, the rods would stick at the operating position. This would be less hazardous than for one or more rods to be stuck full out. The relative merits of five vs s seven rod bank operation will be studied further and presented in the final report.

A brief description of the calculational models employed is given, followed by a summary of the calculations performed.

TABLE 2.1

TABLE OF CORE LOADINGS

Fixed Element Loadings

$\mathrm{U}-235$ (gm/element)

B-10 (gm/element)
SM-1 Core I ${ }^{*}$

611.88

0.42813 $\underline{\text { SM-2 Elements }}$

833.4

1.3055

Control Rod Fuel Element Loadings

U-235 (gm/element)

B-10 (gm/element)
417.14

655.68

0.29286

1.027

* Similar loadings are used in SM-1A and PM-2A. 


\subsection{CALCULATIONAL APPROACH}

The nuclear analyses in this report were performed by utilizing various IBM-650 and IBM-704 codes to solve the two-group diffusion equations. The IBM-650 codes used were the Program 50 (PROMPT-1), Plate Type. $\mathrm{P}_{3}$, MUFT-III, VALPROD, and the WINDOWSHADE. These codes are described in reference (1). The IBM-704 code used was the PDQ-3. (3)

\subsubsection{Nuclear Parameters}

\subsubsection{Thermal Constants}

For most of the core regions, thermal constants were obtained by the Program 50 and Plate Type $\mathrm{P}_{3}$, IBM-650 codes. In regions that did not require this code, homogenized properties were used. In addition, the absorber region constants, $\left(\sum a\right)_{e}$ and $D_{e}$ (where e means effective), were calculated by methods described in reference (3).

\subsubsection{Fast Constantš}

The fast constants were obtained by calculating the number densities of the material in each region and using them as input to the MUFT III, IBM-650 code:

\subsubsection{Nomenclature}

\begin{tabular}{|c|c|c|}
\hline arameter & Definition & Units \\
\hline$D^{f}$ & Fast Diffusion coefficient & $\mathrm{cm}$ \\
\hline $\mathrm{D}$ & Thermal diffusion coefficient & $\mathrm{cm}$ \\
\hline $\mathrm{K}^{\mathrm{f}}$ & Fast multiplication factor & \\
\hline $\mathrm{K}^{\mathrm{th}}$ & Thermal multiplication factor & \\
\hline$\sum_{a}^{f}$ & Fast macroscopic absorption cross section. & $\mathrm{cm}^{-1}$ \\
\hline$\sum_{a}$ & $\begin{array}{l}\text { Thermal macroscopic absorption corss } \\
\text { section }\end{array}$ & $\mathrm{cm}^{-1}$ \\
\hline$\tau$ & Age & $\mathrm{cm}^{2}$ \\
\hline $\mathrm{L}^{2}$ & Diffusion length & $\mathrm{cm}^{2}$ \\
\hline $\mathbf{P}$ & Resonance escape probability & \\
\hline
\end{tabular}


$\sum$ sl Slowing down cross section

$U \sum \mathbf{f}$

Fast macroscopic fission cross section

$\mathrm{cm}^{-1}$

$v \sum_{\mathbf{f}}$

Thermal macroscopic fission cross section

$\mathrm{cm}^{-1}$

$\sum_{R}$

Regional cross section (i.e., fixed element dead retion)

$\sum_{P}$

Calculated thermal poison macroscopic cross section

$\mathrm{cm}^{-1}$

$\mathrm{cm}^{-1}$

Miscroscopic cross section

$\mathrm{cm}^{2}$

$\bar{\Sigma}$

Flux weighted cross section

$\mathrm{cm}^{-1}$

$\mathrm{N}_{\mathrm{H}} \quad$ Number density of hydrogen oxygen

atoms $/ \mathrm{cm}^{3}$

$\mathrm{NO}_{\mathrm{O}}$

Number density of oxygen

atoms $/ \mathrm{cm}^{3}$

$\mathrm{N}_{\mathrm{SS}}$

Number density of stainless steel

atoms $/ \mathrm{cm}^{3}$

$\mathrm{N}_{\mathrm{B}-10}$

Number density of B-10

atoms $/ \mathrm{cm}^{3}$

NU-235 Number density of U-235

atoms $/ \mathrm{cm}^{3}$

H A Symbol for hydrogen

$\mathrm{O}$

Symbol for oxygen

SS

Symbol for stainless steel

U-235

Symbol for Uranium-235

$\mathrm{X}$

Elemental subscript ( $i_{\circ} e_{\circ} ; H_{2} \mathrm{O}$, etc.)

$\mathrm{N}_{\mathrm{X}}$

Number density of some element $\mathrm{x}$

atoms $/ \mathrm{cm}^{3}$

$P_{\mathrm{x}}$

Density of element X

$\mathrm{gms} / \mathrm{cm}^{3}$

A

Atomic weight

gms/gm-atom

$\mathrm{N}_{\mathrm{A}}$

Avogadro!'s numbers

atoms/gm-atom

$\mathrm{V}_{\mathrm{f}}$

Volume fraction

$\mathrm{V}_{\text {TOT }}$

Total volume

$\mathrm{cm}^{3}$

$\mathrm{V}_{\mathrm{X}}$

Volume of element $\mathrm{X}$

$\mathrm{cm}^{3}$ 


\subsubsection{Power Distributions and Reactivity}

\subsubsection{Radial Power Distributions}

All radial flux and power distributions were calculated using PDQ-3, an IBM-704 code. One problem in using this code was mesh point limitations. It was impossible to mockup a core with 7 rods full in. Thus, it was necessary to use a 5 rod full in PDQ calculation and devise a method to obtain 7 rod bank parameters for use in the axial power distribution calculation. This method will be discussed in the next section.

\subsubsection{Axial Power Distribution}

The axial power distribution for the PM-2A was calculated using an axial VALPROD, an IBM-650 Code. The input nuclear parameters for the VALPROD were obtaine d by flux weighting both the rods-in and the rods-out nuclear constants of the PDQ-3 input by the integrated regional fluxes of the PDQ output. (3) This method has been found to agree much better with experimental results than the WINDOWSHADE code. In the WINDOWSHADE code, a calculated thermal poison cross section, $\Sigma_{P}$ is added to the core group constants in the rodded region:

The axial power distribution with no xenon for the SM-1 and the SM-1A was calculated by the following technique.

1. A 5 rod flux weighted axial VALPROD was run to obtain a $\mathbf{K}_{\text {eff }}$ (as close to 1 as possible) and a rod bank position.

2. A WINDOWSHADE (using SM-2 fixed elément homogenize'd constants) was run searching for a 5 control rod $\sum_{P}$ to be used with the rod bank position and $\mathrm{K}_{\text {eff }}$ obtained from the axial VALPROD.

3. When a $\sum_{P}$ for 5 rods was obtained in this fashion, a $\sum_{P}$ for 7 rods was obtained using the $\mathrm{Jo}^{2}$ method described in reference (1).

4. After obtaining $\sum_{\mathrm{P}}$ for 7 rods, another WINDOWSHADE using the $7 \mathrm{rod} \sum \mathrm{p}$ (with a $\mathrm{K}_{\mathrm{eff}}$ of 1.00 ) was run to obtain the proper $7 \mathrm{rod}$ bank position and corresponding axial power distribution.

\subsubsection{Reactivity Calculations}

Reactivity values for all three cases were obtained from the PDQ-3 output by the following:

$$
\dot{\rho}=\frac{\mathrm{K}_{\text {eff }}-1}{\mathrm{~K}_{\text {eff }}}
$$


From previous studies employing the same analytical models, it was found that the predicted reactivities underestimated the measured values by approximately $2 \% \rho$. Therefore a model correction of $2 \% \rho$ was added to all calculated reactivities.

Also evaluated by use of PDQ-3 were the rod bank worths in each of the cores. This was calculated by performing PDQ-3's for rods full-in and rods full-out cases. The value of the control rod bank worth was then obtained by:

$$
\rho_{\text {rods }}=\frac{\left(\mathrm{K}_{\text {eff }}\right)_{\text {out }}-\left(\mathrm{K}_{\text {eff }}\right)_{\text {in }}}{\left(\mathrm{K}_{\text {eff }}\right)_{\text {out }}}
$$

\subsection{POWER DISTRIBUTION CALCULATIONS}

\subsubsection{SM-1 Core}

This section contains a preliminary analysis of the power distribution and radial power factors for the SM-1 core $(\mathrm{Fig}, 2.1)$ at $68^{\circ} \mathrm{F}$ and $440^{\circ} \mathrm{F}$. using SM-2 fuel elements. The power generation within the core must be known in order to perform a thermal analysis. To perform this thermal : analysis, certain nuclear factors must be available; these include:

\footnotetext{
$F_{n}(\triangle T)=$ nuclear hot spot factor to allow for uncertainty in the calculated power distribution used in the.calculation of bulk coolant temperature rise.

$F_{n}(\Delta \theta)=$ nuclear hot spot factor to allow for uncertainty in the calculated power distribution used in the calculation of the film temperature rise.
Q $(\triangle T)=$ power generation rate for worst channel in each element, normalized to an average radial power of one over the whole core.

$\overline{\mathrm{Q}(\triangle \mathrm{T}):}=$ average power generation rate in each element, normalized to an average radial power of one over the whole core.

$\mathrm{Q}(\Delta \theta)=$ power generation rate at the hottest spot in each element normalized to an average radial power of one over the whole core.

$\psi(\Delta \mathrm{T})=$ fraction of total reactor power generated in the core.
} 

$\psi(\Delta \theta)=\begin{aligned} & \text { fraction of total reactor power generated in the fuel } \\ & \text { plates }\end{aligned}$
L $\quad=$ active core height
$\begin{aligned} \mathrm{N}= & \text { total number of space increments within the core, } \\ & \text { as used in the WINDOWSHADE calculations. }\end{aligned}$

To obtain the radial power peaking factors, four PDQ-3 cases were performed:

1. Rods Out, $\mathrm{T}=440^{\circ} \mathrm{F}$

2. Rods In, $\mathrm{T}=440^{\circ} \mathrm{F}$ (5 rod bank)

3. Rods Out, $\mathrm{T}=68^{\circ} \mathrm{F}$

4. Rods In, $\mathrm{T}=68^{\circ} \mathrm{F}$ ( 5 rod bank)

Figures 2.2 through 2.9 show graphically the calculated radial power distributions along the central radial plane both parallel and perpendicular to the fuel plates, for the hot and cold cores, rods in and rods out, for the SM-1 core with SM-2 elements.

Figures 2.10 through 2.13 show the radial values obtained from the SM-1 Core I PDQ' S. (4) In comparing Fig. 2.3 with Fig. 2.11 it is noticed that the intercell power peaking is greater in the SM-1 core with SM-2 elements due to the higher absorption in the SM-2 elements. The wider meat region in the SM-2 elements decreases the relative value of the power peaks, but the relatively high SM-2 loading (Table 2.1 ) tends to override this effect and increases the peaking.

Table 2.2 lists the radial $(\mathrm{x}, \mathrm{y})$ maximum-to-average power ratio for various elements in the core. Central element values are essentially the same for both cases, but the ratio in the outer elements is substantially higher for the SM-2 element core. This is due once again to the higher loading. in the SM-2 elements. 
TABLE 2.2

MAXIMUM -TO-AVERAGE RADIAL POWER PEAKING VALUES

FOR SM-1 CORE I AND SM-1. CORE WITH SM-2 ELEMENTS, $440^{\circ} \mathrm{F}$

Perpendicular To Fuel Plates

Element No.

44 (Control Rod C)

45

46 (Control Rod 2)

47
SM-1 Core I

1.039

1.100

1.175

1.464

$\underline{\text { Parallel To Fuel Plates }}$
Element No.

44 (Control Rod C)

34

24 (Control Rod 1)

14
SM-1 Core I

1.124

1.150

1.243

1.318
SM-1 Core (SM-2 Elements)

1.085

1. 157

1. 181

2. 100
SM-1 Core (SM-2 Elementsi)

1.158

1. 233

1.215

1. 800

The axial power distributions were callculated by the WINDOWSHADE and VALPROD codes. As mentioned in Section 2.1.2.2, flux weighted values for axial VALPROD inputs are calculated from the PDQ output.

Five rod bank axial VALPRODS were run with and without $\mathrm{Eu}_{2} \mathrm{O}_{3}$ flux suppressors at the bottom of the fixed fuel elements. Figures 2.14 and 2.15 show graphically the axial power distribution for each case. The use of flux suppressors effectively eliminates the power spike but increases the power peak within the core.

Five rod bank calculations were converted to 7 rod bank calculations by the method described in Section 2.1.2.2. Figure 2.16 shows the axial power distribution obtained from both the 5 and 7 rod WINDOWSHADE。 The WINDOW-

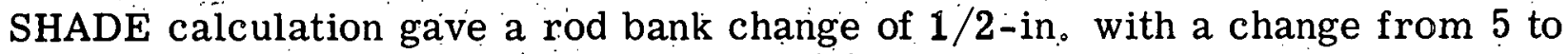
7 rods. Based on Fig. 10 in reference $(6)$, a value closer to one inch is predicted. The effect of this difference on power distribution is negligible. 
A comparison was made between the axial power distribution in the SM-1 Core I and SM-1 with SM-2 elements. Figures 2.16 and 2.17 show that except for an axial shift due to rod bank position, the relative values for the 5 rod SM-1 Core I and the 7 rod SM-1 with SM-2 elements are very similar for the initial case. Figures 2.14 and 2.15 show that a flux suppressor causes a higher power peak inside the core, while effectively eliminating the power spike at the bottom of the core; therefore, if flux suppressors were used in the calculations presented in Fig. 2.17, the power distributions would be in better agreement with the 7 rod bank curve in Fig. 2.16.

When the analyses of the radial and axial power distributions were completed, calculation of the power peaking factors was possible.

$F_{n}(\triangle T)$ and $F_{\mathfrak{n}} .(\Delta \theta)$ were assigned values of 1.05 and 1.10 respectively. $(8)$

The factor $\mathbf{Q}(\Delta \theta)$ is calculated by the following equations:

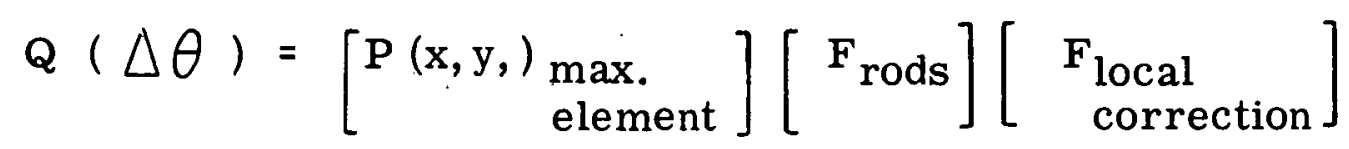

Where $P(x, y,)_{\text {max }}$; element is the hottest spot in each element as calculated by the $P D Q-3$ code, and $F$ rods and $F$ local correction are correction factors which will be discussed in another section.

The factor $Q(\Delta T)$ is calculated with the following equation:

$$
\begin{aligned}
& Q(\Delta T)=\left[P_{\text {hot plate }}\right]\left[F_{T}\right] \\
& \text { where } F_{T}=\left[F_{\text {rods }}\right] \\
& \text { The value of } \frac{\left.F_{\text {local correction }}\right]}{Q(\Delta T) \text { is obtained from the equation: }} \\
& \overline{Q(\Delta T)}=\left[P_{\text {element }}\right] F_{T}
\end{aligned}
$$

Correction factors, $\mathrm{F}_{\text {rods }}$ and $\mathrm{F}$ local correction, were incorporated to bring calculated radial power values more into agreement with measured values. $F_{\text {rods }}$ is used to make the calculated value of the power at the center of each element agree with the experimental values of the power at the center of each element. The equation for $\mathrm{F}_{\text {rods }}$ for a given element is: 
$F_{\text {rods }}:=\frac{\left[\frac{P(x, y, z) \text { measured at the center of the element }}{P(\text { measured with a core average of } 1.0)}\right]}{\left[\frac{P(x, y) \cdot P(z) \text { calculated at the center of the element }}{P(\text { calculated with a core average of } 1.0)}\right]}$

where

$$
\begin{aligned}
& \mathrm{P}(\mathrm{x}, \mathrm{y}, \mathrm{z}) \quad=\text { the power measured by a foil count } \\
& \mathbf{P}(\mathrm{x}, \mathrm{y}) \quad=\text { radial power from a PDQ calculation } \\
& \mathbf{P}(\mathrm{z})
\end{aligned}
$$

$F_{\text {local correction is a correction factor used to make the calculated power values }}$ at the edge of each element agree with the experimental power value at the edge

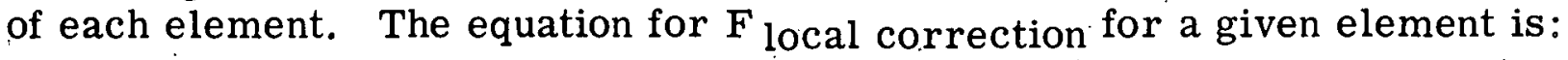

$\mathrm{F}$ local correction

$$
\left[\frac{P(x, y, x) \text { measured at the edge of the element }}{P(x ; y, x) \text { measured at the center of the element }}\right]
$$

$$
\left[\begin{array}{ll}
\mathrm{P}(\mathrm{x}, \mathrm{y}) & \mathrm{P}(\mathrm{z}) \text { calculated at the edge of the element } \\
\mathrm{P}(\mathrm{x}, \mathrm{y}) & \mathrm{P}(\mathrm{z}) \text { calculated at the center of the element }
\end{array}\right]
$$

In this report a value $\mathrm{F}_{\mathrm{T}}$ was used. This is the product of the above two correction factors.

Table 2.3 lists the values of $Q(\Delta \theta)_{0}, Q(\Delta T)_{0}$, and $\overline{Q(\Delta T)_{O}}$ for the SM-1 at $440^{\circ} \mathrm{F}$ and 0 MWYRS. These values will not be the most severe encountered due to the mode of burnup of SM-2 elements. Table 2.3 also lists the values of $Q(\Delta \theta)_{B}, Q(\Delta T)_{B} Q(\Delta T)_{B}$ estimated to be their maximum value using SM-2 data. These values were used in the thermal analysis together with the axial power distribution calculated at. 0 MWRY.

The heat release factors are:

$$
\begin{aligned}
& \Psi(\Delta T)=1.00 \\
& \Psi(\Delta \theta)=0.95
\end{aligned}
$$

These values are reported in reference (8). The value of $L$ is $55.88 \mathrm{~cm}$ or 22 in. The value of $\mathrm{N}$ is 44 calculational points, or a point at every $1 / 2 \mathrm{in}$. in the WINDOWSHADE calculations.

Figure 2.16 shows the relative axial power values used in the thermal calculation. These results were obtained from a WINDOWSHADE calculation. 
TABLE 2.3

RADIAL POWER FACTORS FOR SM-1 CORE

WITH SM-2 ELEMENTS, $\mathrm{T}=440^{\circ} \mathrm{F}$

Element No.

O MWYR

Estimated Maximum

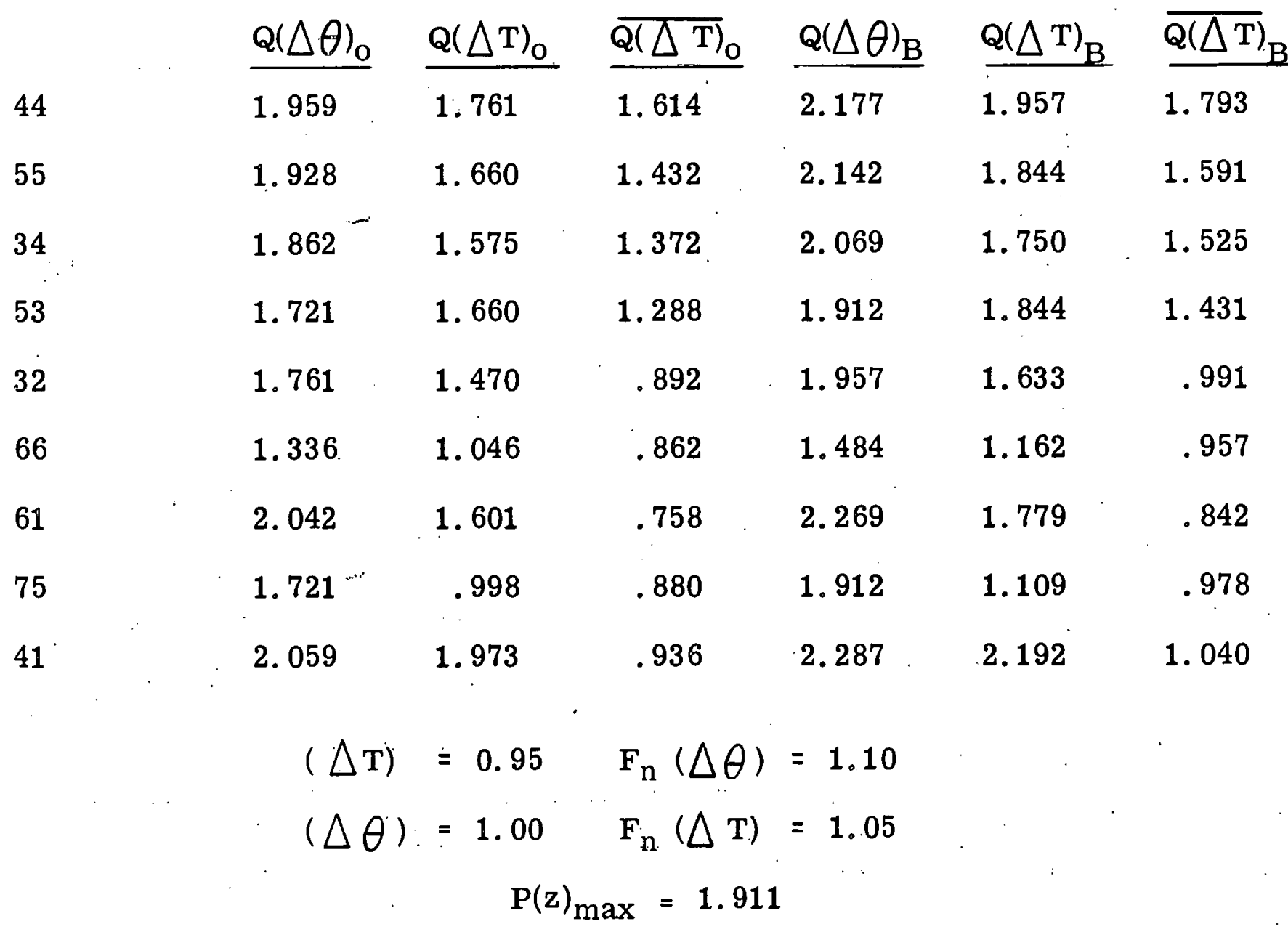

\subsubsection{SM-1A Core}

The SM-1A core is essentially the same as the SM-1. It has 38 fixed fuel elements and seven control rod fuel elements in a closed array (Fig. 2.18). The fuel loadings are the same. The SM-1A differs from the SM-1 in that all the fuel plates in the outer rows of elements in the SM-1A are perpendicular to the water reflector. This modification was incorporated to decrease the power peaking in the outer row of fuel elements. 
O

LOG N CHAMBER $\bigcirc$

SAFETY CHAMBER 20

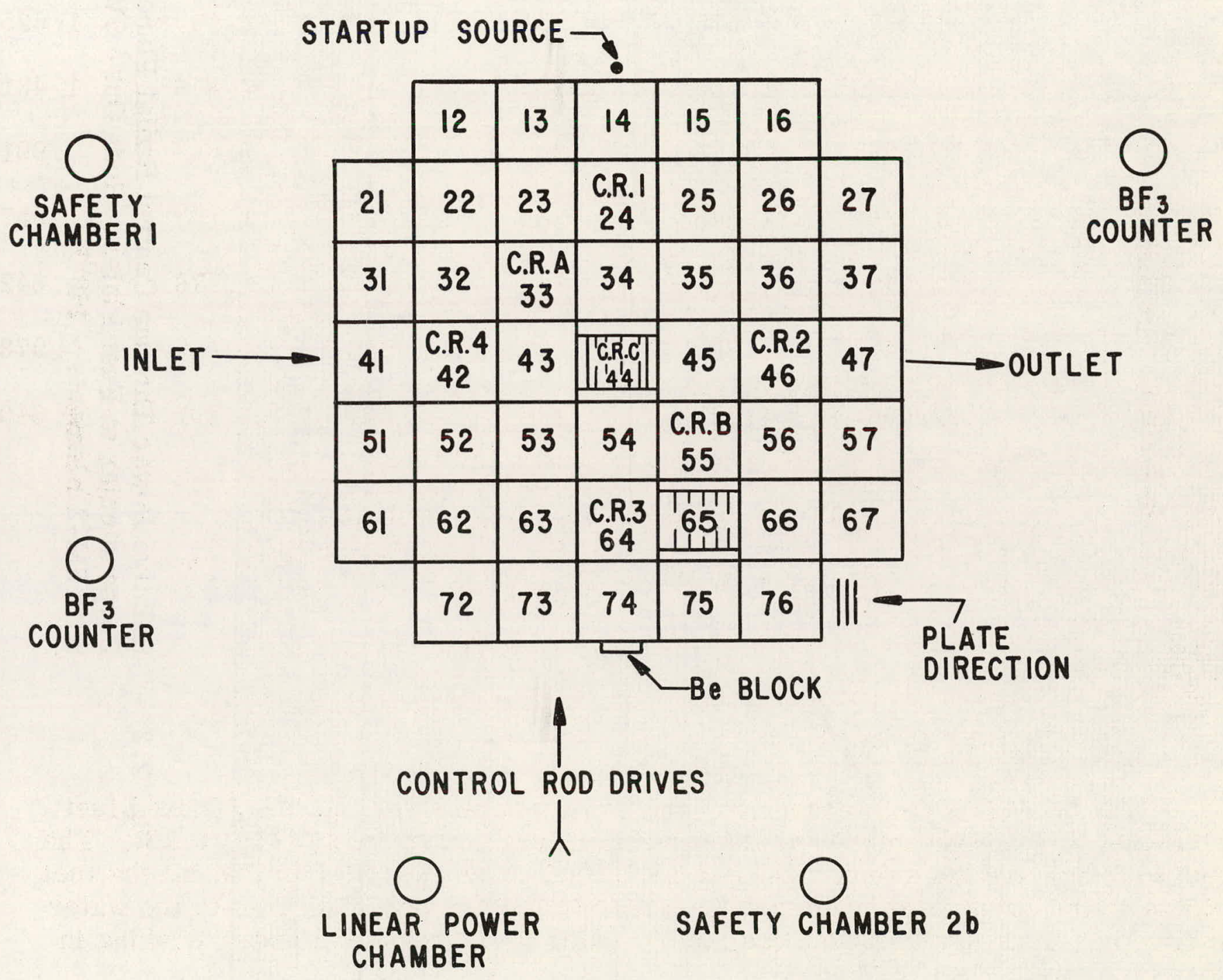

Fig. 2.1 - SM-1 Core Layout 


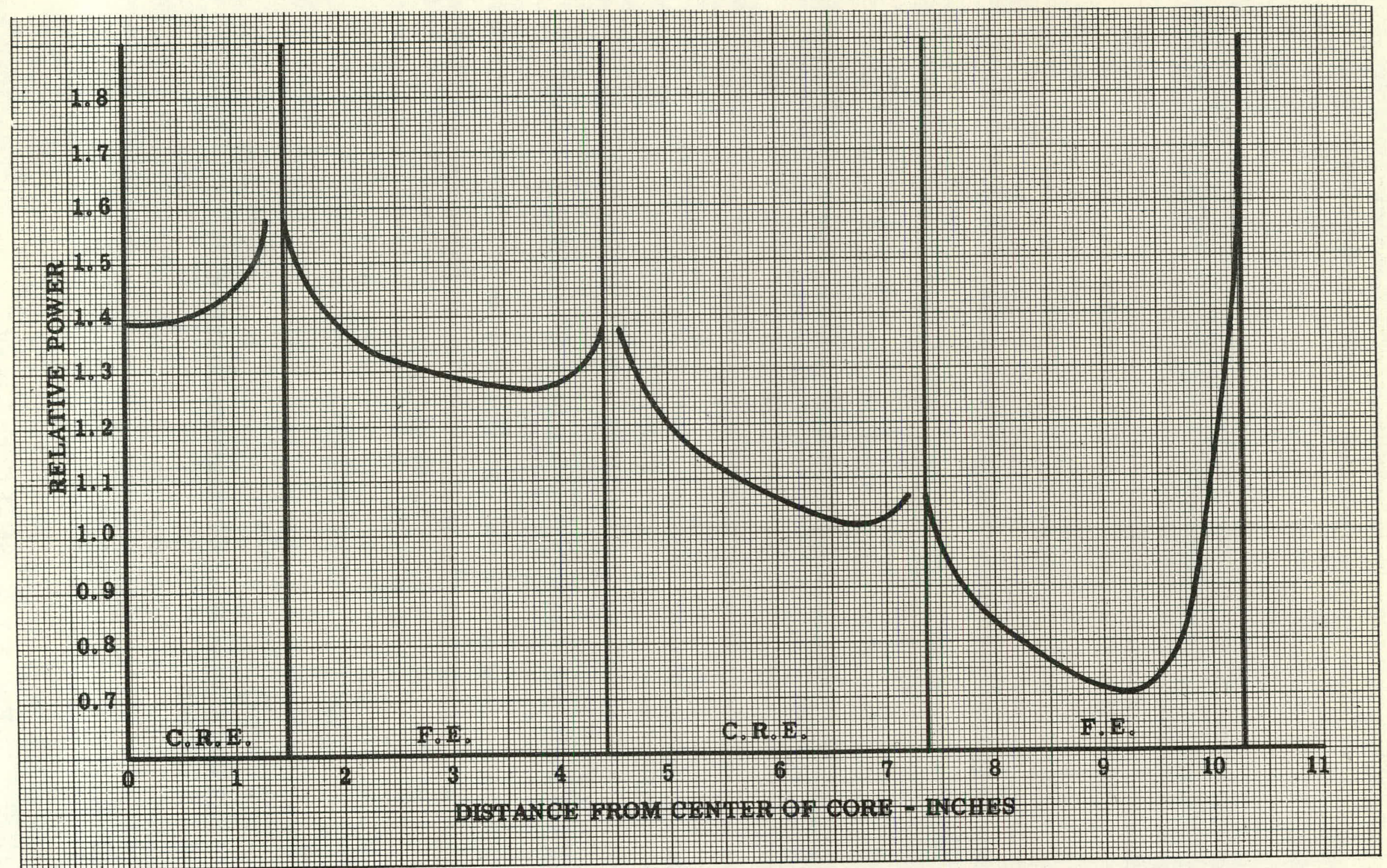

Fig. 2.2 - Relative Power Through Central Radial Plane Perpendicular to Fuel Plates - Rods Out - SM-1 Core With SM-2 Elements $-440^{\circ} \mathrm{F}$ 


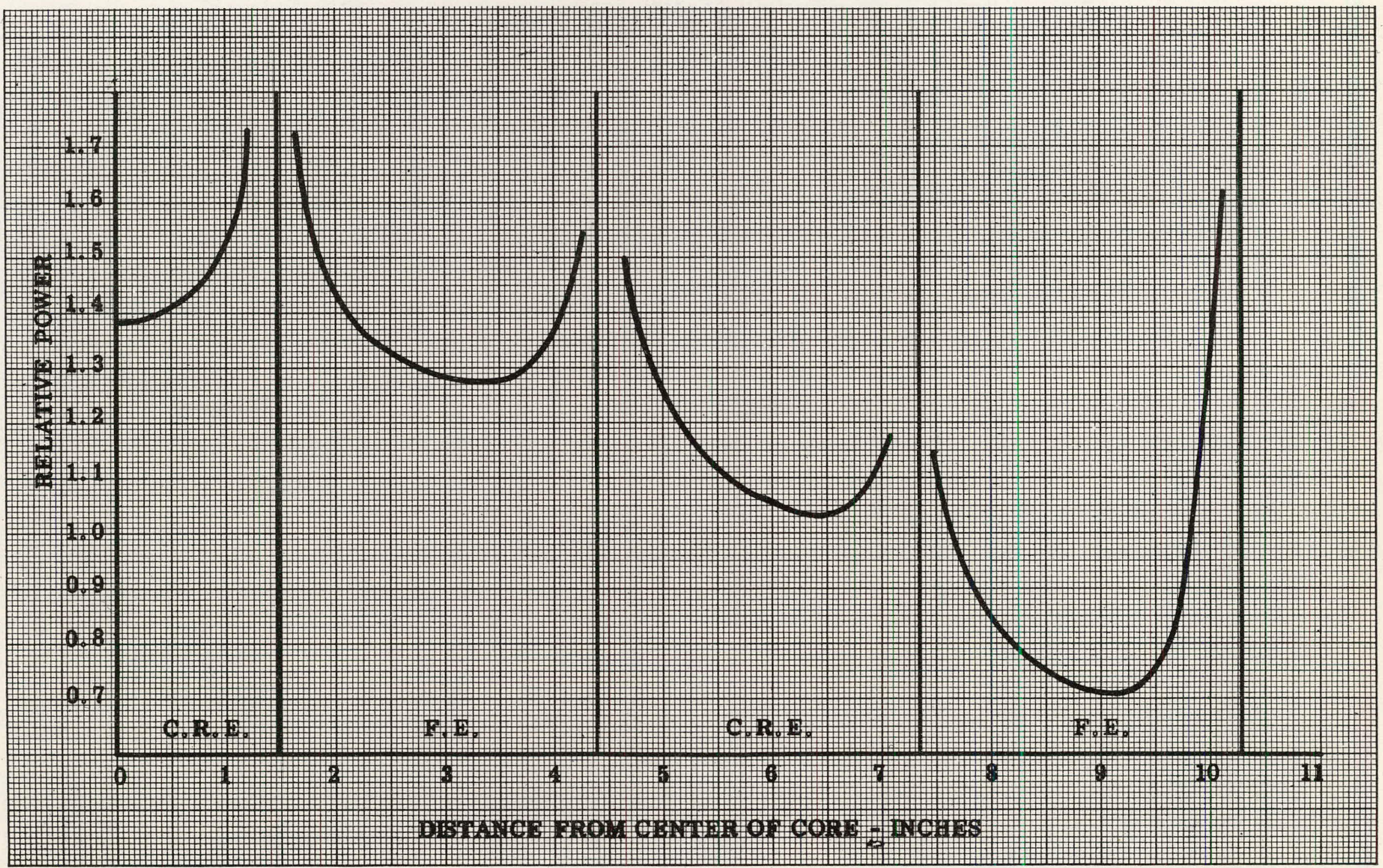

Fig. 2.3 - Relative Power Through Central Radial Plane Parallel to Fuel Plates - Rods Out - SM-1 Core With SM-2 Elements - $440^{\circ} \mathrm{F}$ 


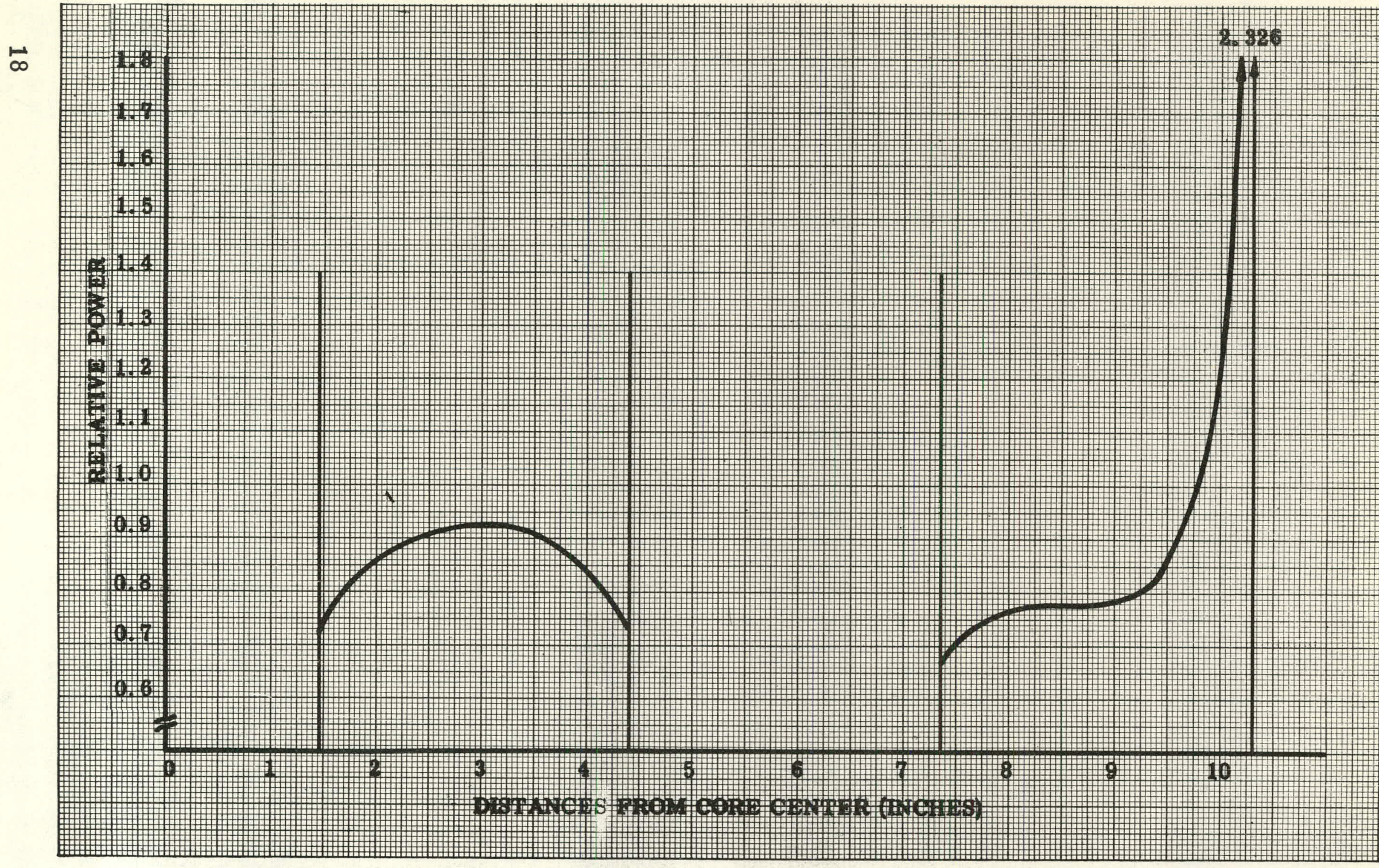

Fig. 2.4 - Relative Power Through Central Radial Plane

Perpendicular to Fuel Plates - 5 Rods in - SM-1 Core

With SM-2 Elements - $440^{\circ} \mathrm{F}$ 


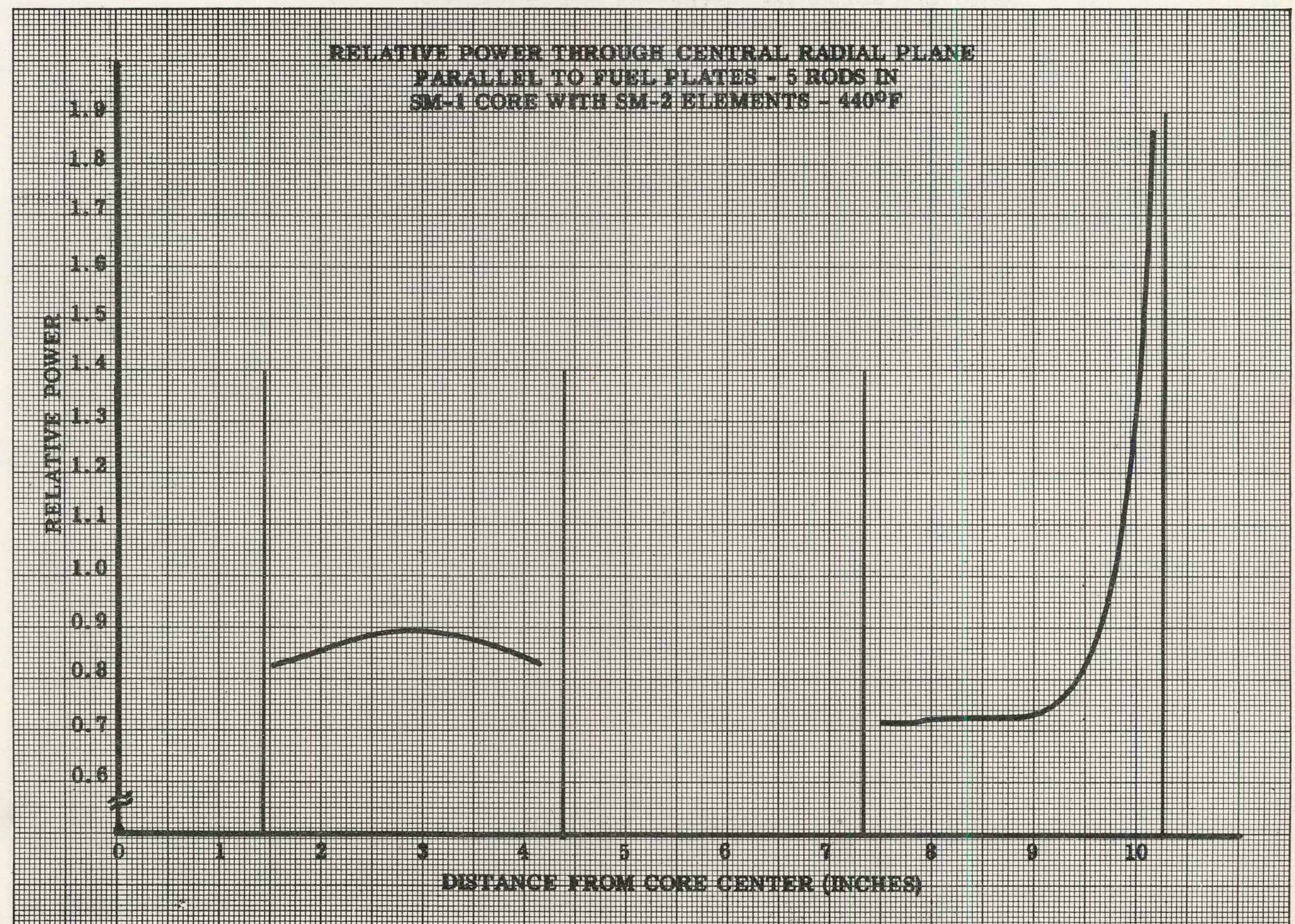




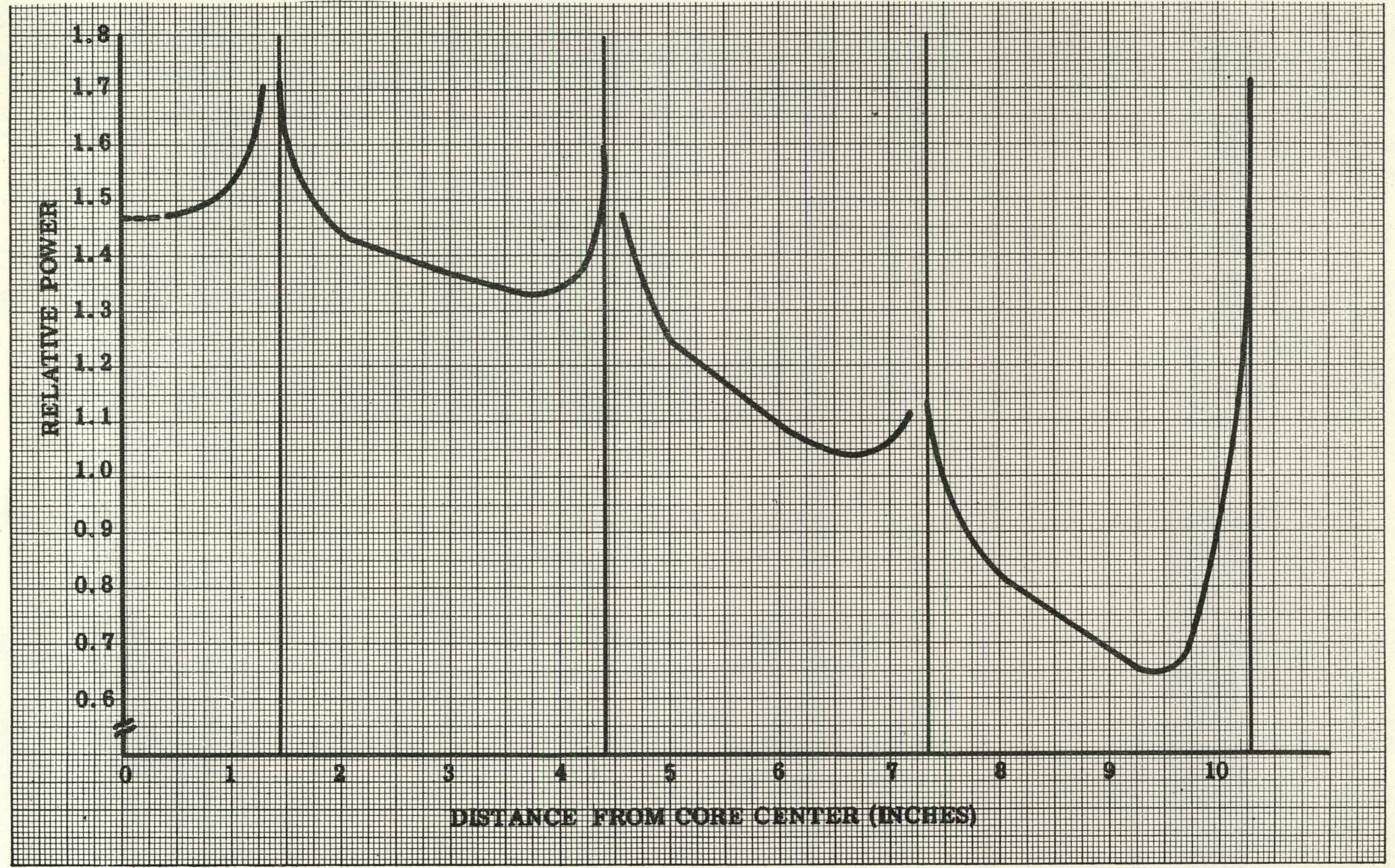

Fig. 2.6 - Relative Power Through Radial Plane Perpendicular To Fuel Plates - Rods Out - SM-1 Core With SM-2 Elements $-68^{\circ} \mathrm{F}$ 


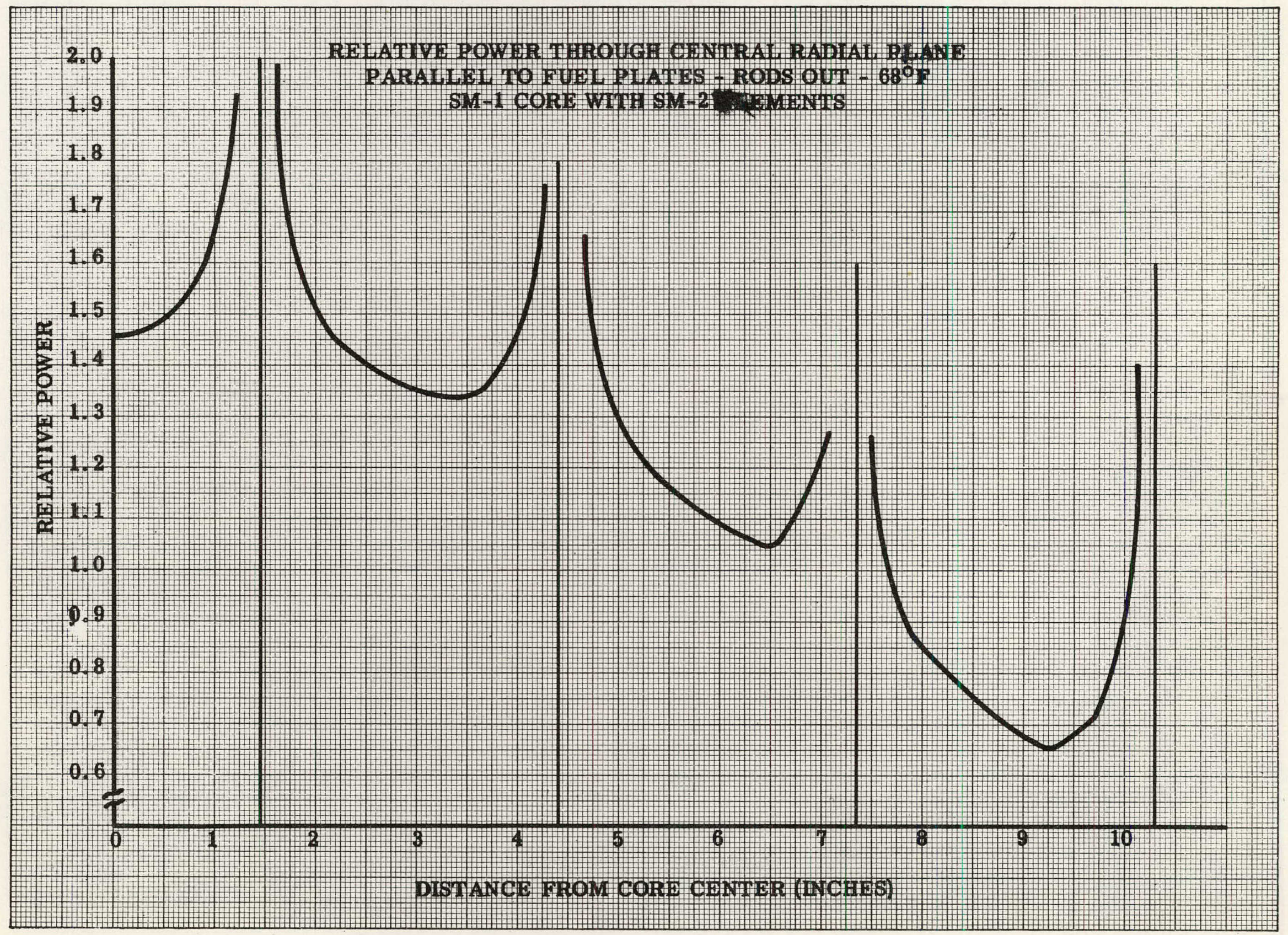

Fig. 2.7 - 
ธิ

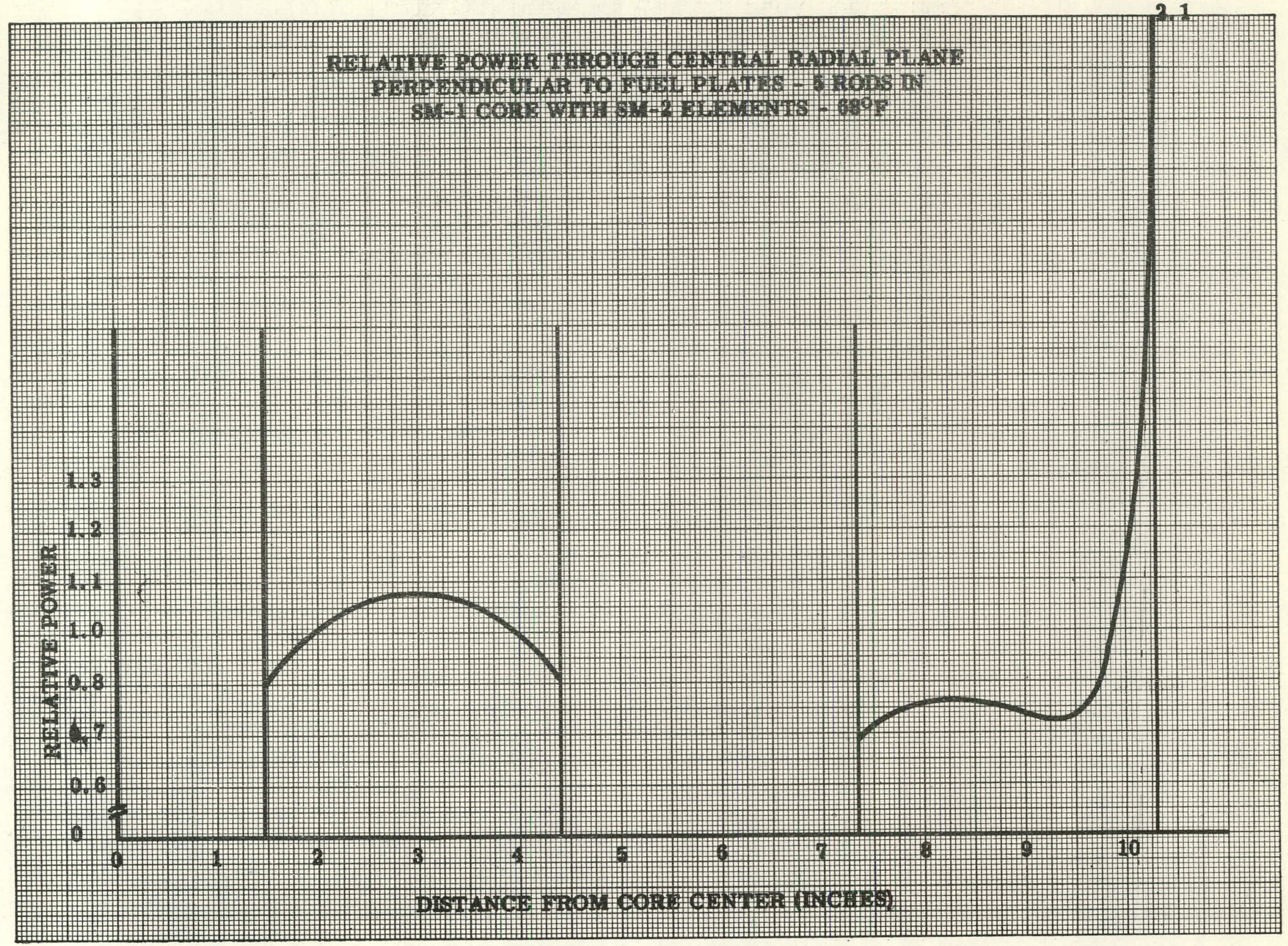

Fig. 2.8 - 


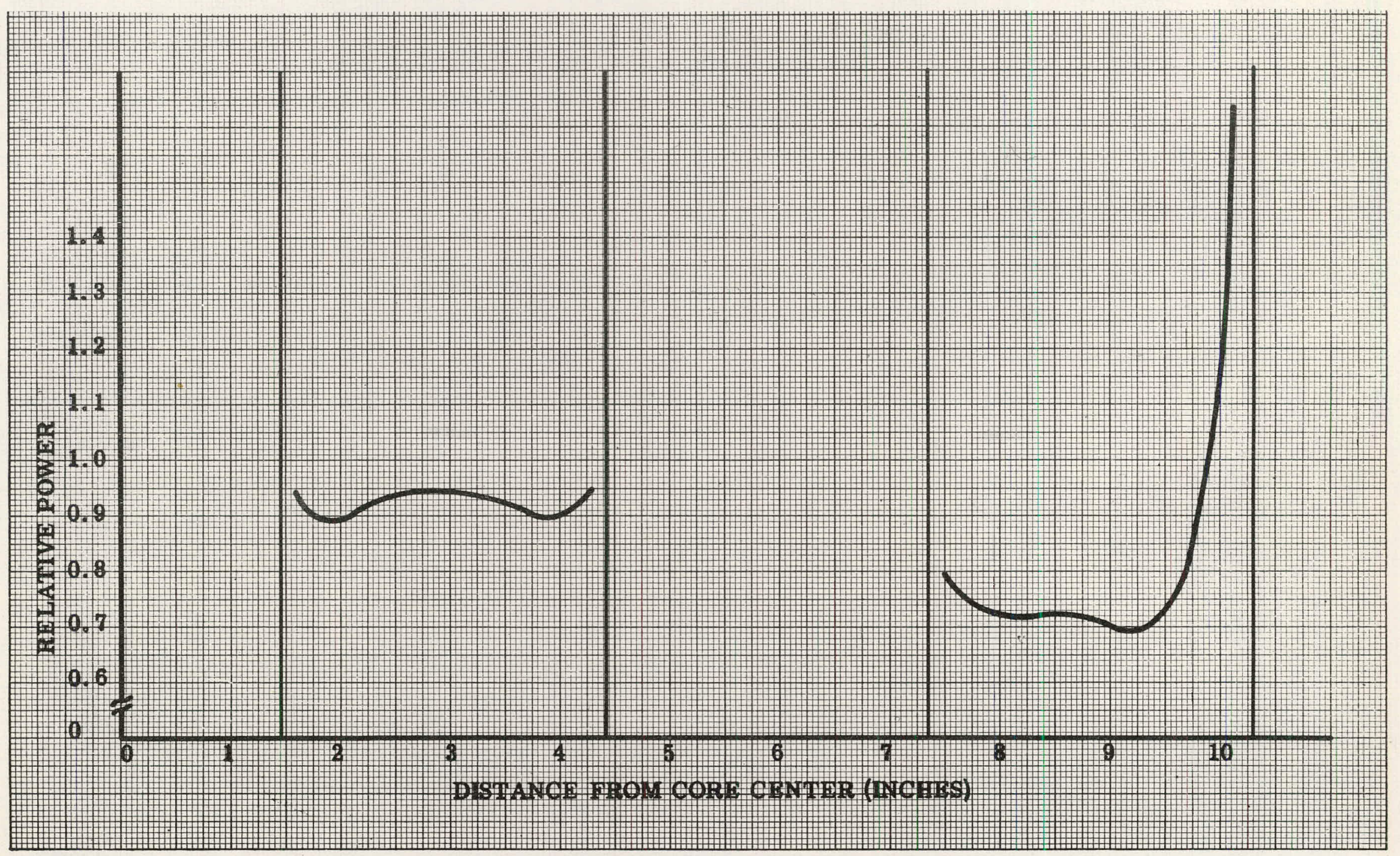




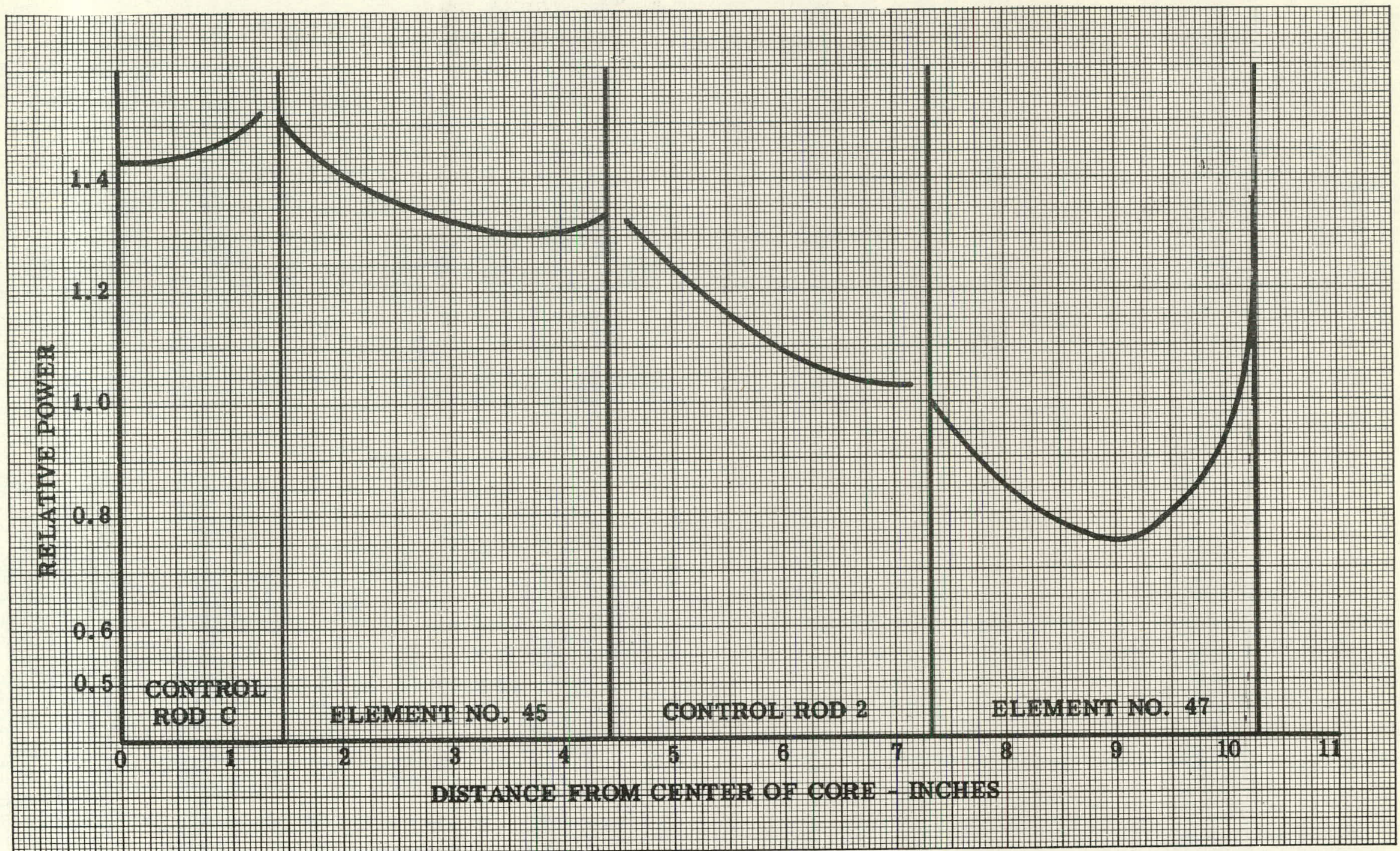

Fig. 2.10 - Relative Power Through Central Radial Plane Perpendicular To Fuel Plates - SM-1 Core I - $440^{\circ} \mathrm{F}$ 


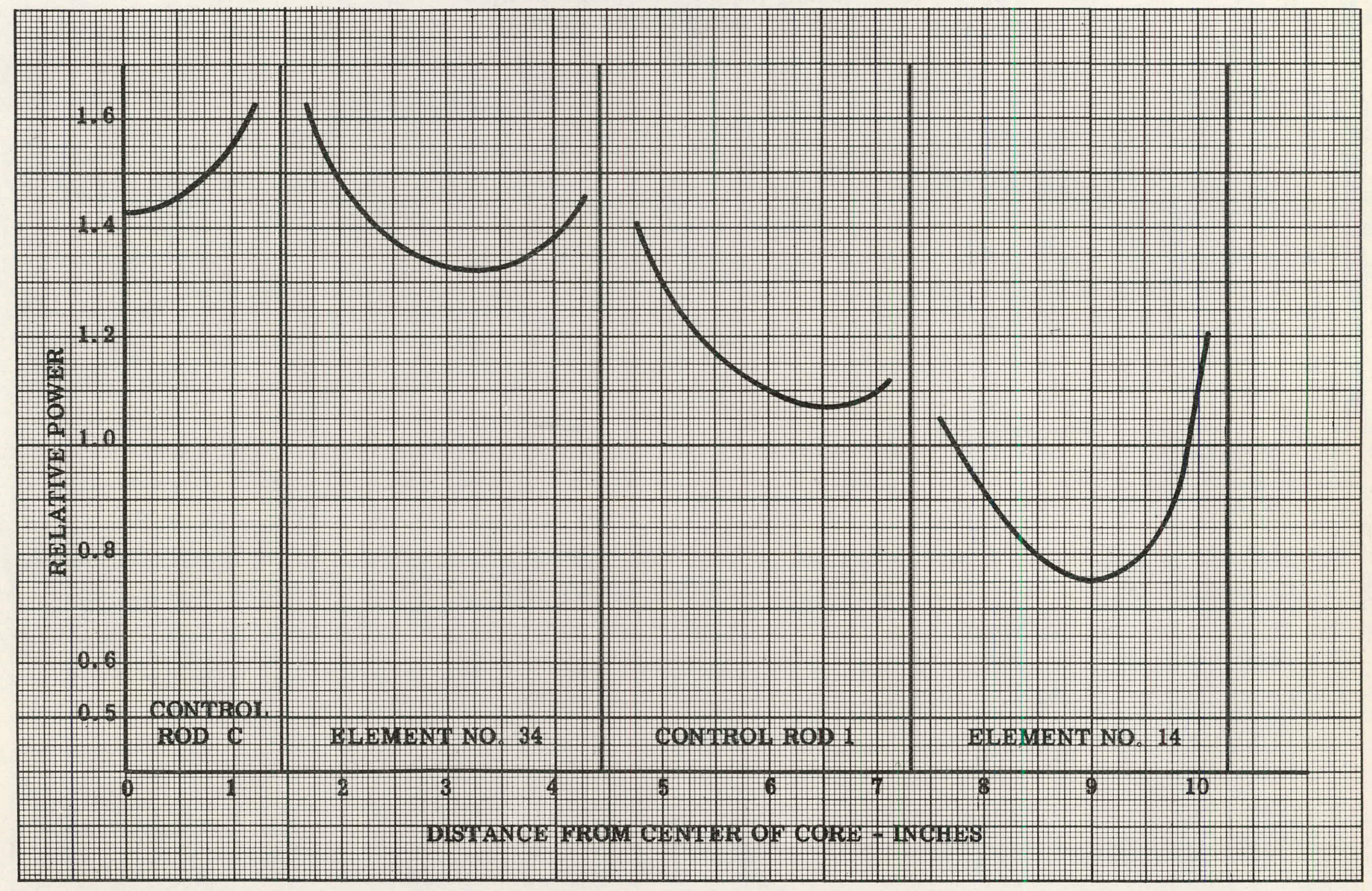
Fuel Plates - SM-1 Core I - $440^{\circ} \mathrm{F}$ 


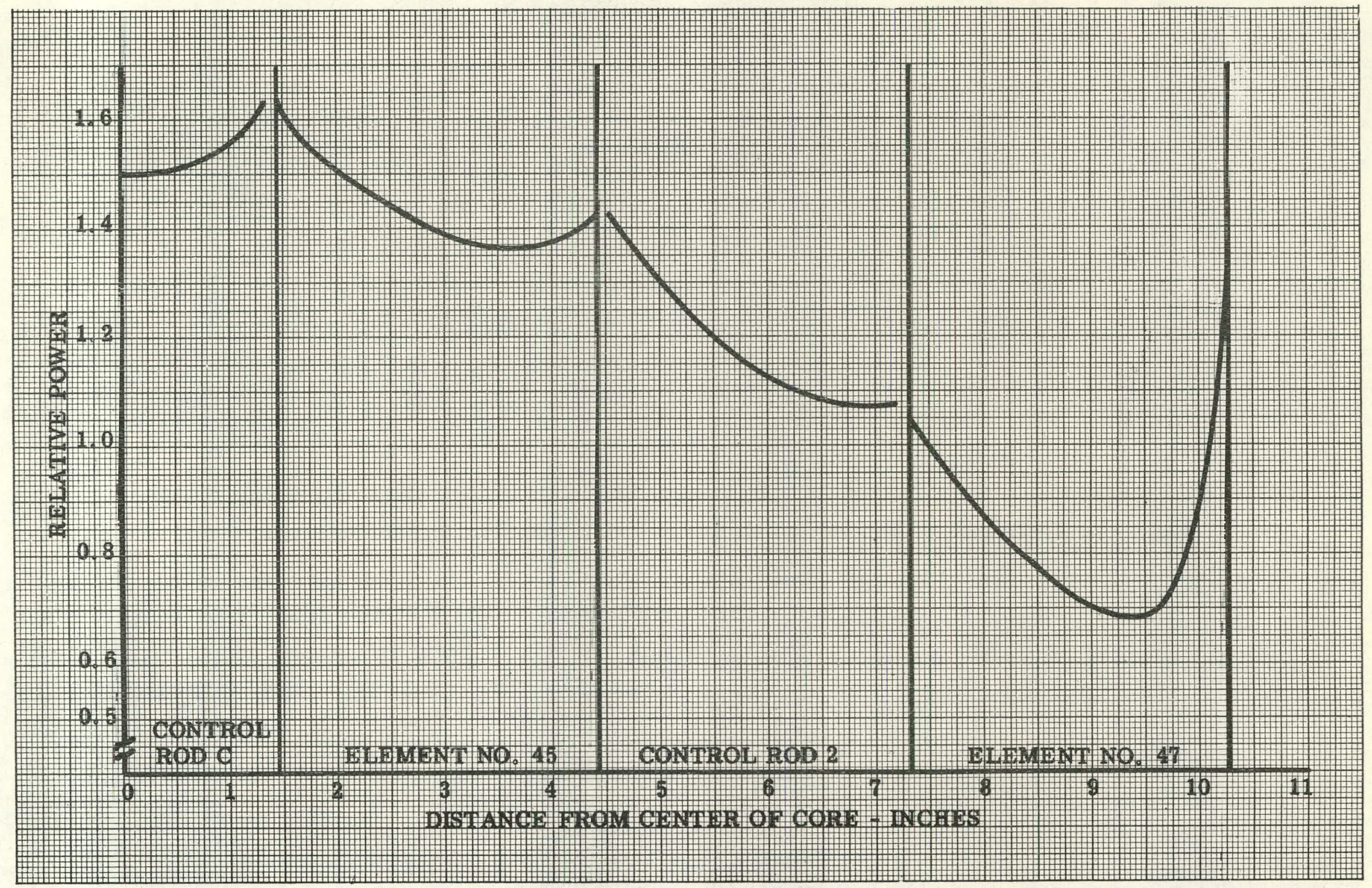

Fig. 2.12 - Relative Power Through Central Radial Plane Perpendicular To Fuel Plates - SM-1 Core I $68^{\circ} \mathrm{F}$ 


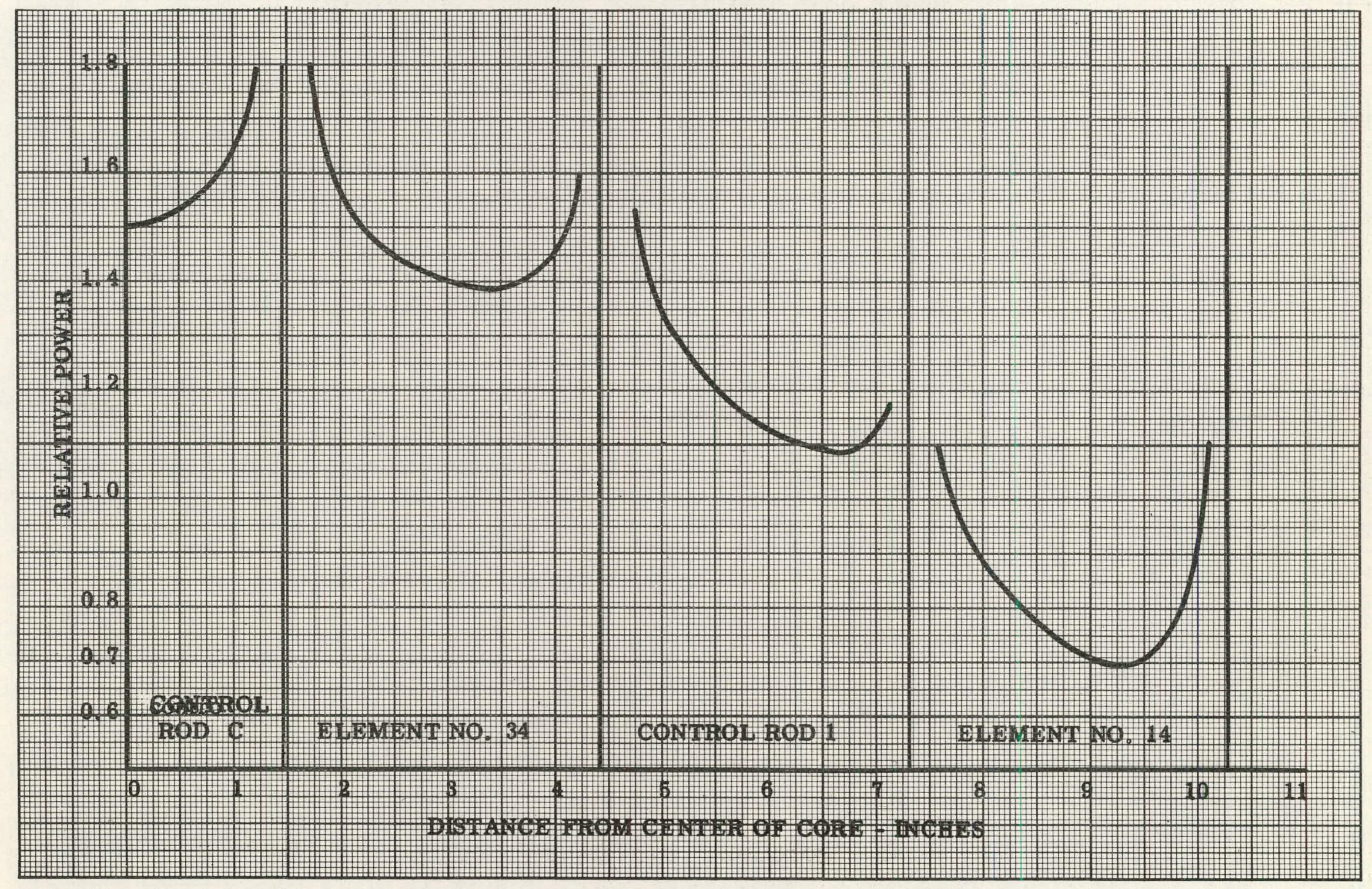




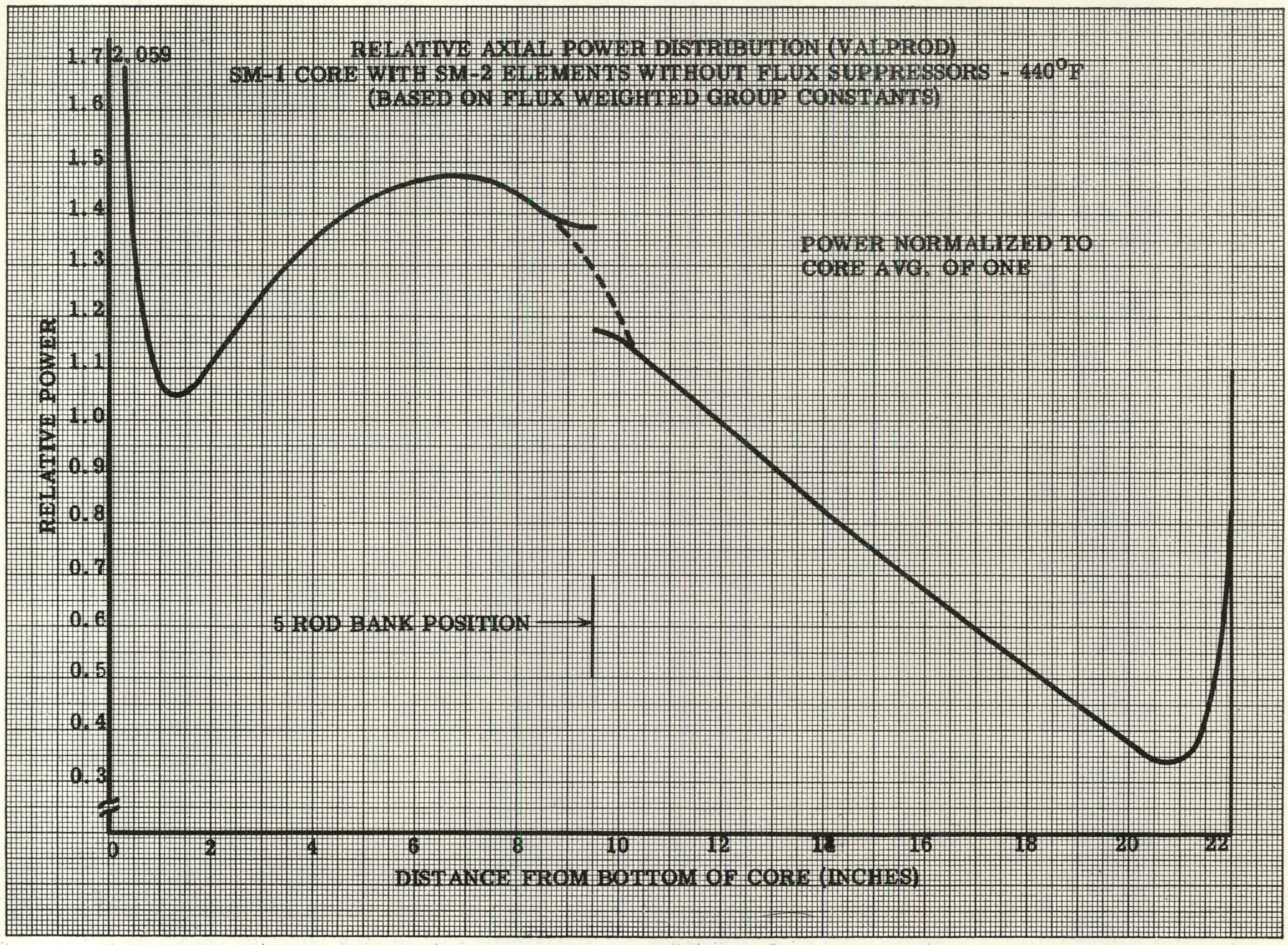

Fig. 2.14 - 


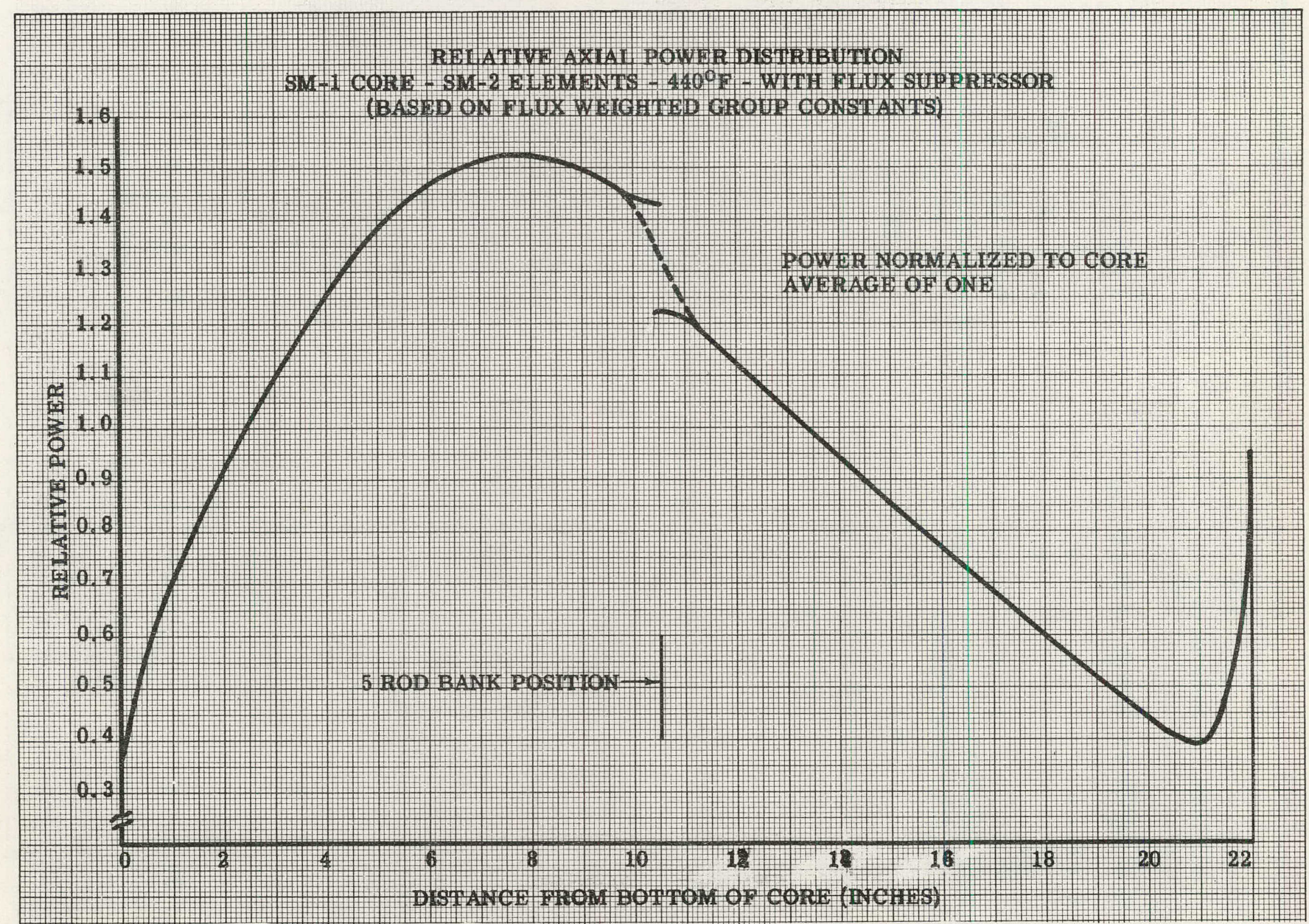

Fig. 2.15 - 


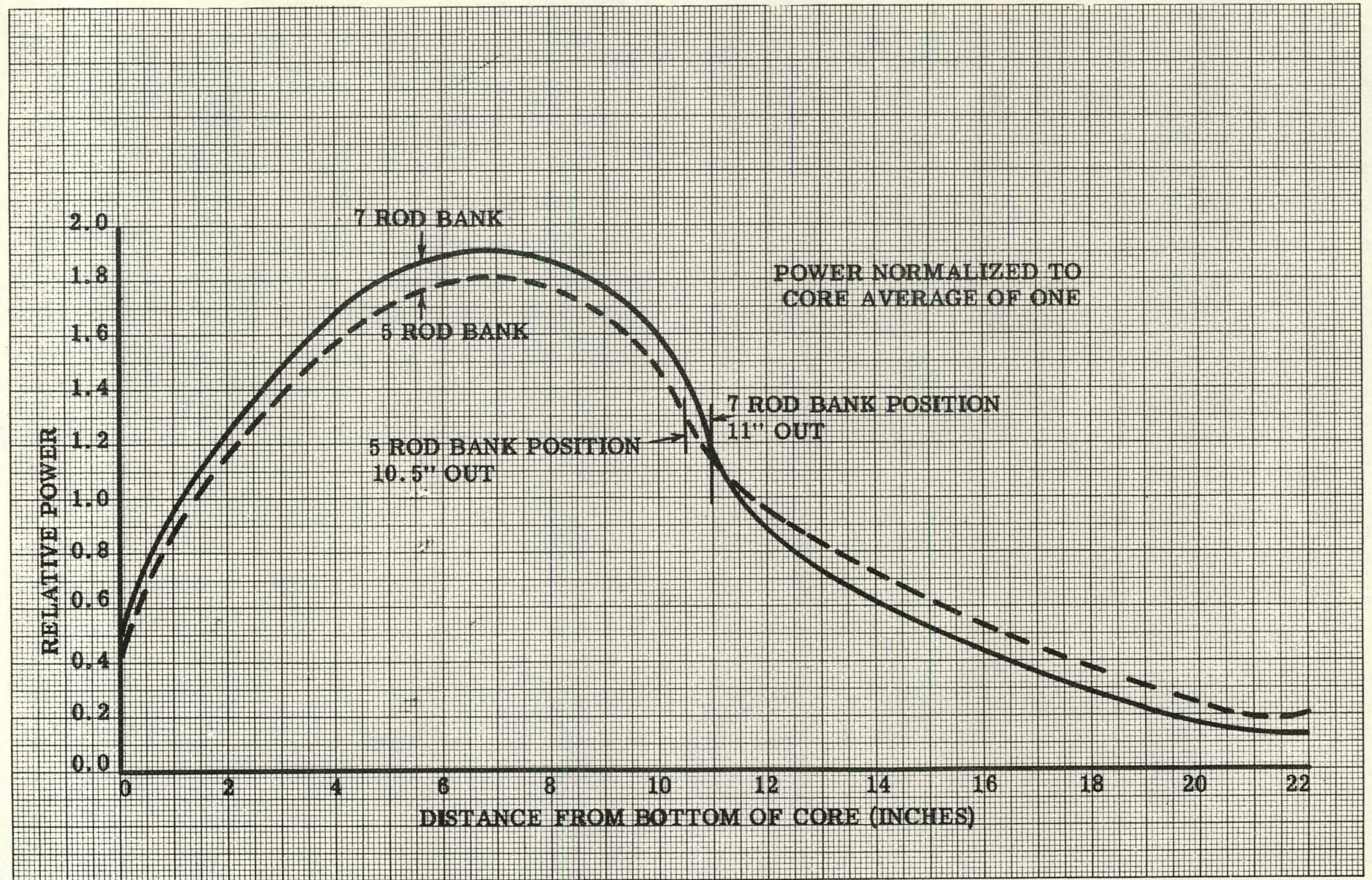

Fig. 2.16 - Relative Axial Power (Windowshade) - SM-1 Core SM-2 Elements - $440^{\circ} \mathrm{F}$ - With Flux Suppressor 


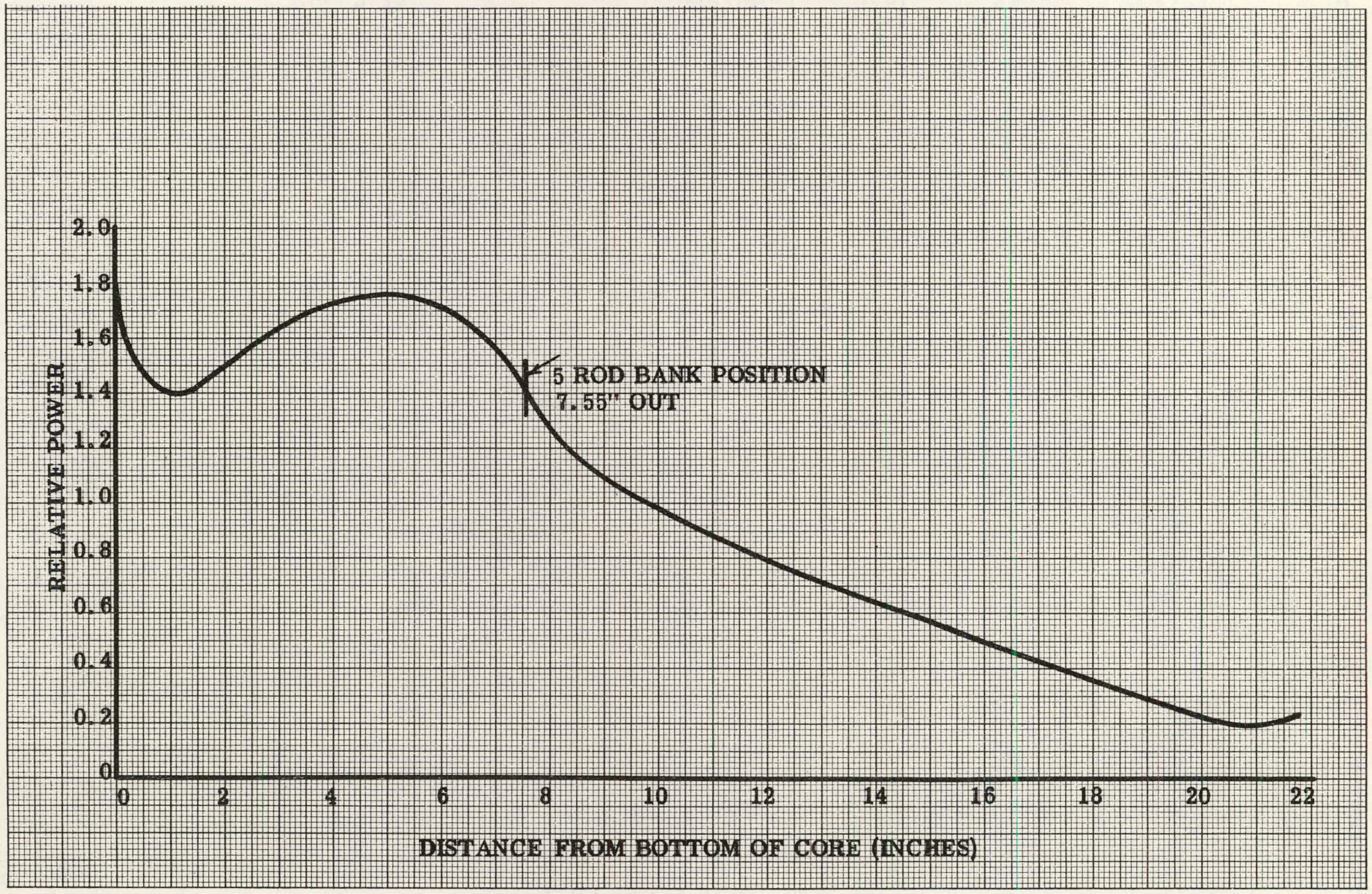


THIS PAGE

WAS INTENTIONALLY

LEFT BLANK 
The method of analysis for the SM-1A was the same as that for the SM-1. Figures 2.19 to 2.24 show graphically the radial power distribution along the central radial plane of the SM-1A. These distributions were obtained, using the IBM-704, PDQ-3 code. The input used was the same as that for the SM-1, except for the geometrical difference of turning the two outside rows of elements.

The PDQ output yielded the results expected along the outer row of fuel elements. Figure 2.19 shows the radial power in the outer element in the SM-1A to be less than that shown in Fig. 2.2 for the SM-1, with the fuel plates $90^{\circ}$ out of phase, while the power distribution in the direction common to both cores is the same. There is a $16 \%$ reduction in the value of the reflector power peaks in the SM-1A compared to SM-1.

The axial power distribution with no xenon in the SM-1A was assumed to be the same as that in the SM-1.

The parameters $F_{n} .(\Delta T)$ and $F_{n} .(\Delta \theta)$ were kept the same as the SM-1: 1.05 and 1.10, respectively.

Table 2.4 lists the values obtained for $\mathbf{Q}(\Delta \theta)_{0}, \mathbf{Q}(\Delta \mathrm{T})_{\mathrm{O}}$ and $\overline{Q(\triangle T)}$ at 0 MWYR in the SM-1A. The estimated maximum power for the SM-1A is the same as the SM-1. Table 2.4 also lists the values of $Q(\Delta \theta)_{B}$, $\mathrm{Q}(\triangle \mathrm{T})_{\mathrm{B}}$ and $\overline{\mathbf{Q}(\triangle T)_{\mathrm{B}}}$ which were the values used to calculate reactor conditions in the most severe cases.

The heat release factors are:

$$
\begin{aligned}
& \psi(\Delta \mathrm{T})=1.00 \\
& \psi(\Delta \theta)=0.95
\end{aligned}
$$

The value of $\mathrm{L}$ is $55.88 \mathrm{~cm}$ or 22 in.

The value of $\mathrm{N}$ is 44 as in the SM-1; no WINDOWSHADES were run for this case since SM-1 axial data was used. 
TABLE 2.4

RADIAL POWER FACTORS FOR SM-1A CORE WITH SM-2 ELEMEN TS, T $=440^{\circ} \mathrm{F}$

Element No.

0 MWYR

Estimated Maximum

\begin{tabular}{|c|c|c|c|c|c|c|}
\hline & $\mathbf{Q}(\Delta \theta)_{0}$ & $Q(\Delta T)_{0}$ & $\overline{Q(\Delta T)_{0}}$ & $\mathbf{Q}(\Delta \theta)_{\mathbf{B}}$ & $Q(\Delta T)_{B}$ & $\overline{\mathbf{Q ( \Delta T ) _ { E }}}$ \\
\hline 44 & 1.963 & 1.765 & 1.617 & 2.181 & 1. 961 & 1. 797 \\
\hline 46 & 1. 698 & 1.523 & 1.136 & 1.887 & 1. 692 & 1. 262 \\
\hline 67 & 2.196 & 1.550 & .503 & 2.440 & 1.120 & .892 \\
\hline$\dot{5} 4$ & 1.962 & 1.654 & 1. 452 & 2.180 & 1.838 & 1. 613 \\
\hline 43 & 1.876 & 1.662 & 1.390 & 2. 084 & 1.847 & 1.545 \\
\hline 32 & 1.776 & 1.494 & 1.147 & 1.973 & 1.660 & 1.275 \\
\hline 63 & 1.689 & 1.395 & 1.136 & 1. 877 . & 1.550 & i. 262 \\
\hline 36 & 1.516 & 1.242 & 1.069 & 1.684 & 1. 380 & 1.188 \\
\hline 66 & 1.331 & 1.050 & .866 & 1.479 & 1.167 & .963 \\
\hline & $\psi(\Delta \theta)$ & 0.95 & $F_{n}:(\Delta \theta)$ & -1.10 & . & \\
\hline & $\psi(\Delta, T)$ & 1.00 & $F_{n}:(\triangle T)$ & -1.05 & & \\
\hline & & $\mathrm{P}(\mathrm{z})_{\text {max }}$ & -1.911 & & & \\
\hline
\end{tabular}

\subsubsection{PM-2A Core}

The analysis for the PM-2A Core (Fig. 2.25) is almost an exact duplicate, in outline, as the SM-1 and SM-1A core analysis. Figures 2.26 to 2.33 show graphically the radial power distributions obtained in each case. The axial power distribution and rodbank positions were calculated using the axial VALPROD code. Figure 2.34 shows the axial power distribution used for the thermal analysis.

Values of $\mathbf{Q}(\Delta \theta)_{0} \cdot \mathbf{Q}(\triangle \dot{T})_{0}$ and $\mathbf{Q}(\overline{\Delta T})_{0}$ are tabulated in Table 2.5 . Table 2.5 also lists the values of $\mathbf{Q}(\Delta \theta \cdot)_{B}, \mathbf{Q}(\Delta \mathrm{T})_{\mathrm{B}}$ and $\overline{\mathbf{Q}}(\Delta \mathrm{T})_{\mathrm{B}}$ at their estimated maximum. The other values used for thermal information were the same as the SM-1 and SM-1A. 


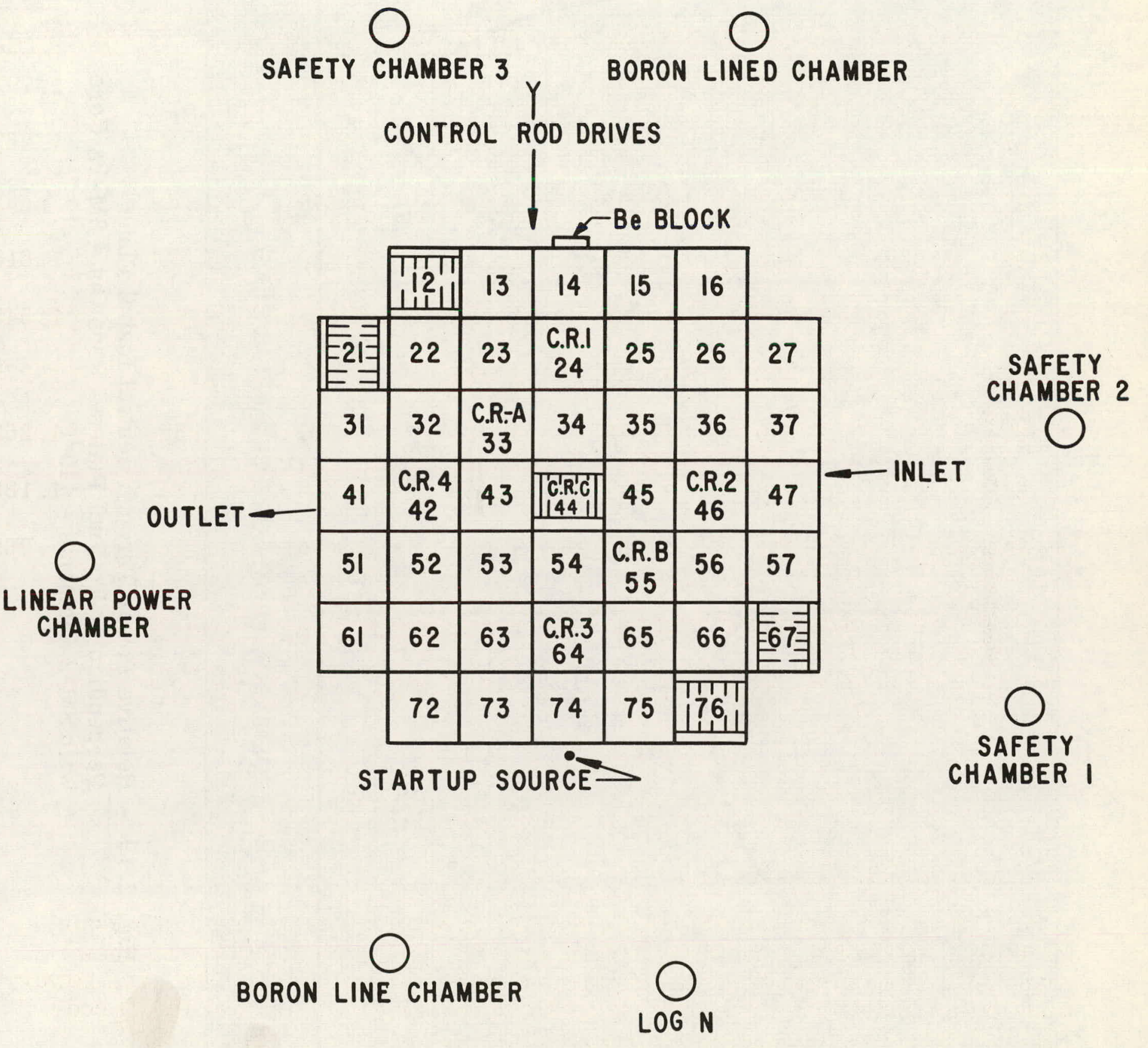

Fig. 2.18 - SM-1A Core Layout 
ळ

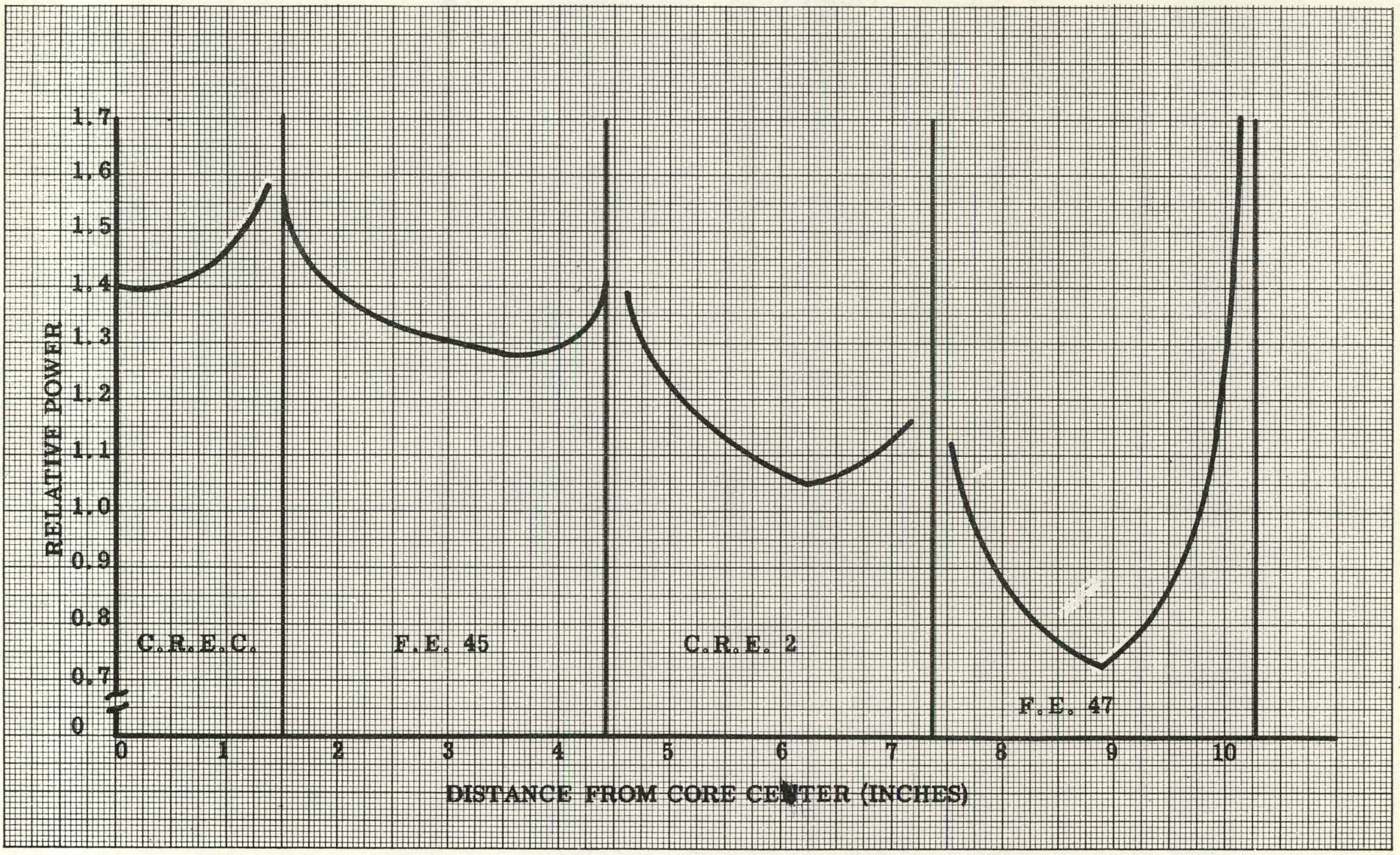

Fig. 2.19 - Relative Power Through Central Radial Plane Perpendicular To Fuel Plates - Rods Out - SM-1A Core With SM-2 Elements - $440^{\circ} \mathrm{F}$ 


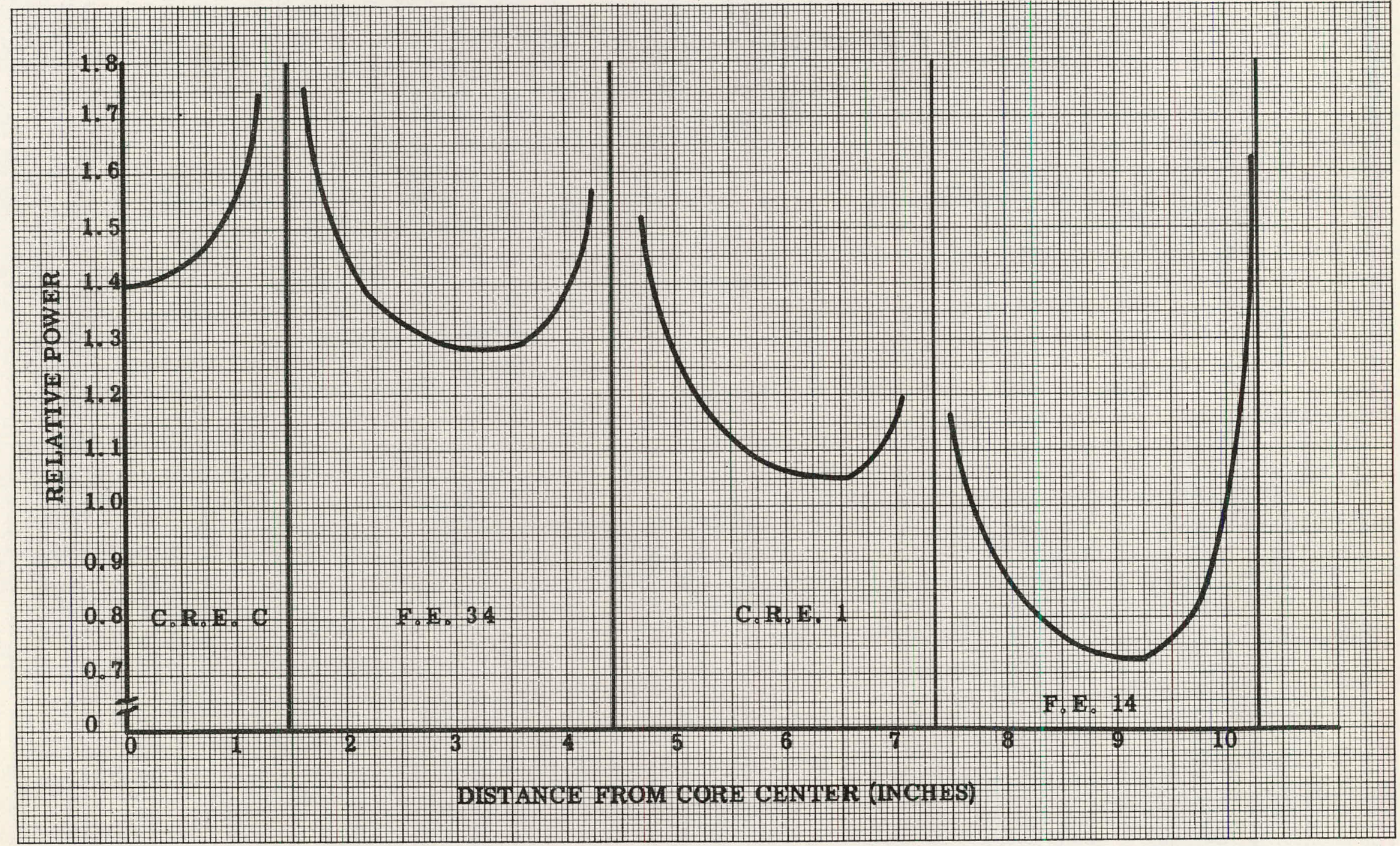

Fig. 2.20 - Relative Power Through Central Radial Plane Parallel To Fuel Plates - Rods Out - SM-1A Core With SM-2 Elements $-440^{\circ} \mathrm{F}$ 


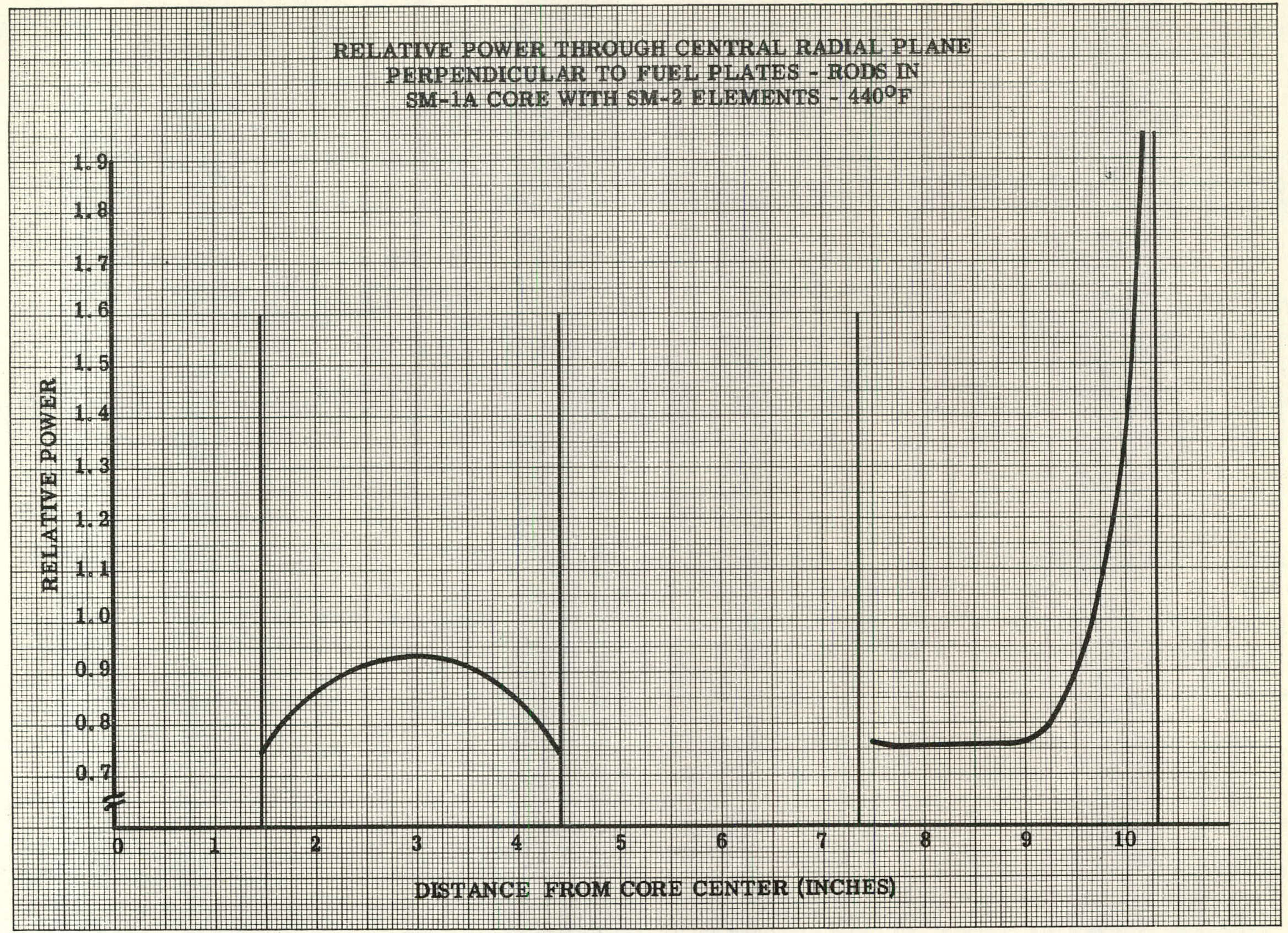

Fig. 2.21 - 


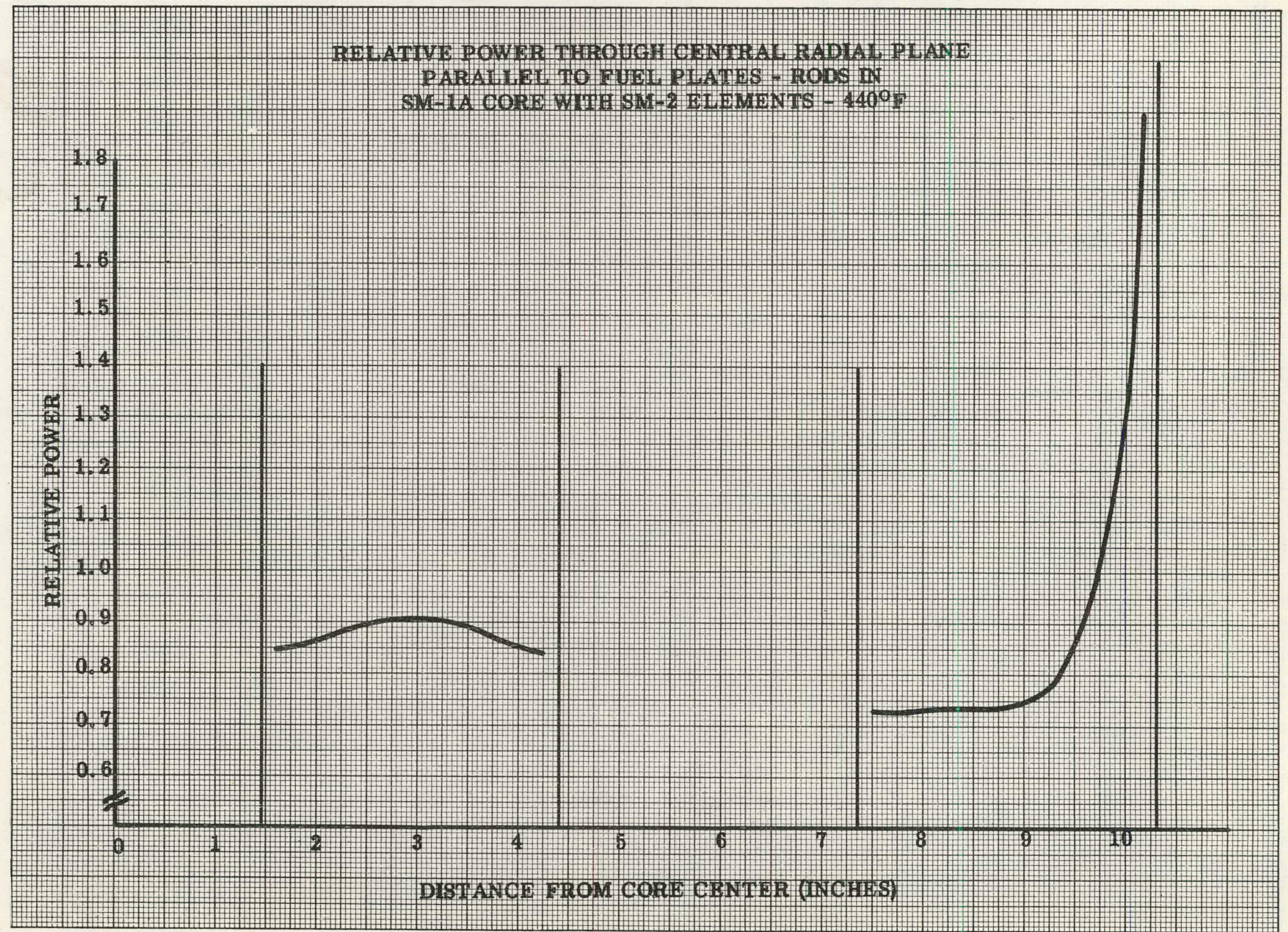




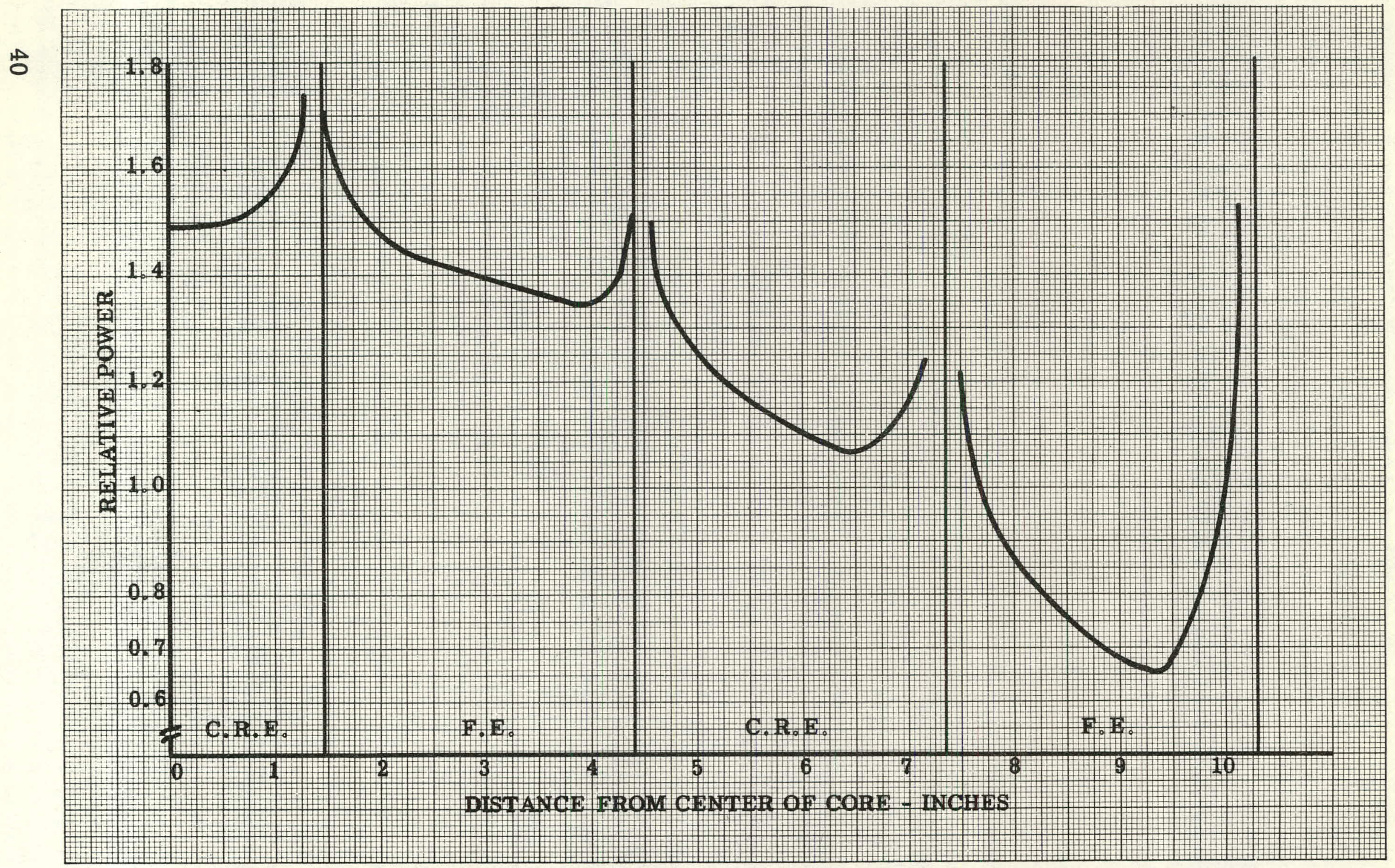

Fig. 2.23 - Relative Power Distribution Through Central Radial Plane Perpendicular To Fuel Plates - SM-1A With SM-2

Elements - Rods Out - $68^{\circ} \mathrm{F}$ 


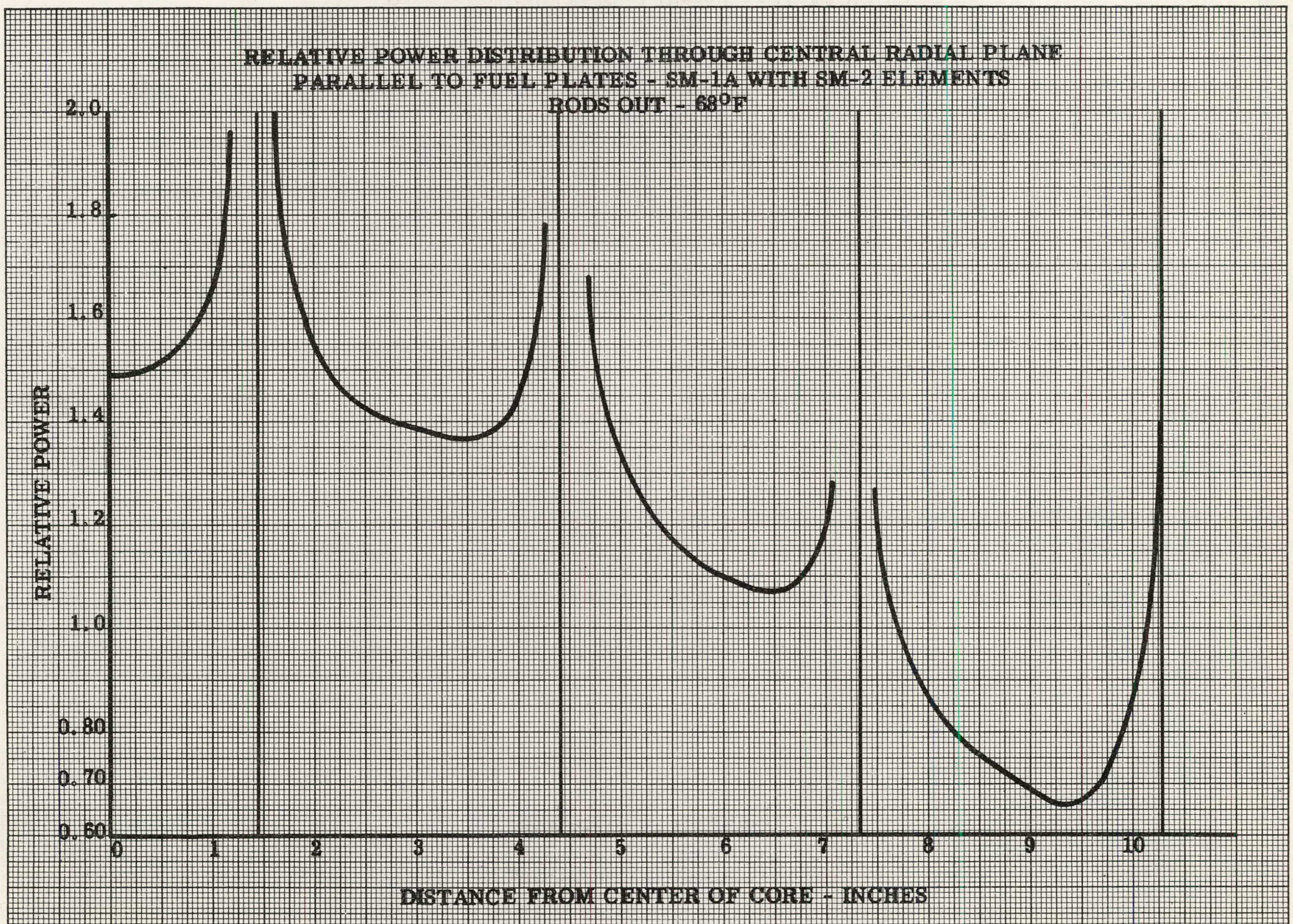

占

Fig. 2.24 - 
THIS PAGE

WAS INTENTIONALLY

LEFT BLANK 
$\underline{2.3}$ ROD WORTH; REACTIVITY AND ROD BANK POSITION, SM-1, SM-1A, PM-2A

The total control rod bank worth was obtained using the following equation:

$$
\rho_{\text {rods }}=\frac{\left(\mathrm{K}_{\text {eff }}\right)^{\text {rods out }}-\left(\mathrm{K}_{\text {eff }}\right)^{\text {rods in }}}{\left(\mathrm{K}_{\text {eff }}\right) \text { rods out }}
$$

where:

Pods $=$ the rod bank worth

$\left(K_{\text {eff }}\right)$ rods out $=$ the eigenvalue with the rods fully withdrawn

$\left(\mathrm{K}_{\mathrm{eff}}\right)$ rods in $=$ the eigenvalue with the rods fully inserted

The values of $\mathrm{K}_{\text {eff }}$ were obtained from $\mathrm{PDQ}-3$ cases run for the various cores with SM-2 elements: A $2 \%$ model correction was applied to all the calculated $\mathrm{K}_{\text {eff' } \mathbf{s}}$ 。

The core reactivity was calculated using the following equation:

$$
\rho=\frac{\mathrm{K}_{\text {eff }}{ }^{-1}}{\mathrm{~K}_{\text {eff }}}
$$

The results of the calculations for SM-1, SM-1A, and PM-2A are listed in Tables $2.6,2.7$, and 2.8 respectively. 
TABLE 2.5

RADIAL POWER FACTORS FOR PM-2A

WITH SM-2 ELEMENTS, $\mathrm{T}=510^{\circ} \mathrm{F}$

Element No.

0 MWYR

Estimated Maximum

\begin{tabular}{|c|c|c|c|c|c|c|}
\hline & $\mathrm{Q}(\Delta \theta)_{\mathrm{O}}$ & $\mathrm{Q}(\triangle \mathrm{T})_{\mathrm{O}}$ & $\overline{Q(\Delta T)_{0}}$ & $\mathbf{Q}(\Delta \theta)_{\mathrm{B}}$ & $\mathrm{Q}(\triangle \mathrm{T})_{\mathrm{B}}$ & $\mathrm{Q}(\triangle \mathrm{T})_{1}$ \\
\hline 44 & 1. 871 & 1. 744 & 1.581 & 2. 079 & 1.938 & 1. 757 \\
\hline 34 & 1. 721 & 1.377 & 1.380 & 1.912 & 1.530 & 1. 534 \\
\hline 55 & 1.666 & 1.333 & 1.226 & 1. 851 & 1. 481 & 1.362 \\
\hline 23 & 2.016 & 1.628 & 1. 346 & 2.240 & 1.809 & 1.496 \\
\hline 56 & 1.515 & 1.203 & 1.042 & 1. 683 & 1.337 & 1.158 \\
\hline 22 & 2.016 & 1.674 & .934 & 2.240 & 1.860 & 1.038 \\
\hline 37 & 1.322 & 1.118 & .844 & 1. 469 & 1.242 & .938 \\
\hline 14 & 1.095 & .757 & .750 & 1. 217 & .841 & .834 \\
\hline 73 & 1.582 & 1.497 & .795 & 1.758 & 1.663 & .883 \\
\hline
\end{tabular}

$\psi(\Delta \theta) \quad 0.95$

$F_{\mathrm{n}}(\Delta \theta)=1.10$

$\psi(\triangle \mathrm{T}) \quad 1.00$

$\mathrm{F}_{\mathrm{n}}(\Delta \mathrm{T})=1.05$

$\mathrm{P}(\mathrm{z})_{\max }=1.439$ 
TABLE 2.6

MISCELLANEOUS SM-1 CORE CALCULATIONS

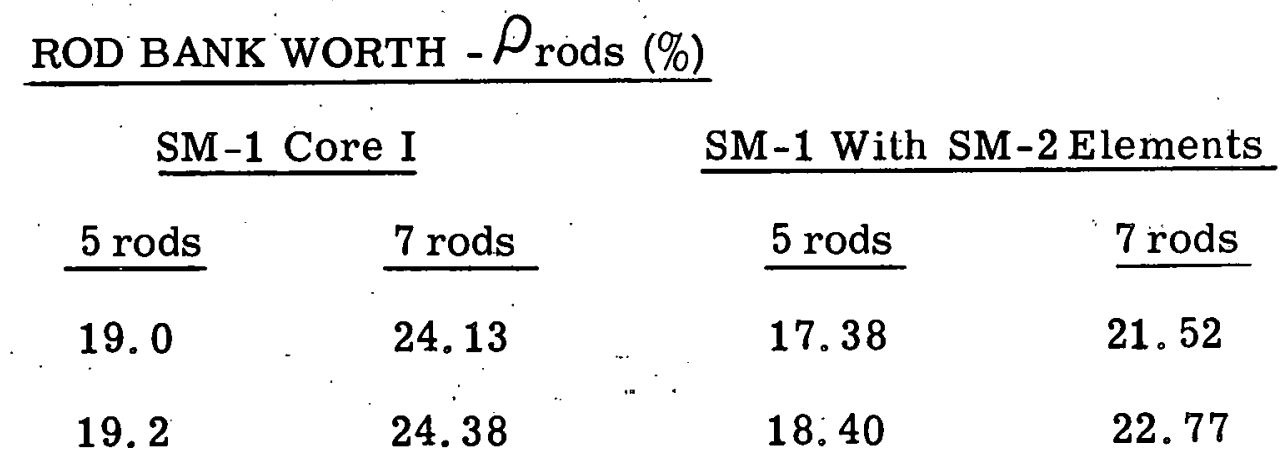

\section{INITIAL CORE REACTIVITY $(\% \rho)$}

SM-1 Core I

Temp

$68^{\circ}$

$440^{\circ}$ (No xenon)

$440^{\circ}$ (Equilibrium xenon)

15.4

10.4

8. 2
SM-1 With SM-2 Elements.

PDQ Model corrected.

9.39

11.39

6.05

8.05

6.33

\section{ROD BANK POSITION (INCHES FROM BOTTOM OF CORE)}

\section{SM-1 Core I}

Temp :

$68^{\circ}$

$440^{\circ}$ (No xenon)

$440^{\circ}$ (Equilibrium xenon)
5 Rods

3.7

6. 7

8.3
SM-1 With SM-2 Elements

5 rods

7 rods

6.0

10.5

11.0

MAXIMUM CORE REACTIVITY (ESTIMATED)
$15.1 \% \rho$ 
TABLE 2.7

MISCELLANEOUS SM-1A CORE CALCULATIONS

ROD BANK WORTH - Prods (\%)

SM-1 Core I

SM-1 With SM-2 Elements

Temp

5 rods

7 rods

5 rods

7 rods

68

16.60

20.62

17.13

21.23

$440^{\circ}$

18.13

22.47

INITIAL CORE REACTIVITY $(\% \rho)$

SM-1A Core I

$\underline{\text { Temp }}$

$68^{\circ}$

$440^{\circ}$ (No xenon)

$440^{\circ}$ (Equilibrium xenon)

15.62

10.3

7.5
SM-1A With SM-2 Elements PDQ Model corrected

9.33

11.33

5.76

7.76

5.30

ROD BANK POSITION (INCHES FROM BOTTOM OF CORE)

SM-1A Core I

Temp

$68^{\circ}$

$440^{\circ}$ (No Xenon)

$440^{\circ}$ (Equilibrium xenon)

MAXIMUM CORE REACTIVITY (ESTIMATED)
5 Rod Bank

3.6

6.9

8. 9
10.5

SM-1A With SM-2 Elements

5 Rod Bank 7 Rod Bank

11.0

$68^{\circ} \mathrm{F}$, No Xe, Midlife

$15.0 \%, \rho$ 
TABLE 2.8

MISCELLANEOUS PM-2A CORE CALCULATIONS

$\underline{\text { ROD BANK WORTH }-(5 \text { rods })-P_{\text {rods }(\%)}}$

$\underline{\text { PM-2A Core I }}$

PM-2A With SM-2 Elements

Temp

$68^{\circ}$

21. 6

19.93

$510^{0}$

20.49

INITIAL CORE REACTIVITY $(\% \rho)$

PM-2A Core I

Temp

$68^{\circ}$

$510^{\circ}$ (no xenon)

$510^{\circ}$ (eq. xenon)

14.30

7.48

5.34
PM-2A With SM-2 Elements PDQ Model corrected

8.45

10.45

2.53

4.53

2.57

ROD BANK POSITION (INCHES FROM BOTTOM OF CORE)

$\underline{\text { PM-2A Core I }}$

$\underline{\text { PM-2A. With SM-2 Elements }}$

Temp

$68^{\circ}$

6.45

$510^{\circ}$ (no xenon)

10.45,

17.5

$510^{\circ}$ (eq. xenon)

12.50

MAXIMUM CORE REACTIVITY (ESTIMATED)

$68^{\circ} \mathrm{F}$, No Xe, Midlife

$14.4 \% \rho$ 


\section{THIS PAGE}

\section{WAS INTENTIONALLY \\ LEFT BLANK}




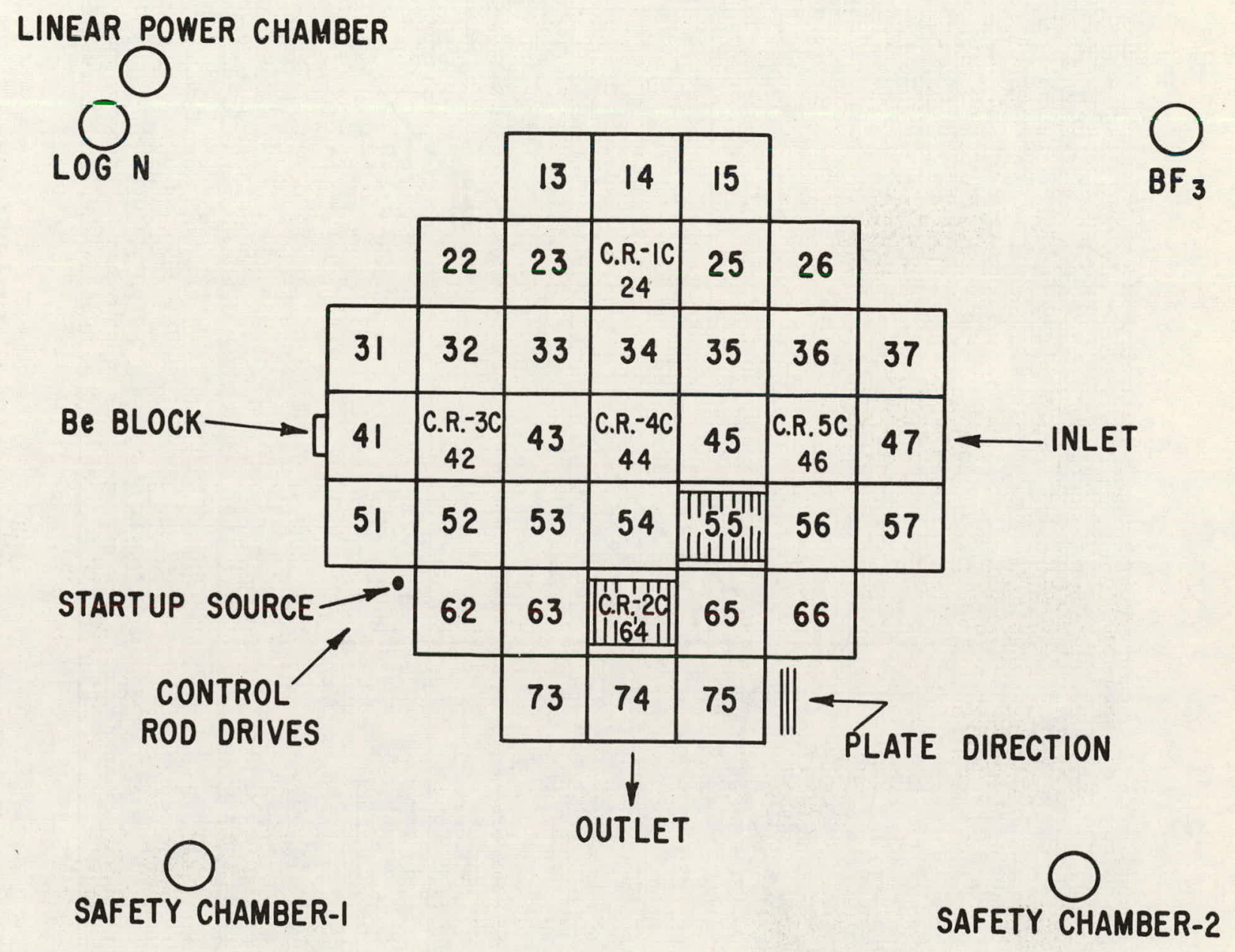

Fig. 2.25 - PM-2A Core Layout 


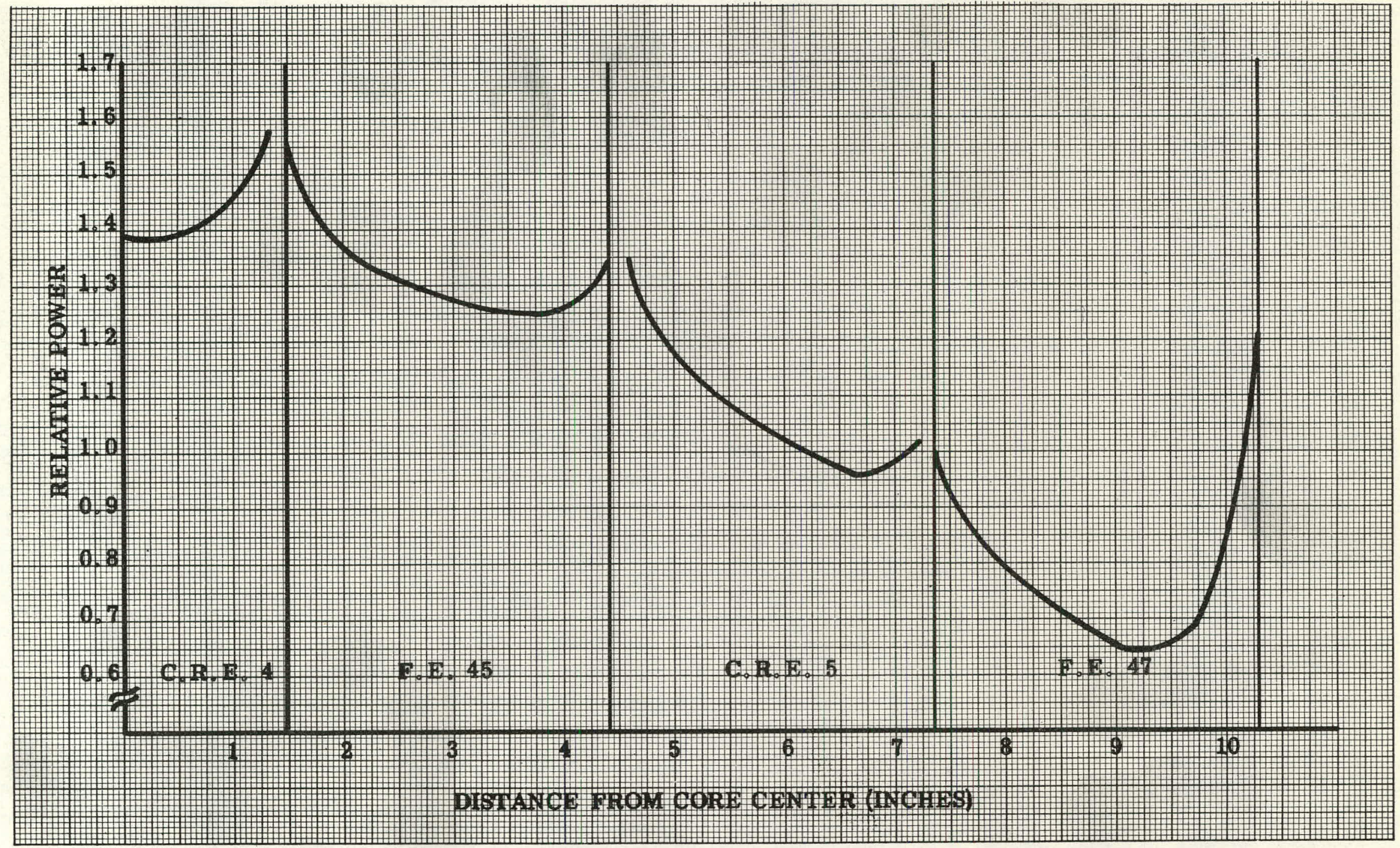

Fig. 2.26 - Relative Power Through Central Radial Plane

Perpendicular To Fuel Plates - Rods Out - PM-2A

Core With SM-2 Elements - $510^{\circ} \mathrm{F}$ 


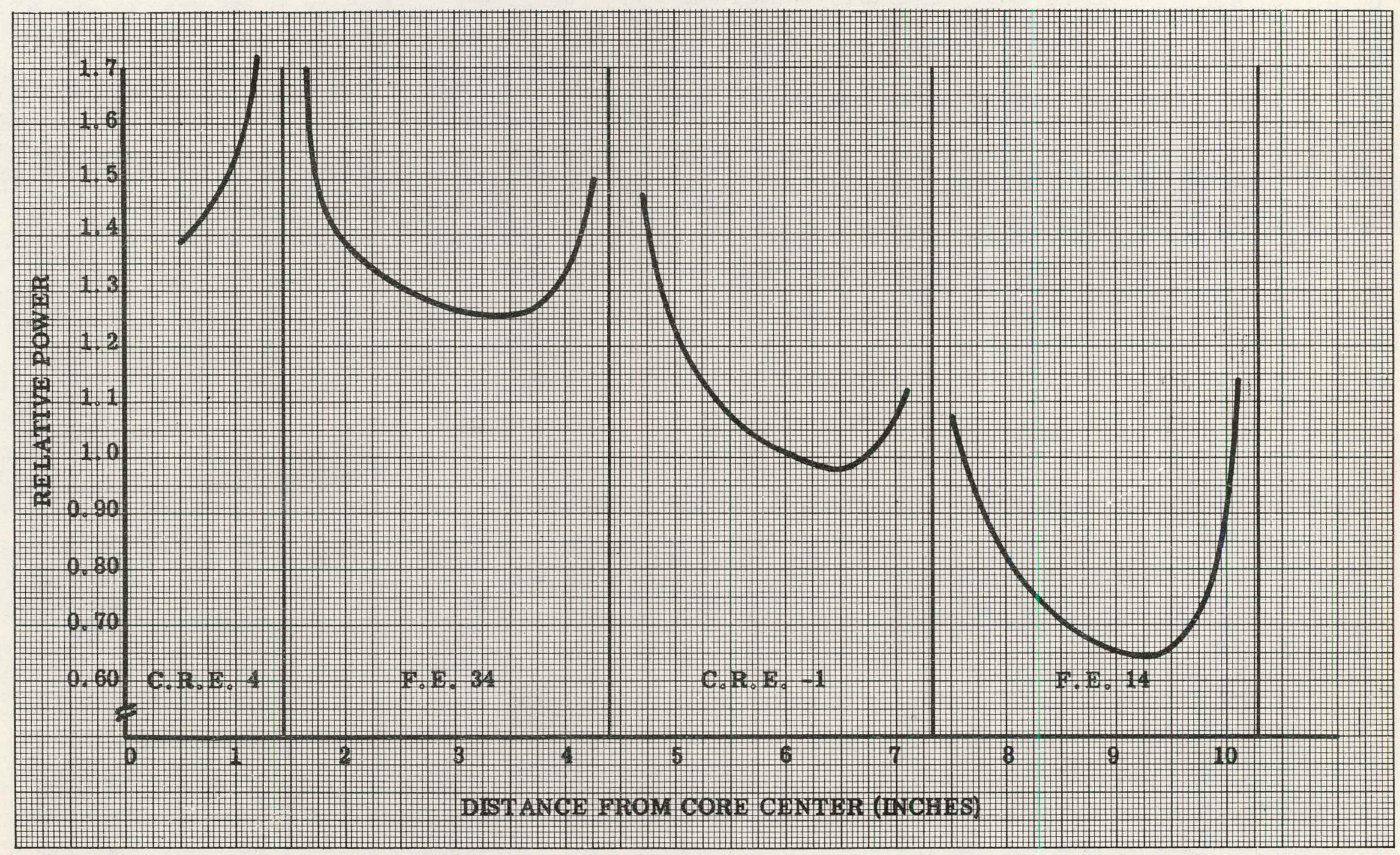

Fig. 2. 27 - Relative Power Through Central Radial Plane Parallel To Fuel Plates - Rods Out - PM-2A Core With SM-2

Elements $-510^{\circ} \mathrm{F}$ 


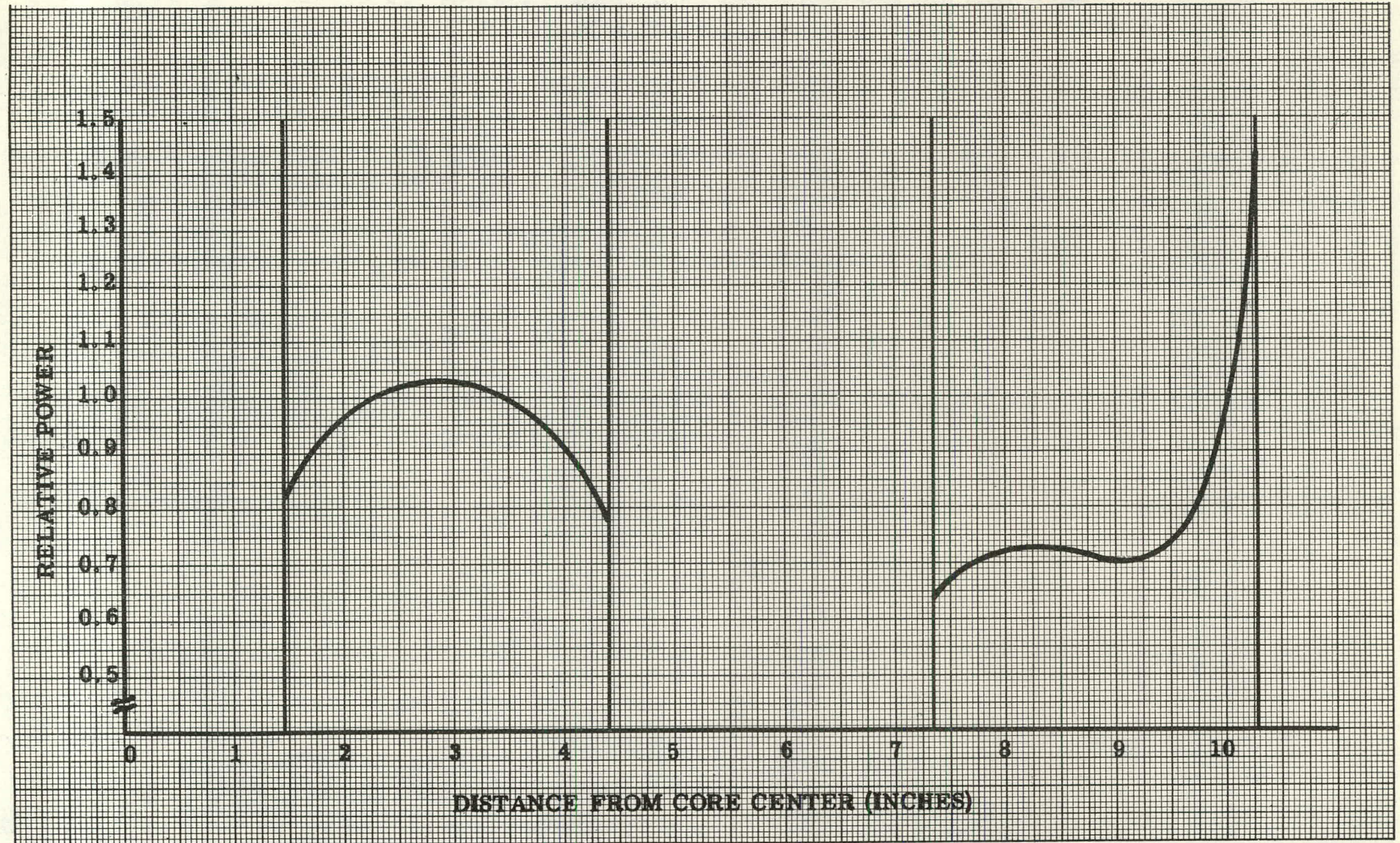

Fig. 2.28 - Relative Power Through Central Radial Plane Perpendicular to Fuel Plates - Rods In - PM-2A Core With SM-2 Elements - $510^{\circ} \mathrm{F}$ 


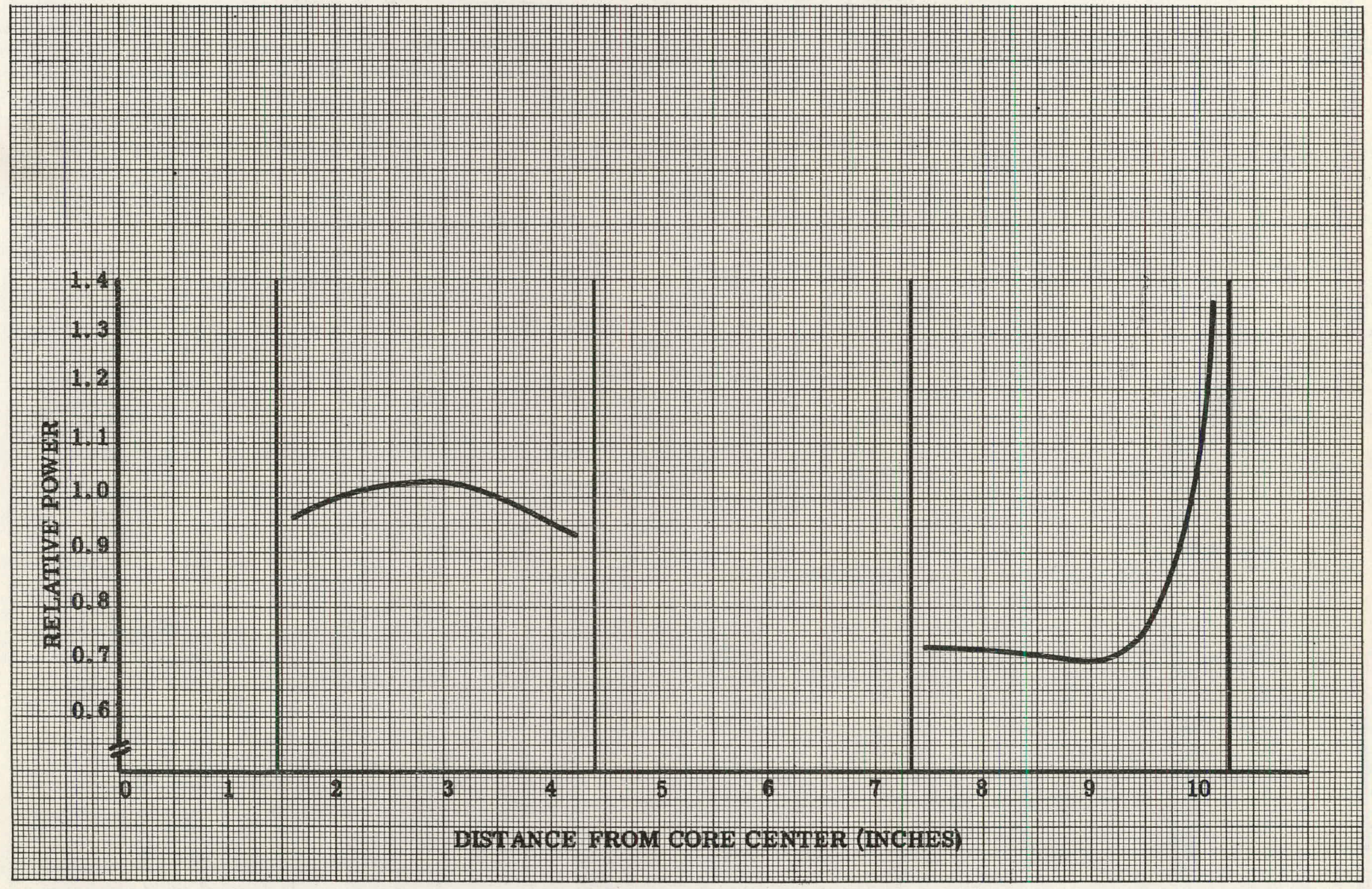




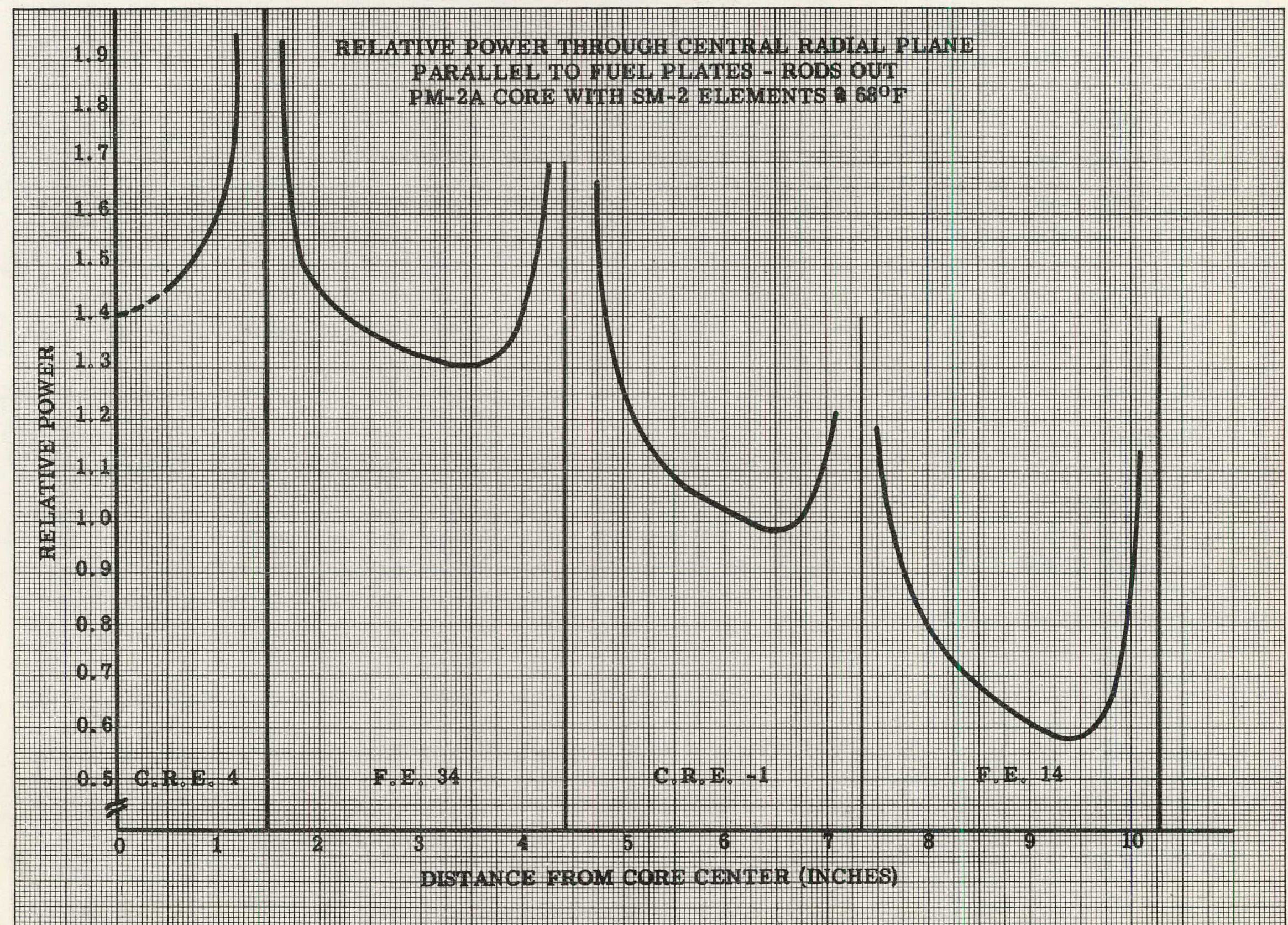

ケ゚

Fig. 2.31 - 


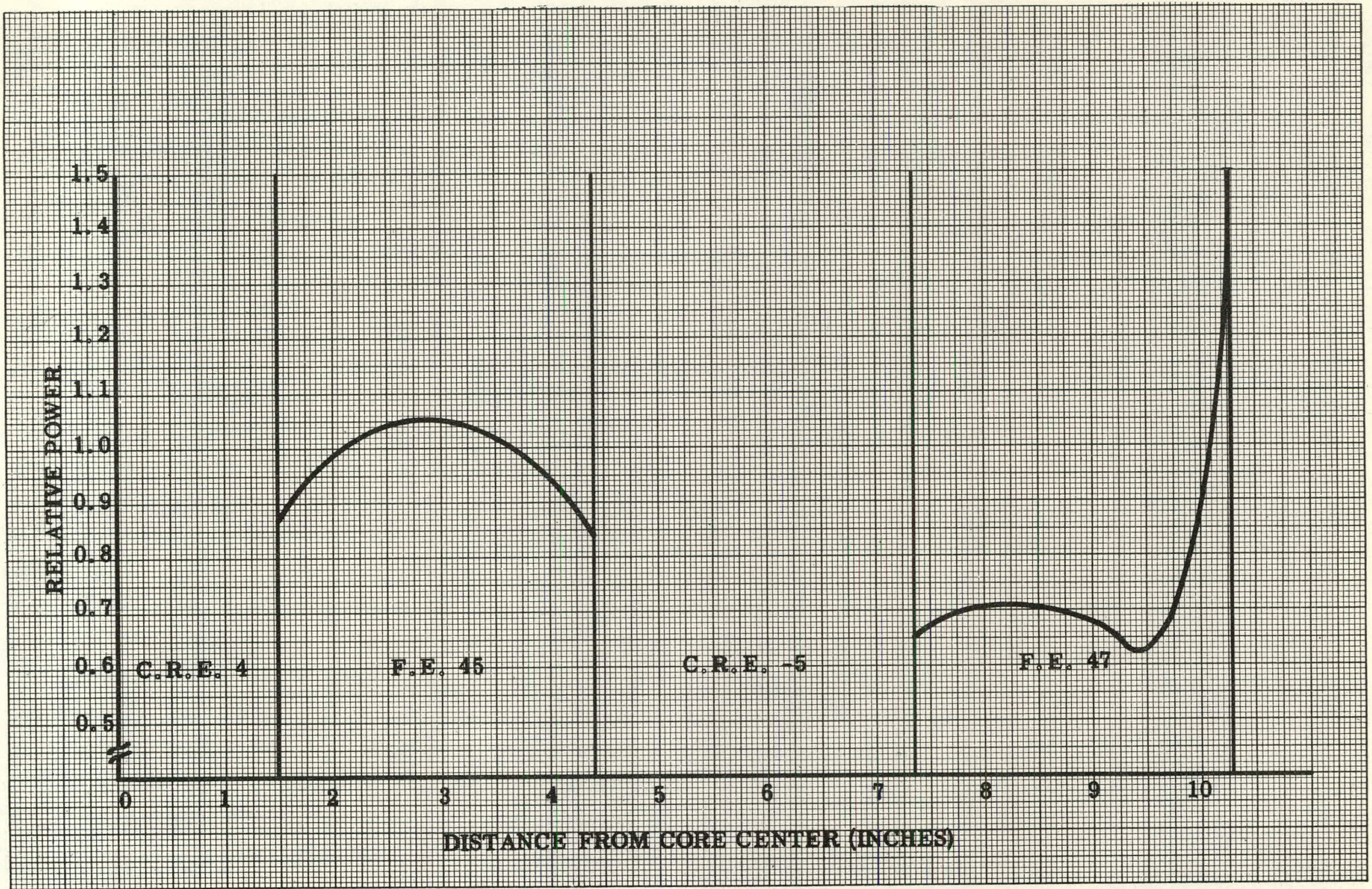

Fig. 2.32 - Relative Power Through Central Radial Plane Perpendicular To Fuel Plates - Rods In - PM-2A Core With SM-2 Elements - $68^{\circ} \mathrm{F}$ 


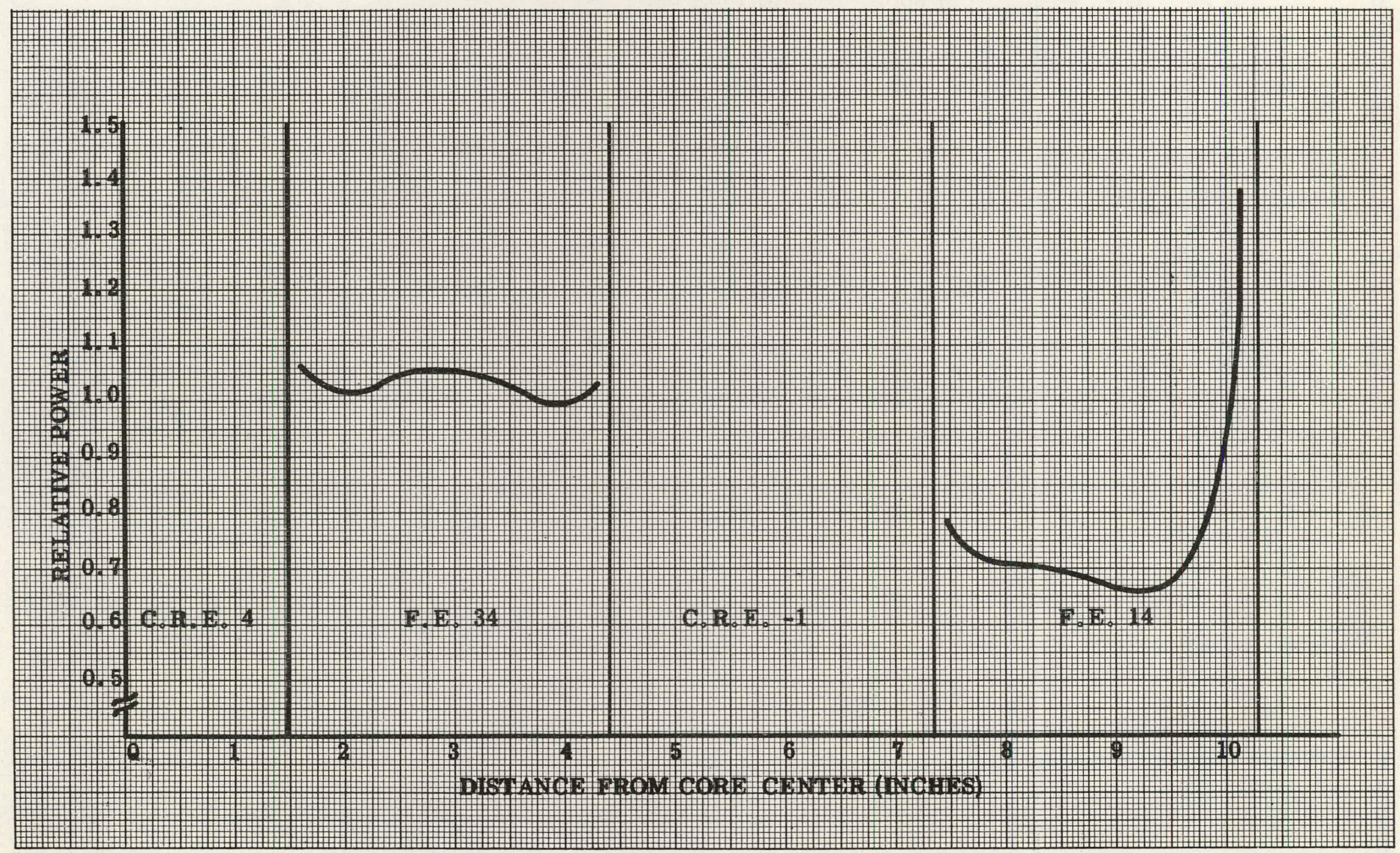




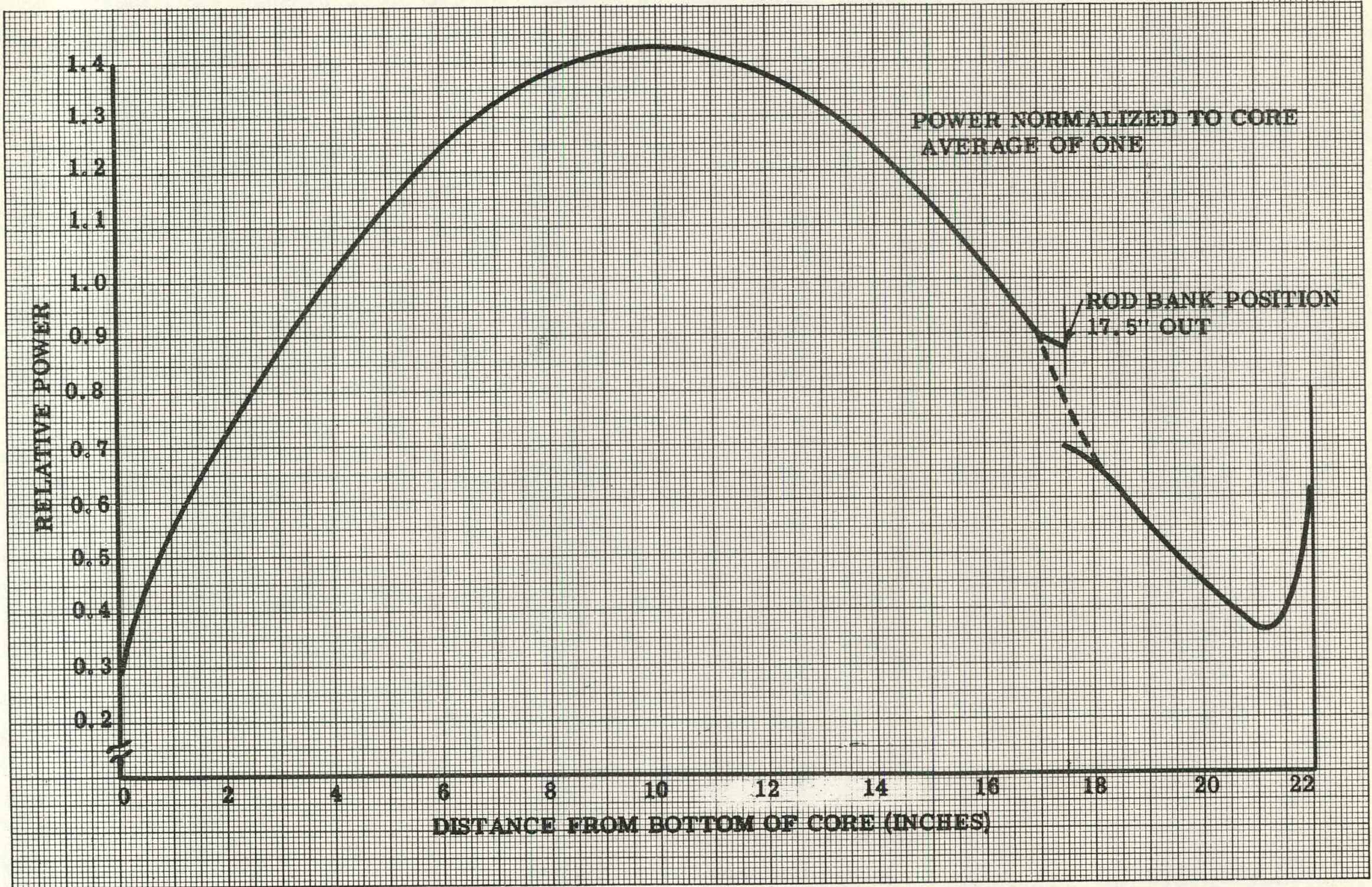

Fig. 2.34 - Relative Axial Power Distribution (Valprod) - PM-2A Core With SM-2 Elements - $510^{\circ} \mathrm{F}$ - With Flux Suppressors 


\subsection{RESULTS}

1. Based upon the preliminary analyses, it was found that the overall maximum-to-average power ratios, for the SM-1, SM-1A, and PM-2A with SM-2 fuel elements, are 4.4, 4.7, and 3.2 respectively. These values occur in fuel element locations 41,67 , and 22 respectively. In each case, the maximum power peaking occurs in an outside fuel element, at the core reflector interface. The maximum peaking occurs, in each case at sometime during core life, whereas for the original cores of the SM-1, SM-1A, and PM-2A, the maximum peaking occurs at core startup. This is due to the fact that for the cores employing SM-2 elements, during the first stages of core life, the decrease in radial power peakings is more than offset by the increase in the axial peak due to the rod bank motion.

2. The maximum power in the SM-1 with SM-2 elements may be compared to that calculated, using the same analytical techniques, for the SM-1 Core $I^{(4)}$. For the latter core, ignoring the power spike at the bottom of the active core, the maximum-to-average power ratio was calculated to be 2.8 , which occurs at core startup; this may be compared to the value of 4.4 for the SM-1 with SM-2 elements. In the SM-1 Core I, the maximum power peaking occurs in element 44, the central control rod fuel element. Using SM-2 elements with their relatively high fuel and poison loadings, the maximum peaking occurs at the core-reflector interface.

3. In the above analysis, seven rod bank operation was assumed for the SM-1 and SM-1A with SM-2 fuel elements. The axial peak-to-average power ratios were calculated to be 1.91 and 1.81 , for the seven and five rod bank, respectively. Even though the axial peaking is more severe for seven rod bank operation, this mode of operation was chosen because of stuck rod considerations. The final mode of rod operation will be studied further and presented in the final report.

4. The maximum reactivity to be controlled for the SM-1, SM-1A and PM-2A with SM-2 fuel elements occurs at about midlife, at $68^{\circ} \mathrm{F}$, and no xenon; the calculated values were found to be $15.1 \% \rho, 15 \% \rho$, and $14.4 \% \rho$, respectively. The total available rod worths were calculated to be about $22 \% \rho$, $22 \% \rho$, and $20 \% \rho$, respectively. Therefore, no control problems are expected.

\subsection{CONCLUSIONS}

Based upon the preliminary nuclear analysis of power distributions, core reactivities, and total control rod bank worths, no serious probfems are expected by using SM-2 fuel elements as replacement cores for the SM-1, SM-1A, and PM-2A. 


\section{THIS PAGE}

\section{WAS INTENTIONALLY \\ LEFT BLANK}




\subsection{INTRODUCTION}

A preliminary thermal analysis of use of SM-2 elements in SM-1, SM-1A and PM-2A cores was performed to determine whether any serious problems existed. The limitations of this analysis are:

1. The most adverse power distributions were based on analytical predictions corrected by the use of SM-2 analysis and experimental deviations.

2. Velocity variation within the SM-2 fuel elements in the various cores was only estimated.

3. Loss of pump problem was treated as a quasi-steady state model。

The above limitations will be removed in the final thermal analysis by:

1. Comparison of analytical power distributions and measurements in the critical experiment mockups using SM-2 elements in SM-1, SM-1A and PM-2A configurations.

2. Measurements will be made of the velocity variations within SM-2 fuel plate bundles in SM-1, SM-1A and PM-2A end box and core support configurations.

3. A detailed transient analysis will be performed with the SM-2 elements in the SM-1, SM-1A and PM-2A during loss of flow transients and decay heat removal.

\subsection{METHODS OF ANALYSIS}

\section{$\underline{3.2 .1}$ Steady State}

The steady state analysis was performed using the STDY -3 code. This code is a one-dimensional steady state code written for pressurized water reactors by WAPD. The code performs a complete steady-state parallel channel analysis resulting in enthalpy, temperature rise and quality calculations for the nominal channel; and enthalpy, steam quality, plate surface temperature, bulk water temperature, meat centerline temperature, and burnout ratios for the hot channel. Results are given for each axial channel point based on input properties and two-phase core pressure drop equations where applicable. If local or bulk boiling exists, the axial position at which the phenomena starts is designated. 
The correlations programmed into this code to determine burnout and local boiling are of utmost concern in considering the safe operation of these cores and will be discussed in detail. The remainder of the design equations programmed in the code are described in reference (11).

The burnout correlations used in the code are controlled by the local enthalpy, the channel mass flow rate and the system pressure. The general equation selected for system pressure $1850 \mathrm{psia}$ is given by

$$
\text { DNB BOC }\left[\frac{\mathrm{H}_{\mathrm{j}}}{1000}\right]^{-2.5} \mathrm{e}^{-.0012 \mathrm{~L} / \mathrm{S}}
$$

where:

$$
\begin{aligned}
\mathrm{DNB} & =\text { Departure from nucleate boiling } \\
\mathrm{BOC} & =\text { Burnout constant } \\
\mathrm{H}_{\mathrm{j}} & =\text { Local enthalpy at a specific axial increment, Btu/lb } \\
\mathrm{L} & =\text { Channel length, in. } \\
\mathrm{S} & =\text { Channel spacing, in. }
\end{aligned}
$$

The ratio of DNB to operating heat flux is found by dividing the result from equation (1) by

$$
\phi_{\text {avg. }}{ }^{\mathrm{F}} \Delta \theta \quad \mathrm{f}^{\mathrm{f}}(\mathrm{z})
$$

where

$$
\phi \text { avg. = Average core heat flux, Btu } / \mathrm{hr}-\mathrm{ft}^{2}
$$

$\mathrm{F} \Delta \theta=$ Local hot channel factor

$f^{\prime}(z)=$ Axial power generation at a specific axial increment.

$$
\text { DNBR }=\frac{\text { DNB }}{\Phi_{\text {avg }}{ }^{\mathrm{F}} \Delta \theta \mathrm{f}^{\prime}(\mathrm{z})}
$$

The criteria for a channel to be in local boiling based on pressure drop only, is if the film drop calculated from equation (3) below. is sequal to or greater than the Jens-Lotte's temperature drop given in equation (4). 
Local boiling exists if $\theta_{\mathrm{f}} \geq \theta_{\mathrm{J} \& \mathrm{~L}}$

$$
\theta_{\mathrm{f}}=\frac{\phi_{\text {avg }} \mathrm{F}_{\Delta \mathrm{T} \mathrm{f}^{i}(\mathrm{z})}}{\mathrm{h}}
$$

where

$$
\begin{aligned}
& \theta_{\mathrm{f}}=\text { Film temperature drop (Plate surface } \\
& \text { temperature - bulk water temperature }),\left({ }^{\mathrm{O}} \mathrm{F}\right) \\
& \mathrm{h}=\text { Film heat transfer coefficient, } \frac{\mathrm{Btu}}{\mathrm{hr}-\mathrm{ft}^{2}-{ }^{\mathrm{O}} \mathrm{F}} \\
& \theta_{J \& L}=T_{\text {sat }}+\frac{60\left(\frac{\phi \text { avg } F_{\Delta T} f_{(z)}}{10^{6}}\right)^{1 / 4}}{e^{P / 900}}-T_{j}
\end{aligned}
$$

where $\theta_{\mathrm{J} \& \mathrm{~L}}=$ Difference between the plate surface temperature and the bulk fluid temperature as given by the Jens and Lottes correlation

$$
\begin{aligned}
& \mathbf{T}_{\text {sat }}=\text { Saturation temperature of the fluid, }{ }^{{ }} \mathbf{F} \\
& \mathbf{P}=\text { System pressure, psia } \\
& T_{j} \quad=\text { Bulk temperature of fluid at a specific axial increment }(j),{ }^{\circ} \mathbf{F}
\end{aligned}
$$

Plate surface temperature $\left(T_{S}\right)$ is calculated by adding the film drop to the bulk temperature at any particular axial location $(j)$

$$
\mathrm{T}_{\mathrm{s}}=\mathrm{T}_{\mathrm{j}}+\theta_{\mathrm{f}}
$$

\section{$\underline{3.2 .2}$ Transients}

A pseudo transient analysis was performed for the SM-1, employing SM-2 fuel elements, using the STDY-3 code. This analysis treats a loss of flow accident as a series of steady state points at reduced core flow rates. The primary objective of this analysis. was to approximate the variation of burnout heat flux ratio.

The analysis was based on the loss of flow test results as reported in the Final Report for Test 600, (19) performed on the SM-1at. Fort Belvoir. The results of this test at SM-1 for a loss of flow are plotted in Fig。3.1 from which values of power and flow rates can be obtained for various times after pump failure. 
THIS PAGE

WAS INTENTIONALLY

LEFT BLANK 


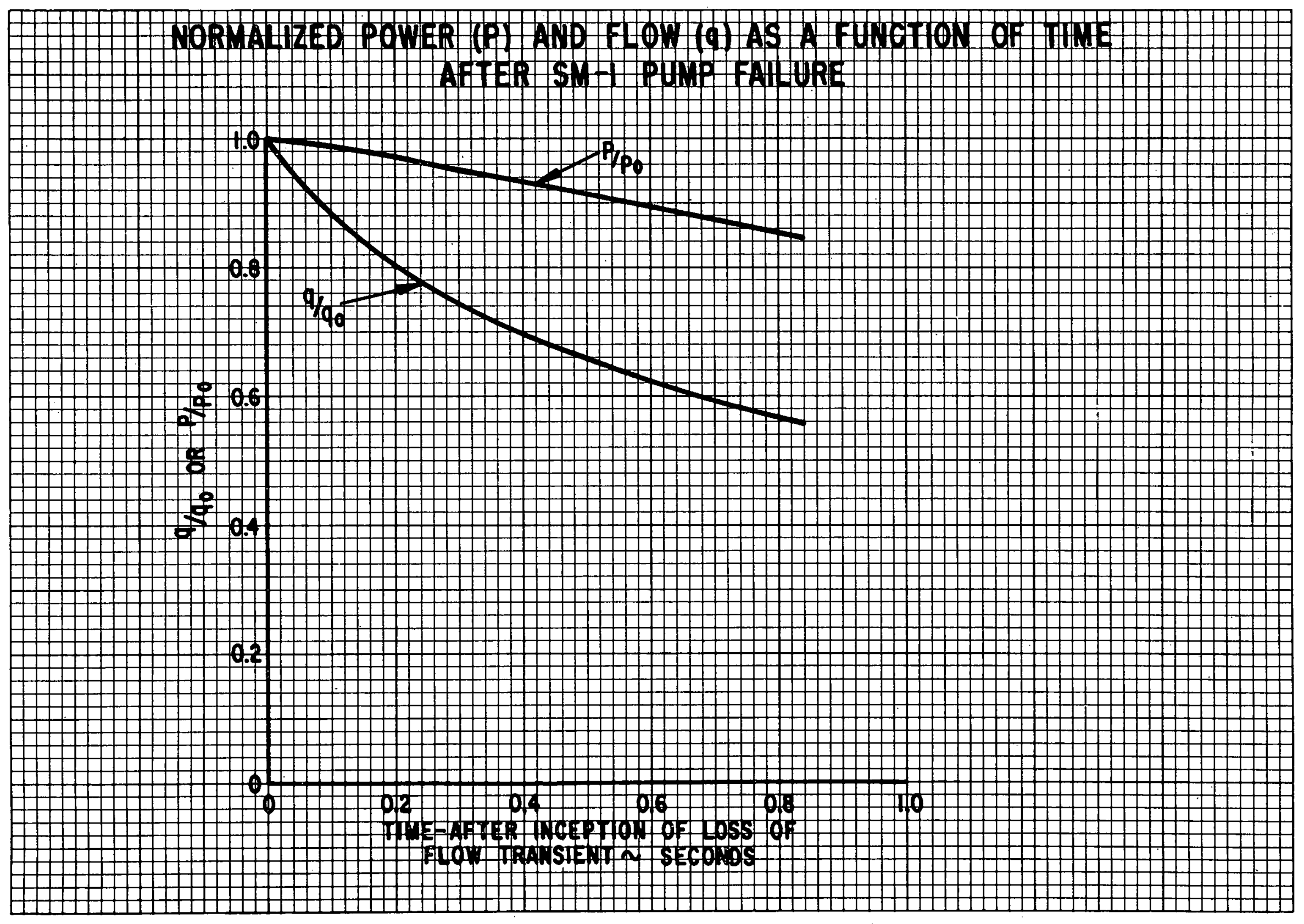
요

Fig. 3.1 - 


\section{THIS PAGE}

\section{WAS INTENTIONALLY \\ LEFT BLANK}




\subsubsection{Maximum Power For Each Reactor}

In order to place the analysis of the use of SM-2 elements in the SM-1, SM-1A and PM-2A cores on the most conservative basis, the steady state analysis is performed at the scram power level. This condition might be obtained by operator's error or on a slow rod withdrawal ${ }_{1}$ Scram power level settings are for the $\mathrm{SM}-1,13 \mathrm{MW},(12) \mathrm{SM}-1 \mathrm{~A}, 24.2 \mathrm{MW},(13)$ and PM-2A, $12 \mathrm{MW}$. (14) These power levels and the core heat transfer areas were used to calculate the average core heat flux. The maximum expected core heat fluxes with SM-2 elements are $79,193 \mathrm{Btu} / \mathrm{ft}^{2}$ for the $\mathrm{SM}-1,142,591 \mathrm{Btu} / \mathrm{hr}-\mathrm{ft}^{2}$ for the SM-1A and $87,268 \mathrm{Btu} / \mathrm{hr}-\mathrm{ft}^{2}$ for the PM-2A.

\subsubsection{Axial and Radial Power Distribution}

Power distribution and the method for calculation is described in the core analysis section of this report. A description of how the axial and radial factors were used in the thermal analysis follows:

The average and local radial peaking factors were used to select the worst element positions in their respective cores. The element with the highest average änd local radial peaking and the lowest available flow rate was selected for each core thermal analysis.

The average and local radial peaking factors were also used to determine hot channel factors for both the nominal and hot channel. Both of these factors are a multiple of the average and local hot channel factor for the nominal and hot channel cases. These-are applied as follows:

For the nominal channel: $\quad{ }^{\mathrm{F}} \Delta \mathrm{T}_{\mathrm{N}}=\mathrm{F}_{\mathrm{N}} \mathrm{F}_{\Psi} \overline{\mathrm{Q}}_{\triangle \mathrm{T}}$

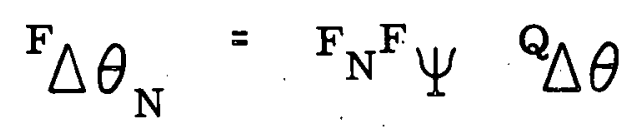

For the hot channel:

$$
\begin{aligned}
& \mathrm{F}_{\Delta \mathrm{T}}^{\mathrm{F}}=\mathrm{F}_{\mathrm{N}}^{\mathrm{F}} \Psi{ }^{\mathrm{Q}}{ }_{\Delta \mathrm{T}}{ }_{\mathrm{M} \Delta \mathrm{T}}^{\mathrm{F}} \\
& \mathrm{F}_{\Delta \theta}=\mathrm{F}_{\mathrm{N}} \mathrm{F}_{\mathrm{L}}{ }^{\mathrm{Q}} \Delta \theta^{\mathrm{F}}{ }_{\mathrm{M}}{ }^{\mathrm{N}}
\end{aligned}
$$

where

$$
{ }_{\Delta \mathrm{T}_{\mathrm{N}}}^{\mathrm{F}}{ }^{\mathrm{F}} \Delta \mathrm{T},{ }_{\Delta \theta_{\mathrm{N}}}, \quad, \quad{ }_{\Delta \theta}=\begin{aligned}
& \text { the average and local hot } \\
& \text { channel factors respectively }
\end{aligned}
$$




$\begin{array}{ll}\mathrm{F}_{\mathrm{N}}, \mathrm{F}_{\mathrm{N}} & =\begin{array}{l}\text { nuclear uncertainty factor for average or local } \\ \text { condition }\end{array} \\ \mathrm{F}_{\Psi}, \mathrm{F}_{\Psi_{\mathrm{L}}} & \begin{array}{l}\text { power generation factor for average or local } \\ \text { condition }\end{array} \\ \mathrm{Q} \triangle \mathrm{T} & =\text { average radial peaking factor in the hot channel } \\ \overline{\mathrm{Q}} \triangle \mathrm{T} & =\begin{array}{l}\text { average radial peaking factor in nominal or average } \\ \text { channel }\end{array} \\ \mathrm{Q} \triangle \theta \quad & \text { local radial peaking factor } \\ \mathrm{F}_{\mathrm{M}} \Delta \mathrm{T}, \mathrm{F}_{\mathrm{M}} \Delta \theta=\begin{array}{l}\text { mechanical hot channel factor excluding plate } \\ \text { spacing factor and plenum maldistribution factor. } \\ \text { Average and local respectively. }\end{array}\end{array}$

The relative axial power distribution was averaged over each axial increment. One value of each axial increment for each channel is used in the analysis.

\subsection{HOT CHANNEL FACTORS}

The mechanical hot channel factors used in this analysis include average and local deviations for meat length, uranium content, and clad thickness. The preceding factors were calculated by methods described in reference (18) and appear in Table 3.1.

Plate spacing and flow maldistribution factors do not appear in the STDY-3 Coade as hot channel factors. Plate spacing appears in the hot and nominal channel description as an average and local dimension. A thermal rippling distortion factor was applied to the hot channel and used as the local dimension of the hot channel. Flow maldistribution is a separate item included as a plenum factor. A $12 \%$ maldistribution of flow was used to account for uncertainties in channel-to-flow caused by end: box effects and orificing tolerances. An experimental program is presently underway to determine channel-to-channel distribution with SM-2 plates in SM-1, SM-1A and PM-2A stationary and control rod elements. This program will define the value of a mal distribution factor.: 
TABLE 3.1

COMPOSITE MECHANICAL HOT CHANNEL FACTORS

Meat length

1.0233

Stationary

Control Rod

$\mathrm{F}_{\mathbf{M}}$

$\triangle \mathrm{T}$

${ }^{\mathbf{M}_{\Delta \theta}}$

Uranium content

1.0050

1.0233

Same

Uranium content

1.0071

$1.015 n$

Same

Clad thickness

1.0119

Same

Composite" Mèchanical

Factors

$$
\begin{aligned}
& \mathrm{F}_{\Delta} \mathrm{T}=1.0357 \\
& \mathrm{~F}_{\Delta \theta}=1.0510
\end{aligned}
$$

\subsection{ADDITIONAL FACTORS INCLUDED IN THE THERMAL ANALYSIS} in design:

In the analysis the following additional factors were used for conservatism

a. Nuclear uncertainty Factor - To allows for uncertainties in the calculated power distribution, a nuclear uncertainty factor $\left(F_{N}\right)$ of 1.05 was used for the nominal channel and $\left(F_{N_{L}}\right)$ of 1.10 for the hot channel.

b. Core Power Generation - In order to account for the fraction of fission heat liberated in the coolant directly $F \Psi_{L}$, a factor of 0.95 was applied to the power generated in the fuel plates. The fraction of power generated in the $(F \Psi)$ core is 1.00 .

c. Instrumentation Tolerances - The worst reactor conditions were considered in the thermal analysis and tolerances applied to the reactor instrumentation. The following instrumentation tolerances were used: 
For the SM-1

Instrumentation

Tolerance

Core Power

Inlet Temp

System Pressure

For the PM-2A

Core Power

Inlet Temp.

System Pressure

For the SM-1A

Core Power

Inlet Temp.

System Pressure

$\pm 35 \mathrm{psia}$ at $1750 \mathrm{psia}$

$\pm 4^{\circ}$ At Core Inlet $423^{\circ} \mathrm{F}$

$\pm 25 \mathrm{psia}$ at $1200 \mathrm{psia}$ $\pm 3.5 \%$ at Scram Power Level of $13 \mathrm{MW}$

$\pm 4 \%$ At Core Inlet $427.7^{\circ} \mathrm{F}$

\pm 25 psia At 1200 psia
Value Used.

In Code

13.45 MW

$431.7^{\circ} \mathrm{F}$

1175 psia
12. $42 \mathrm{MW}$

$504^{\circ} \mathrm{F}$

1715 psia

25. 05 MW

$427^{\circ} \mathrm{F}$

1175 psia

\section{$\underline{3.6}$ CORE FLOW DISTRIBUTION}

\subsubsection{SM-1 Core with SM-2 Elements}

The available flow for each element for the SM-1 core was obtained from full scale flow test measurements. (15) It is expected that the flow distribution within the SM-1 core will be identical with SM-2 elements installed. Flow distribution was based on a primary loop.flow rate of $3862 \mathrm{gpm},(12)$ with $14.7 \%$ lattice flow. Figure 3.2 shows the available flow for each element.

\subsubsection{SM-1A Core with SM-2 Elements}

For the SM-1A, core flow distribution was obtained from a full scale air flow rig, reference (16), in which Figure I gave flow distribution in terms of percent of total flow where internal element flow is $72.9 \%$, internal control rod flow $13.9 \%$ and lattice flow $13.2 \%$. Figure 3.3 shows the available core flow distribution for the recommended orifice plate. Since the SM-1A has two pumps having different operating lines, the shaft seal pump which delivers the lower flow of $7400 \mathrm{gpm}$ was used to obtain the flow rates. 
(Element Flow Rates in GPM)

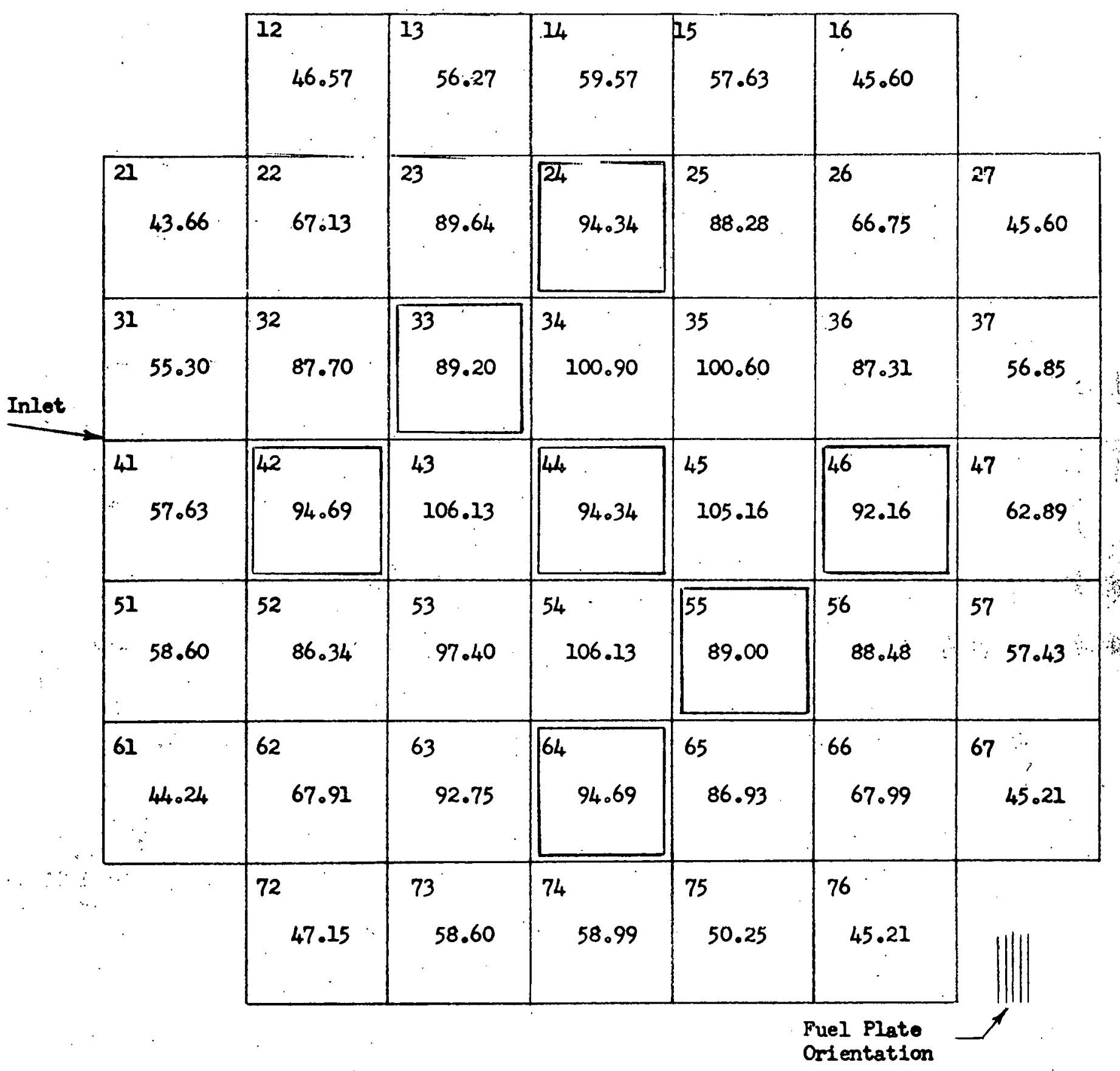

Fig. 3.2 - SM-1 Core Flow Distribution 
(Element Flow Rates In GM)

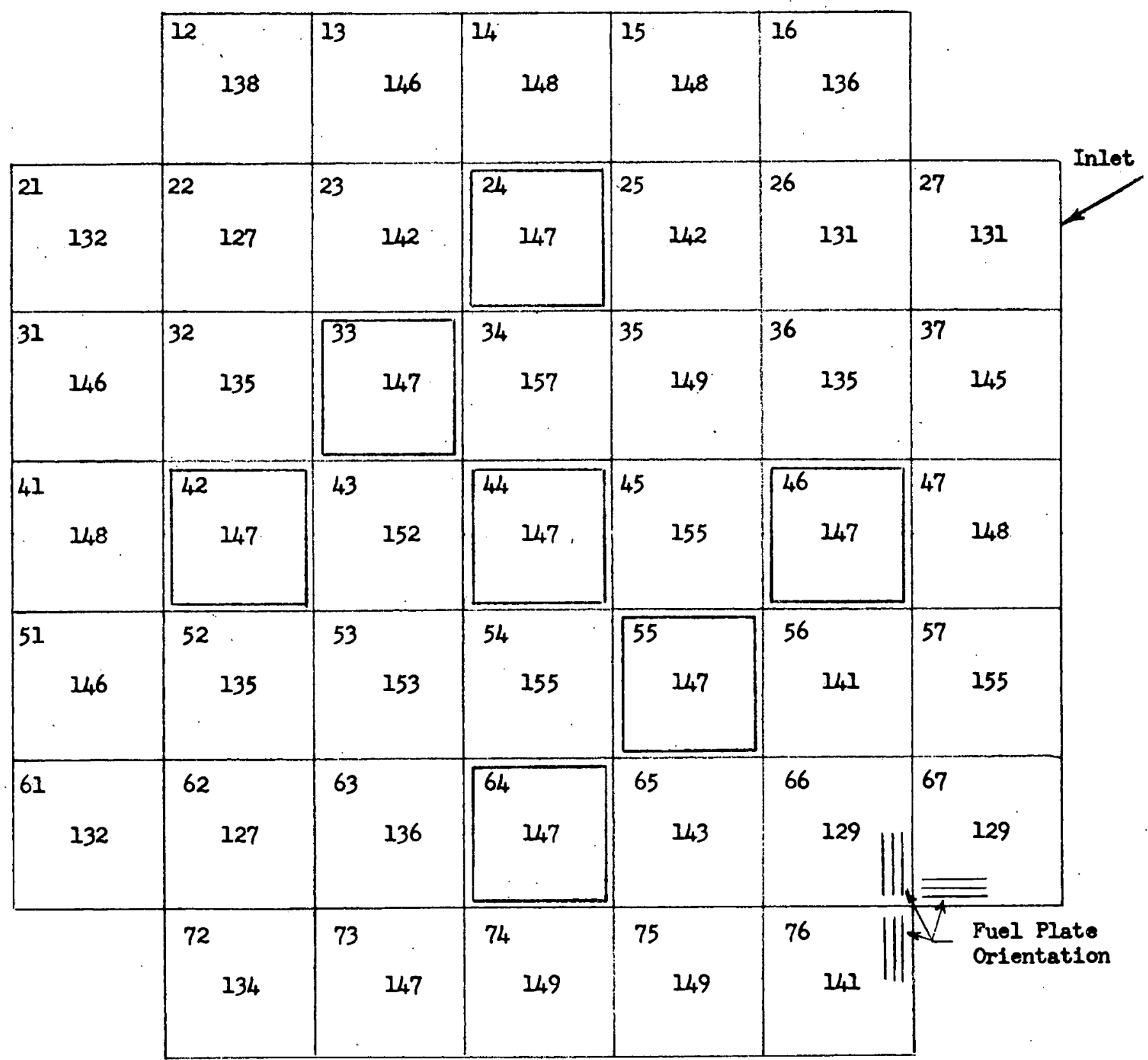

Total Core Flow: $7400 \mathrm{gpm}$

Lattice Flow: $\quad 98 \mathrm{gpm}$

Fig. 3.3 - SM-1A Core Flow Distribution 
(Element Flow Rates In GPM)

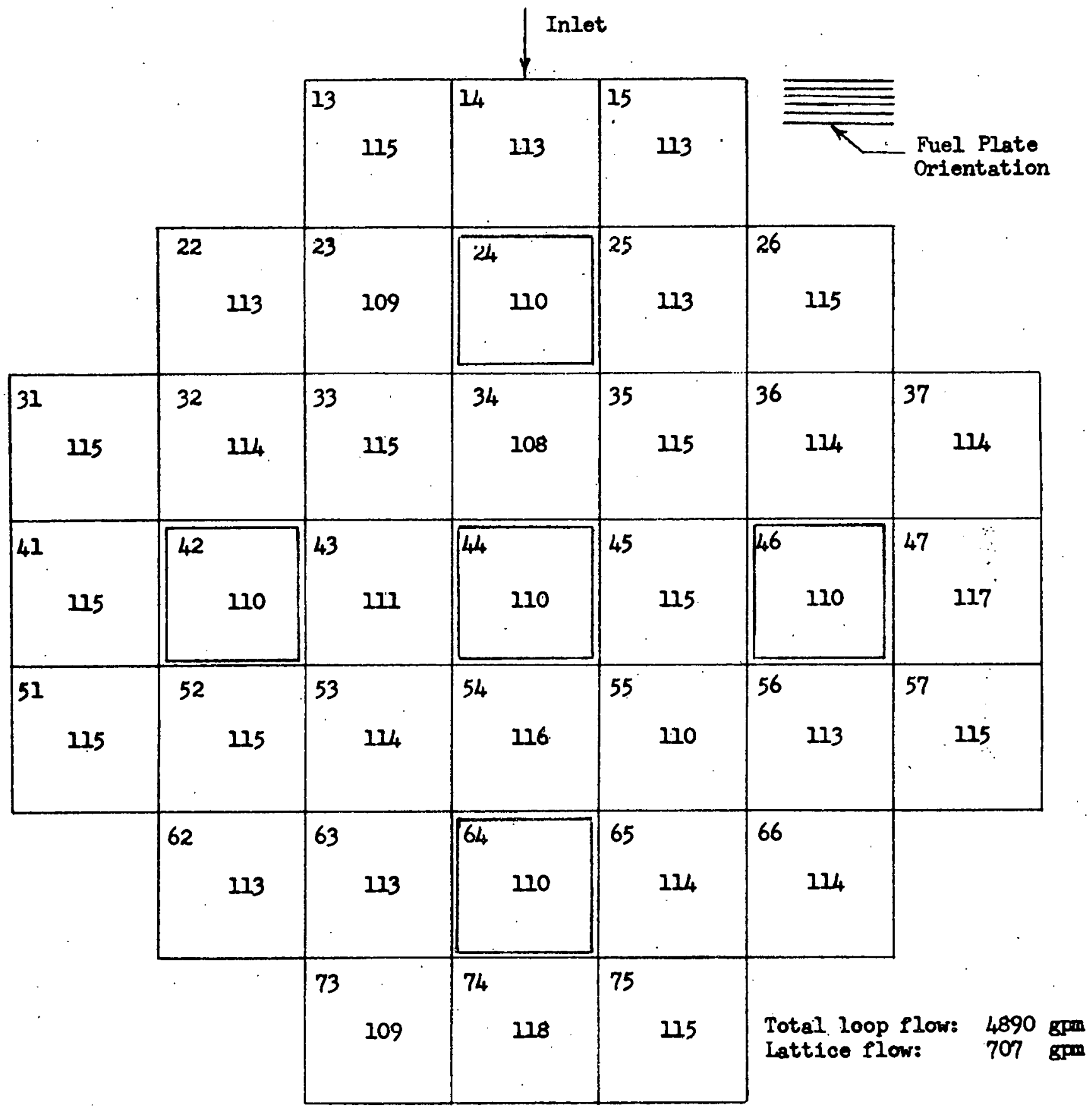

Fig. 3.4 - PM-2A Core Flow Distribution 
THIS PAGE

\section{WAS INTENTIONALLY \\ LEFT BLANK}




\subsubsection{PM-2A Core with SM-2 Elements}

Flow distribution was based on a primary loop flow rate of $4890 \mathrm{gpm}$ measured at Camp Century in the PM-2A startup test program. (20) Internal element flow distribution was taken from Fig. 11 of reference (17) in which: the distribution is expressed in percent of total flow where $14.45 \%$ of totaliow is lattice flow. This data was developed thru flow measurements of each stationary element and control rod element in a full scale flow rig using air as the test fluid. Figure 3.4 shows the available flow for each element.

\subsection{PERFORMANCE OF SM-2 ELEMENTS IN THE SM-1 REACTOR}

\subsubsection{Steady State Design Conditions}

A steady state thermal analysis was perforned on eight element groupings within the SM-1 core. These groupings are based on radial peaking. The element in each group with the maximum peak-to-average power generation was selected for analysis. These elements appear in Table 3.2.

Reactor power was $10 \mathrm{MW}$ with a core heat flux of $63,354 \mathrm{Btu} / \mathrm{hr}-\mathrm{ft}^{2}$ and inlet temperature of $431.7^{\circ}$. The hot channel factors used were calculated based on radial peaking factors presented in the core analysis section of this report, and the manufacturing and metallurgical tolerances presented for SM-2 elements in reference (18). The available flow rates for these elements are shown in Fig. 3.2. Plate surface temperature, bulk water temperature, departure from nucleate boiling, and quality were calculated for one-inch increments up the 22-in. channel.

The results of this analysis at $10 \mathrm{MW}$ are shown in Table 3.2 .

TABLE 3.2 RESULTS OF STEADY STATE THERMAL ANALYSIS, SM-1 CORE, REACTOR POWER 10 MW

\section{Element Position}

61

75
Max。Surface

Temp. ${ }^{\circ} F$

558.4

557.4

554.1

547.3

561.0

551.7

576.5

575.2
Max。 Bulk

$$
\text { Water Temp, }{ }^{\circ} \mathrm{F}
$$

478.7

478. 8

475.1

472.0

478.2

474.2

517.7

486.5
Min。 DNBR Quality

8. 2

8. 4

8. 7

9.4

9.2

12.2

7.6

9.3

\section{0}

0

0

0

0

0

0

0 
The results of this analysis indicate that the SM-1 core with SM-2 elements is safe during steady state $10 \mathrm{MW}$ operation. This is based on DNBR's well above the minimum DNBR of 2.0 and the existence of no local boiling.

\subsubsection{Maximum Operating Conditions}

A steady state analysis of core positions 61 and 44 was made at the reactor scram power level of $13.0 \mathrm{MW}$. The selection of these elements was based on the minimum DNBR presented in Table 3.2. Core inlet temperature was reduced to $429^{\circ} \mathrm{F}$ and core heat flux increased to $79,193 \mathrm{Btu} / \mathrm{hr}-\mathrm{ft}^{2}$. The results of this analysis at 13.0 MW are shown.in Table 3.3.

TABLE 3.3

RESULTS OF STEADY STATE THERMAL ANALYSIS, SM-1 CORE HOT CHANNEL, REACTOR POWER $13 \mathrm{MW}$

\begin{tabular}{|c|c|c|c|c|}
\hline Element Position & $\begin{array}{c}\text { Max. Surface } \\
\text { Temp. }{ }^{\circ} \text { F }\end{array}$ & $\begin{array}{r}\text { Max. Bulk } \\
\text { Water Temp, }{ }^{\circ} F \\
\end{array}$ & $\begin{array}{l}\text { Min. } \\
\text { DNBR }\end{array}$ & Quality \\
\hline 61 & 577.1 & 535.5 & 6.0 & 0 \\
\hline 44 & 577.4 & 487.6 & 6.5 & 0 \\
\hline
\end{tabular}

The results of this analysis indicate that local boiling starts at 5 in. from the bottom of the core for element 61 . Figures 3.5 and 3.6 show a plot of plate surface temperature and bulk water temperature in the hot channel of the stationary element 61 and the control rod element 44 . A relatively flat surface temperature curve is shown for element 61 for approximately $2 / 3$ of the channel. This flatness is attributed to the increase of the heat transfer coefficient near the nucleate boiling region and is typical with the other cores analyzed."

\section{8 PERFORMANCE OF SM-2 ELEMENTS IN THE SM-1A REACTOR}

\subsubsection{Steady State Design Conditions}

A steady state thermal analysis was performed on eight element positions selectedfrom eight element groupings within the SM-1A core. The basis for selection is the same as discussed in section 3.7.1. These elements are listed in Table 3.4. 


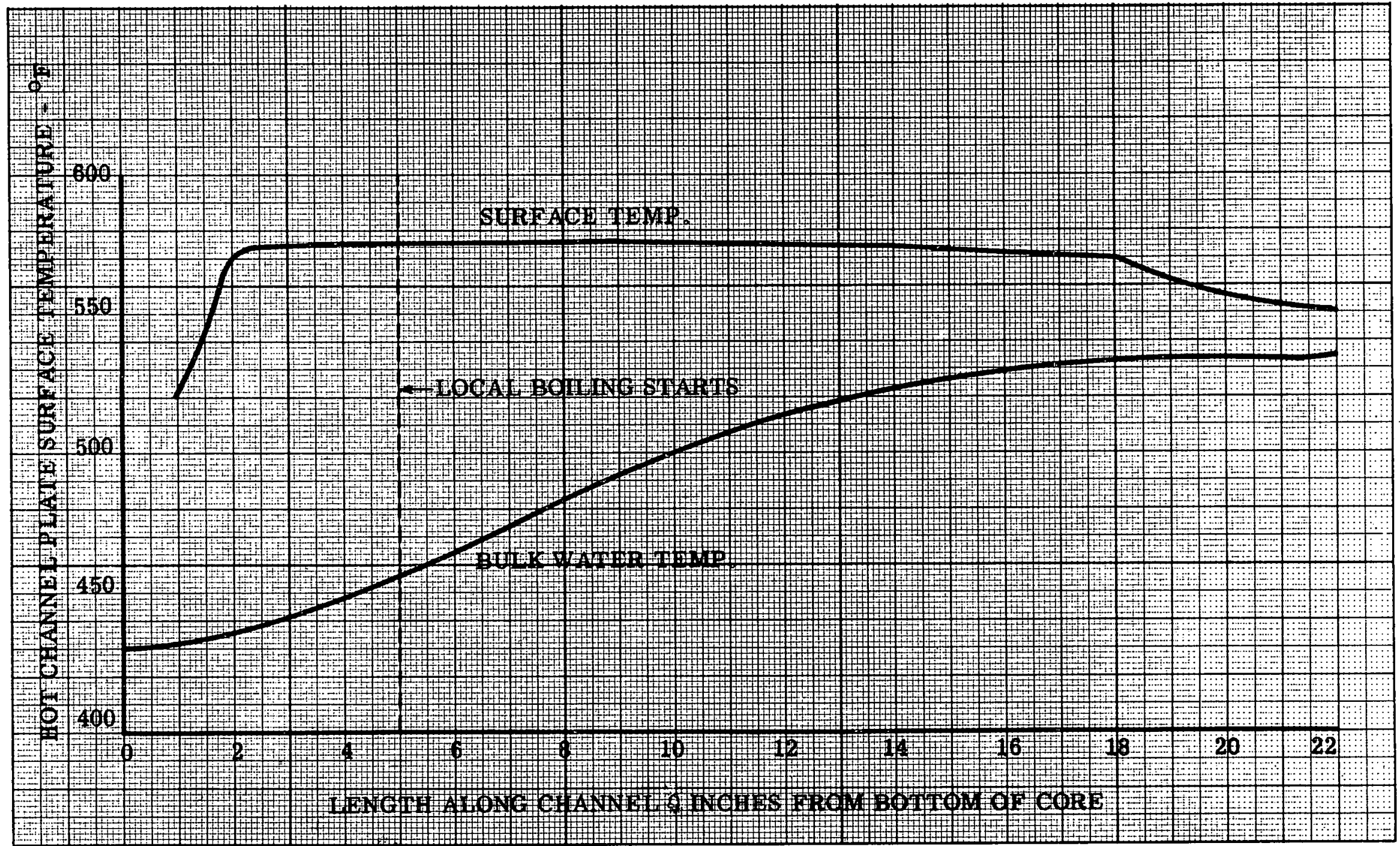

Fig. 3.5 - SM-2 Elements in SM-1 Core, Hot Channel Plate Surface Temp. \& Bulk Water Temp. vs. Length Along Channel From Bottom of Core Element Position 61

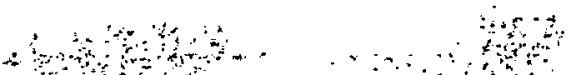


Fig. 3.6 - SM-2 Elements in SM-1 Core, Hot Channel Plate Surface Temp. and Bulk Water Temp. vs. Length Along Channel From bottom of Core Element Position 44 
Reactor power was $20.2 \mathrm{MW}$ with a core heat flux of $118,826 \mathrm{Btu} / \mathrm{hr}-\mathrm{ft}^{2}$ and inlet temperature of $427^{\circ}$. The hot channel factors used were based on radial peaking factors presented in the core analysis section of this report, and the manufacturing and metallurgical tolerances presented for SM-2 elements in reference (18). The available flow rates for these elements are shown in Fig. 3.3.

TABLE 3.4

RESULTS OF STEADY STATE THERMAL ANALYSIS, SM-1A CORE, REACTOR POWER 20.2 MW

\begin{tabular}{|c|c|c|c|c|}
\hline Element Position & $\begin{array}{c}\text { Max. Surface } \\
\text { Temp. }{ }^{\circ} F \\
\end{array}$ & $\begin{array}{c}\text { Max. Bulk } \\
\text { Water Temp。 }{ }^{{ }^{\circ}} \text { F }\end{array}$ & $\begin{array}{r}\text { Miń。 } \\
\text { DNBR }\end{array}$ & Quality \\
\hline 67 & 578.3 & 488.1 & 3.9 & 0 \\
\hline 44 & 578.7 & 482.5 & 4.4 & 0 \\
\hline 46 & 569.1 & 475.9 & 5.0 & 0 \\
\hline 43 & 578.5 & 482.1 & 4.6 & 0 \\
\hline 32 & 578.1 & 482.2 & 4.91 & 0 \\
\hline 63 & 577.9 & 479.1 & 5.1 & 0 \\
\hline 36 & 571.5 & 474.0 & 5.7 & 0 \\
\hline 22 & 560.8 & 471.3 & 6.5 & 0 \\
\hline
\end{tabular}

The results of this analysis indicate that the SM-1A with SM-2 elements is safe during steady state 20.2 MWoperation. This is based on DNBR's well above the minimum DNBR of 2.0 and the existence of no local boiling.

\subsubsection{Maximum Openating Conditions}

A steady state analysis of core positions 67 and 44 was made at the reactor scram power level of 24.2 MW. The selection of these elements. was based on the minimum DNBR's presented in Table 3.5. Core inlet temperature was reduced to $422.9^{\circ}$ and the core heat flux increased to $142,591 \mathrm{Btu} / \mathrm{hr}-\mathrm{ft}^{2}$.

TABLE 3.5

RESULTS OF STEADY STATE THERMAL ANALYSIS, SM-1A CORE, REACTOR POWER 24.2 MW

Element Position

67

44 $\begin{array}{r}\text { Max. Surface } \\ \text { Temp。 }{ }^{\circ} \text { F } \\ \hline\end{array}$

578.9

579.3
Max. Bulk Min。 Water Temp. ${ }^{\mathrm{O}} \mathrm{F}$ DNBR Quality
496.1

3.2

3.6

0

489.4 
The results of this analysis indicate no local boiling and a minimum DNBR above the design criteria of 2.0. Figures 3.7 and 3.8 show a plot of plate surface temperature and bulk water temperature for stationary element 67 and control rod element 44. On the basis of no local boiling and the DNBR's, the scram power level condition does not affect the safe operation of the SM-1A core.

\subsection{PERFORMANCE OF SM-2 ELEMENTS IN THE PM-2A REACTOR}

\subsubsection{Steady State Design Conditions}

A steady state thermal analysis was performed on nine element positions selected from nine element groupings within the PM-2A core. The basis for element selection is the same as discussed in Section 3.7.1. These elements are listed in Table 3,6.

Reactor power was $10.0 \mathrm{MW}$ with a core heat flux of $72,723 \mathrm{Btu} / \mathrm{hr} \mathrm{ft}{ }^{2}$ and inlet temperature of $504^{\circ} \mathrm{F}$. The hot channel factors used were based on radial peaking factors presented in the core analysis section of this report, and the manufacturing and metallurgical tolerances presented for SM-2 elements in reference (18). The available flow rates for these elements are shown in Fig。3.4.

The result of this analysis at $10 \mathrm{MW}$ are shown in Table 3.6 .

TABLE 3.6

RESULTS OF STEADY STATE THERMAL ANALYSIS PM-2A CORE REACTOR POWER 10.0 MW

\begin{tabular}{|c|c|c|c|c|}
\hline Element Position & $\begin{array}{r}\text { Max. Surface } \\
\text { Temp. }{ }^{\circ} F\end{array}$ & $\begin{array}{l}\text { Max. Bulk } \\
\text { Water Temp, }{ }^{\circ} F\end{array}$ & $\begin{array}{l}\text { Min. } \\
\text { DNBR }\end{array}$ & Quality \\
\hline 44 & 604.5 & 549.1 & 8.5 & 0 \\
\hline 34 & 601.8 & 543.8 & 9.3 & 0 \\
\hline 55 & 595.1 & 541.0 & 9.7 & 0 \\
\hline 23 & 617.8 & 550.5 & 7.9 & 0 \\
\hline 56 & 586.9 & 537.4 & 10.6 & 0 \\
\hline 22 & 614.9 & 550.0 & 7.9 & 0 \\
\hline 37 & 576.9 & 534.9 & 12.2 & 0 \\
\hline 14 & 562.6 & 525.5 & 14.8 & 0 \\
\hline 73 & 597.4 & 546.9 & 10.1 & 0 \\
\hline
\end{tabular}




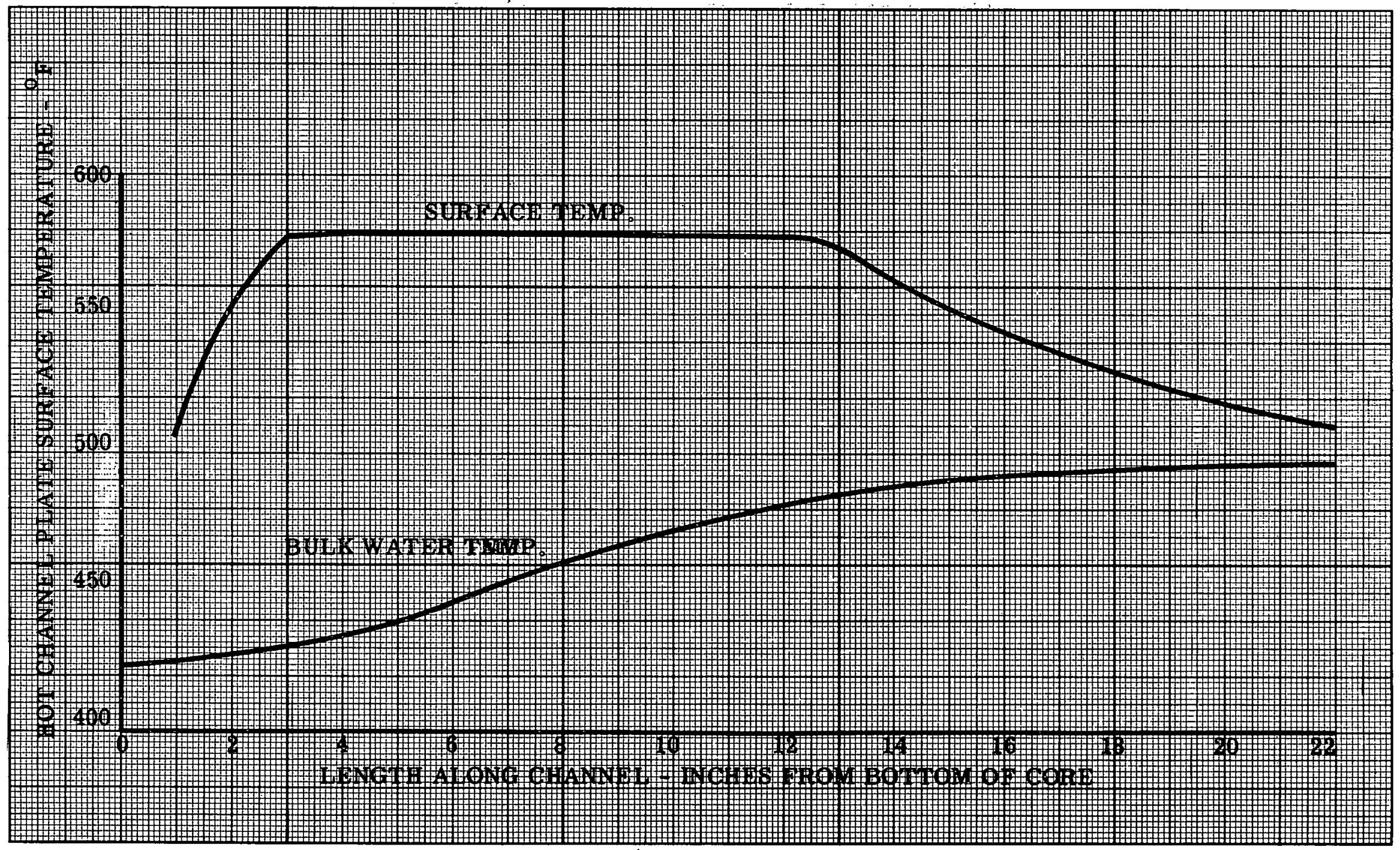
$\because \cdots$

Fig. 3. 7 - SM-2 Elements in SM-1A Core, Hot Channel Plate Surface Temp. and Bulk Water Temp. vs. Length Along Channel From Bottom of Core, Element Position 67

$$
\begin{aligned}
& \text { Nitest }
\end{aligned}
$$

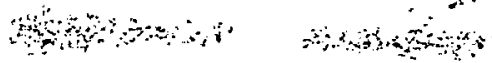




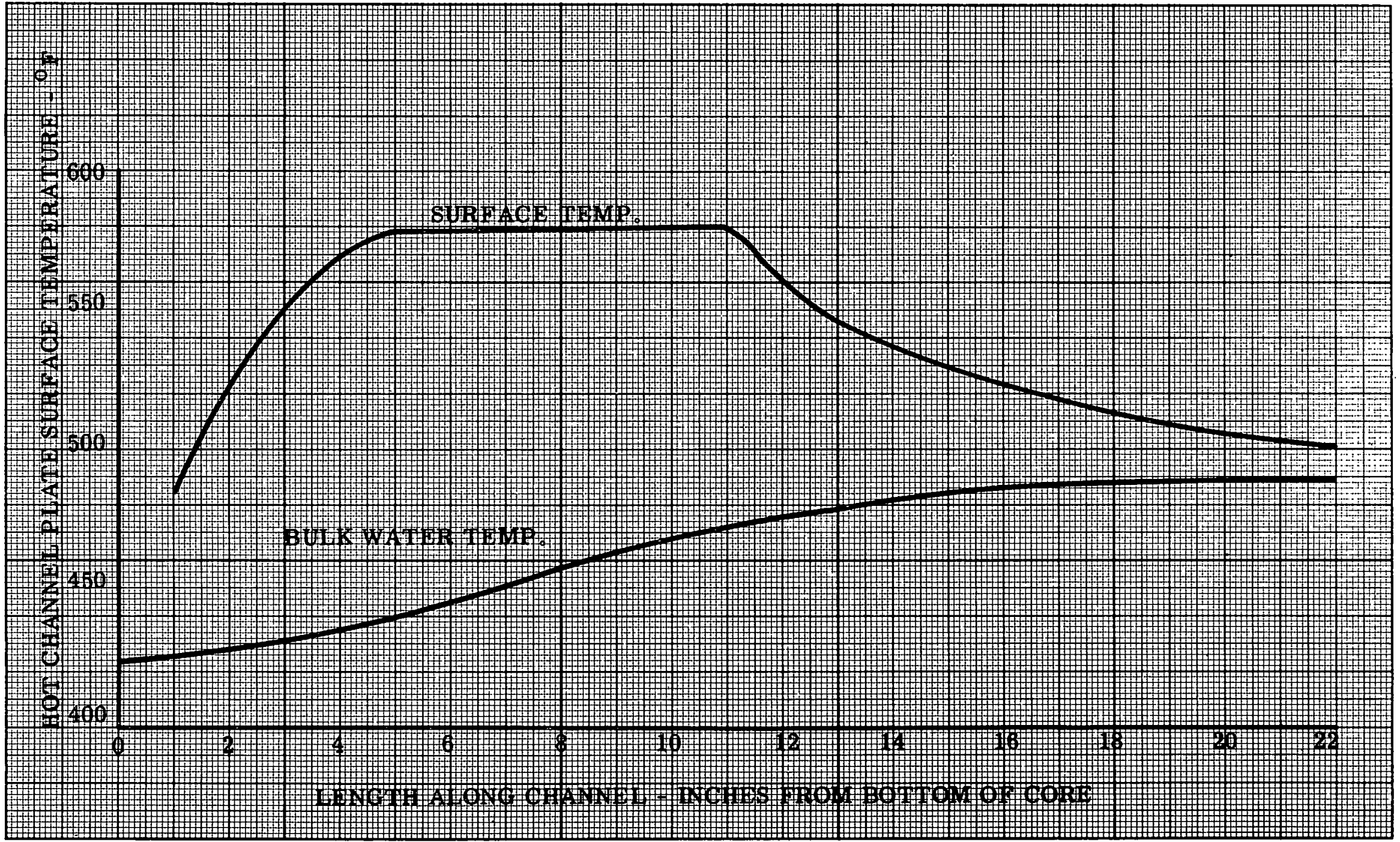

$\therefore$

Fig. 3.8 - SM-2 Elements in SM-1A Core, Hot Channel Plate

$\because: \because:$ Surface Temp. and Bulk Water Temp. vs. Length

$\therefore$ Along Channel From Bottom of Core, Element Position 44 
The results of this analysis indicate no local boiling and minimum DNBR' $s$ above the thermal design criteria of 2.0. On this basis the PM-2A core will operate safely at 10.0 MW with SM-2 elements installed.

\subsubsection{Maximum Operating Conditions}

A steady state analysis of core positions 23 and 44 was made at the reactor scram power level of 12.0 MW The selection of these elements was based on the minimum DNBR's presented in Table 3.6. Core inlet temperature was reduced to $500,4^{\mathrm{O}} \mathrm{F}$ and the core heat flux increased to $87,268 \mathrm{Btu} / \mathrm{hr}-\mathrm{ft}^{2}$.

'l'he results of this allatysis at $12.0 \mathrm{MW}$ arc given in Table 3.7.

TABLE 3.7

RESULTS OF STEADY STATE THERMAL ANALYSIS, PM-2A CORE 2 REACTOR POWER 12.0 MW

\begin{tabular}{|c|c|c|c|c|}
\hline Element Position & $\begin{array}{c}\text { Max. Surface } \\
\text { Temp. }{ }^{\circ}\end{array}$ & $\begin{array}{l}\text { Max。 Bulk } \\
\text { Water Temp, }{ }^{\circ} \text { F }\end{array}$ & $\begin{array}{l}\text { Min. } \\
\text { DNBR }\end{array}$ & Quality \\
\hline 23 & 620.80 & $556.0^{\circ}$ & 6.6 & 0 \\
\hline 44 & .620 .83 & 554.3 & 7.1 & 0 \\
\hline
\end{tabular}

Results indicate no local boiling and minimum DNBR's are above 2.0 . Figures 3.9 and 3.10 show plots of plate surface temperature and bulk water temperature for stationary element 23 and control rod element 44。 The PM-2A core is the safest core(has minimum DNBR's) operating with SM-2 elements installed.

\subsection{TRANSIENT OPERATION OF THE SM-1 CORE WITH SM-2 ELEMENT}

A transient analysis was performed on element 61 in the SM-1 core for a loss of flow accident. This required the reactor's coastdown information given in Figure 3.1 which was taken from the data of Test Procedure 600, (19) conducted at Fort Belvoir. At time intervals of $0.1,0.2,0.3,0.4$ and $0.5 \mathrm{sec}$ after pump failure, flow rates and reactor power were calculated based on a reactor power of 13.45 MW. These were placed in STDY -3 code as a series of steady state runs. The results of this analysis are shown in Fig。3.11. This analysis indicates that the minimum burnout ratio is far above the thermal design requirements of 1 : 5 for safe core transient operation and that DNBR increas es in this loss of pump accident.

A transient analysis will be included in the final report making use of a transient code for the analysis. 


\section{THIS PAGE}

\section{WAS INTENTIONALLY \\ LEFT BLANK}




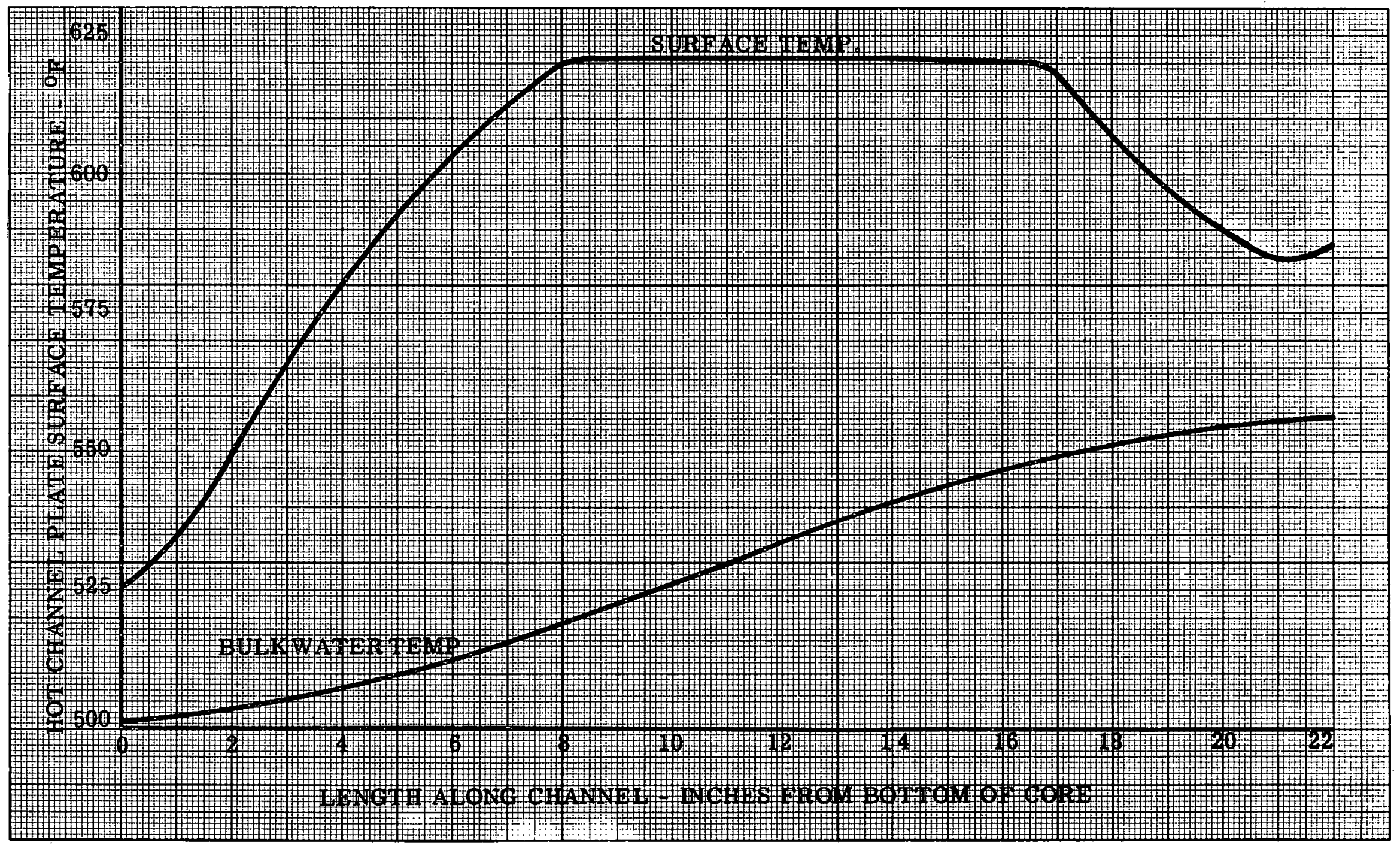

Fig. 3.9 - SM-2 Elements in PM-2A Core, Hot Channel Plate Surface Temp. and Bulk Water Temp. vs. Length Along Channel From Bottom of Core - Element Position 23

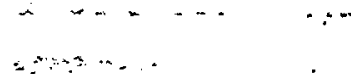




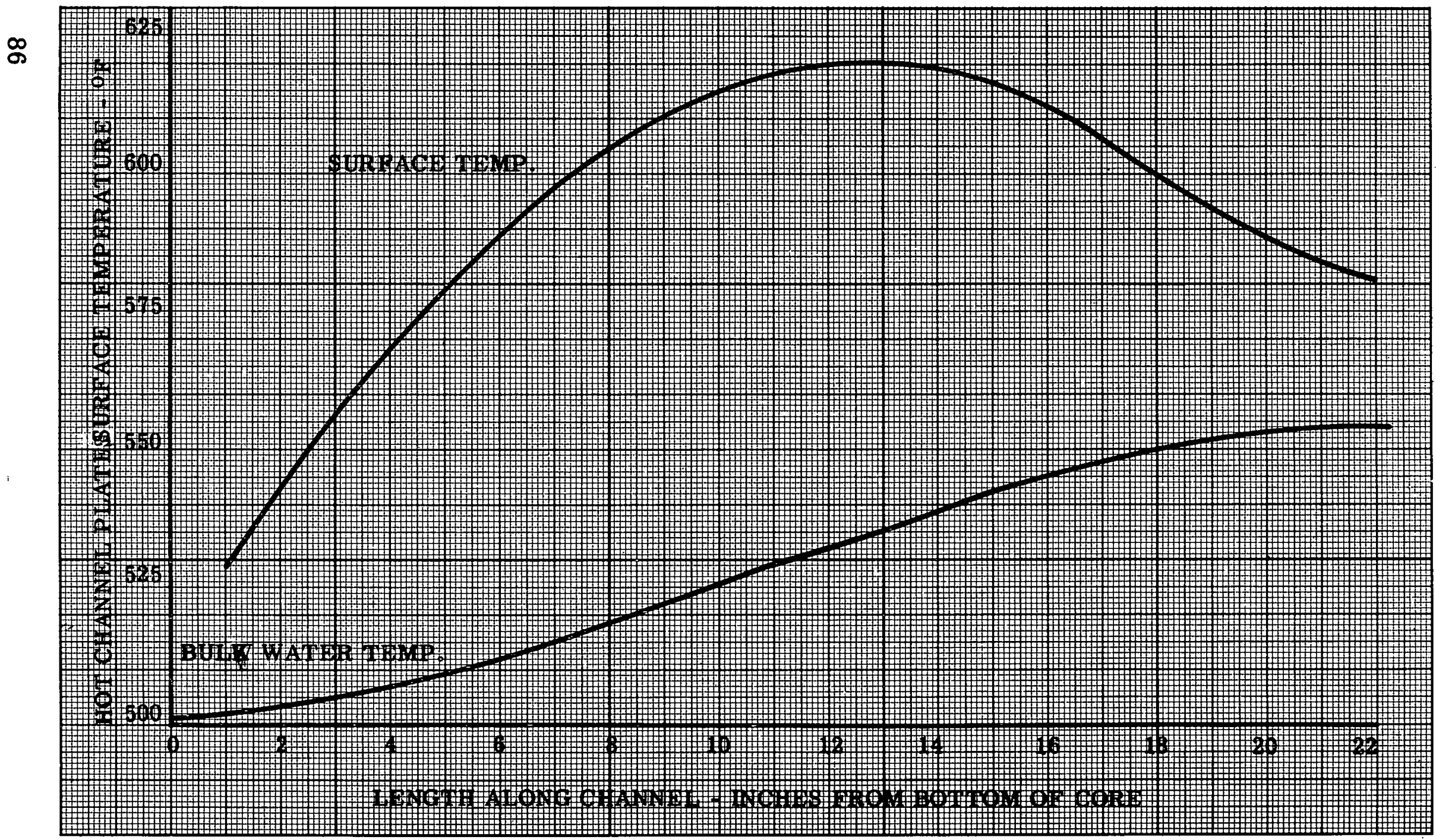

Fig. 3.10 - SM-2 Elements in PM-2A Core, Hot Channel Plate Surface Temp. and Bulk Water Temp. vs. Length Along Channel From Bottom of Core, Element Position 44 


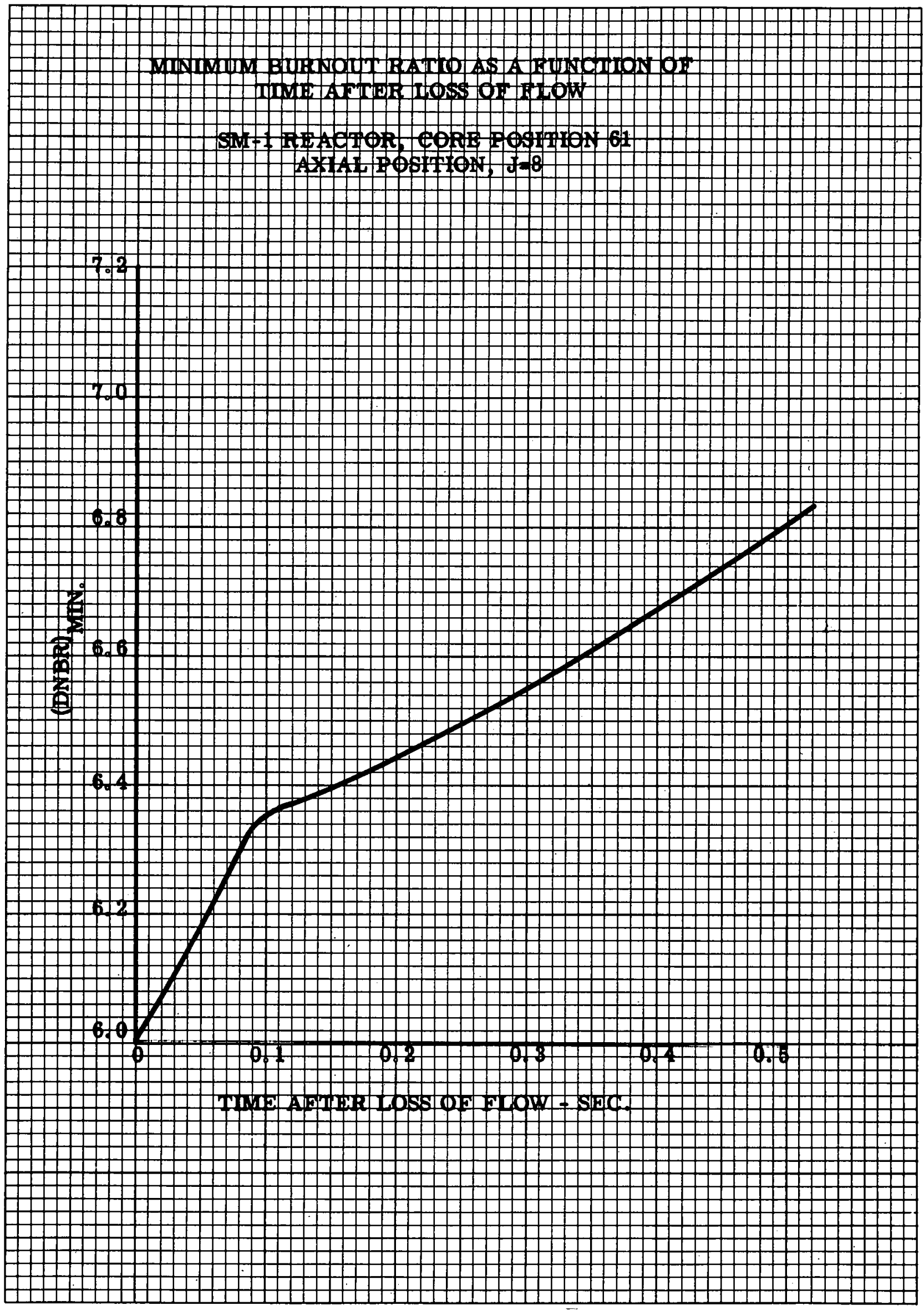

Fig. 3.11 - 


\section{THIS PAGE}

\section{WAS INTENTIONALLY \\ LEFT BLANK}




\subsection{CONCLUSIONS}

1. The preliminary thermal analysis indicates that at design power output the SM-1, SM-1A and PM-2A cores operate safely. There is no evidence of local boiling and DNBR's are above 2. 0 .

2. The preliminary thermal analysis indicates that at the reactor scram power level setting the SM-1A and PM-2A operate safely with no local boiling evident and DNBR's well above $2 \% 0$ 。 In the $S M-1$, element 61 indicates that local boiling exists for approximately $2 / 3$ of its hot channel. Considering the high DNBR $(6,0)$ and the fact that this is the scram level setting, results indicate that the SM-1 will be safe to operate with SM-2 elements.

3. During a loss of pump transient, the preliminary thermal analys is performed on the SM-1 core indicates no local boiling, with DNBR's above the thermal transient criteria of 1.5 . 
THIS PAGE

WAS INTENTIONALLY

LEFT BLANK 


\section{REFERENCES}

1. Bobe, P. E., Editor, "Interim Report of Nuclear Analysis Performed on SM-2 Core and Vessel": APAE No.65, May 27, 1960.

2. Williamson, T. E., Editor, "Reactor Analysis APPR-1 Core II," APAE No。32, July 15, 1958 .

3. Fried, B. E., Alford, M: R。, Oggerino, J。 P。, "SM-2 Flux and Power Distribution for the Reference and Critical Experiment Cores," APAE Memo No. 286, to be published.

4. Paluszkiewicz, S., "Analysis of Zero Power Experiments on SM-1 Core II and SM-1A Core I," APAE No. 71, October 5, 1960.

5. Fried, E。 E。, Oggerino, J. P., Alford, $M_{\circ} R_{\circ}$, "Analysis of Reactivity, Burnup, and Lifetime for the SM-1 and SM-2 Cores Using the CANDLE-2 Code," APAE Memo No. 285, to be published.

6. Geisler, H. W., Editor, "Results and Analysis of the APPR-1 Zero Power Experiments, Part 1," APAE Memo No。61, November 7, 1956.

7. Hoover, $H_{\circ}$ L。, Project Engineer, "SM-2 Core and Vessel Design Analysis," APAE No。69, Vol III, March 8, 1961

8. Byrne, B. Jo, "Power Distribution for APPR - Type Cores, APAE: Memo No。195; July 25, 1959 。

9. Paluszkiewicz, S。, Byrne, B。 J., "Analys is of Zero Power Experiments on the PM-2A Core I," APAE Memo No. 277, January 17, 1961.-

10. Paluszkiewicz, S。, "Nuclear Analysis of Various SPERT-III Critical Experiments," APAE Memo No。279, April 27, 1961。

11. Pyle, R。 S。, "STDY-3 - A Program for the Thermal Analysis of a Pressurized Water Nuclear Reactor During Steady State Operation," WAPD-TM -213, June, 1960 .

12. Rosen, S. S。, "Hazards Summary Report for the Army Package Power Reactor SM-1," APAE 2, Revision 1, May,1960.

13. Gallagher, J. G., "Hazards Summary Report for SM-1A," APAE No. 13,Supplement 2,Rev。1, October 7, 1960 . 
14. "Hazards Summary Report for a Prepackaged Nuclear Power Plant for an Ice Cap Location (PM-2A)," APAE No. 49, Alco Products, Inc. , July 1, 1959 .

15. Ingeneri, S. M., "Coolant Flow Tailoring Program of the APPR-1 Core Employing a Full Scale Model of the Reactor Vessel," APAE Memo No. 108, November, 1957.

16. Matthews, F. T., "Revised Thermal Analysis of the SM-1A Core,". AP Note 307, Alco Products, Inc., December 8, 1960.

17. Matthews, F. To, "Results of the Experimental Flow Distribution Program for the PM-2A Reactor - Summary Report, " AP Note 266, Alco Products, Inc., May 31, 1960.

18. Hoover, H. L。, Project Engineer, ".SM-2 Core and Vessel Design Analysis," APAE No. 69 Volume I, Section 2. - Core Thermal Analysis, March 8, 1961 .

19. Morrison J. H., Lee, D. H., "Evaluation of Loss of Flow Accident in the SM-1," Final Test Report 600, Alco Products, Inc., April 22, 1960。

20. Richards, W. M. , "Primary System Thermal and Hydraulic Performance During Heat-Up of the PM-2A Reactor Plant, Test No. C-603," AP Note 323, Alco Products, Inc., February 15, 1961. 